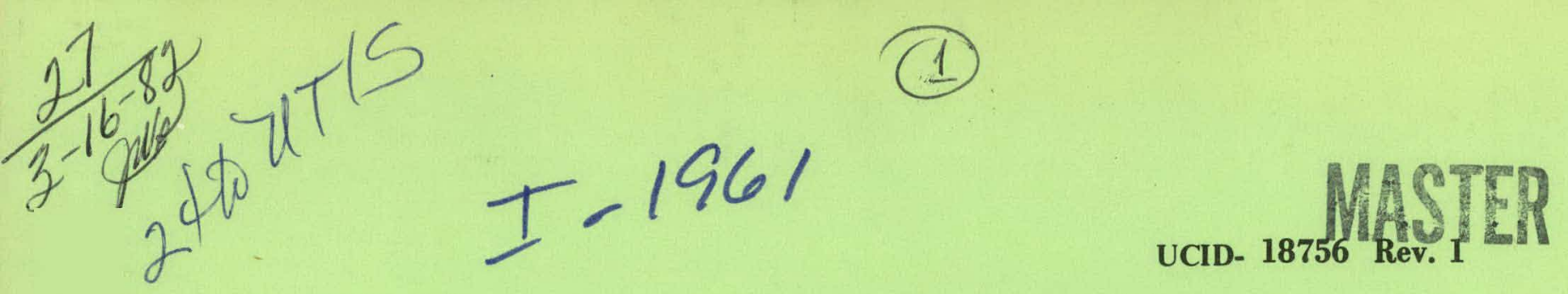

\title{
USER'S MANUAL FOR DYNA2D -- AN EXPLICIT TWO-DIMENSIONAL HYDRODYNAMIC FINITE-ELEMENT CODE WITH INTERACTIVE REZONING
}

John 0. Hallquist

February, 1982

This is an informal report intended primarily for internal or limited external distribution. The opinions and conclusions stated are those of the author and may or may not be those of the Laboratory.

A Work performed under the auspices of the U.S. Department of Energy by the Lawrence Livermore I.ahoratory under Contract W-7405-Eng-48.

\section{NOTICE}

PORTIONS OF THIS REPORT ARE ILLEGIBLE. It has been rearoduced from the best available copy to permit the broadest possible availability. 


\section{DISCLAIMER}

This report was prepared as an account of work sponsored by an agency of the United States Government. Neither the United States Government nor any agency Thereof, nor any of their employees, makes any warranty, express or implied, or assumes any legal liability or responsibility for the accuracy, completeness, or usefulness of any information, apparatus, product, or process disclosed, or represents that its use would not infringe privately owned rights. Reference herein to any specific commercial product, process, or service by trade name, trademark, manufacturer, or otherwise does not necessarily constitute or imply its endorsement, recommendation, or favoring by the United States Government or any agency thereof. The views and opinions of authors expressed herein do not necessarily state or reflect those of the United States Government or any agency thereof. 


\section{DISCLAIMER}

Portions of this document may be illegible in electronic image products. Images are produced from the best available original document. 
UCID--18756 Rev. I

DE82 008613

\section{LAWRENCE LIVERMORE LABORATORY}

University of Cahtomia, Livermore, California, 94550

\section{USER'S MANUAL FOR DYNA2D -- AN EXPLICIT TWO-DIMENSIONAL HYDRODYNAMIC FINITE ELEMENT CODE WITH INTERACTIVE REZONING}

John O. Hallquist

Methods Development Group

Mechanical Engineering Department

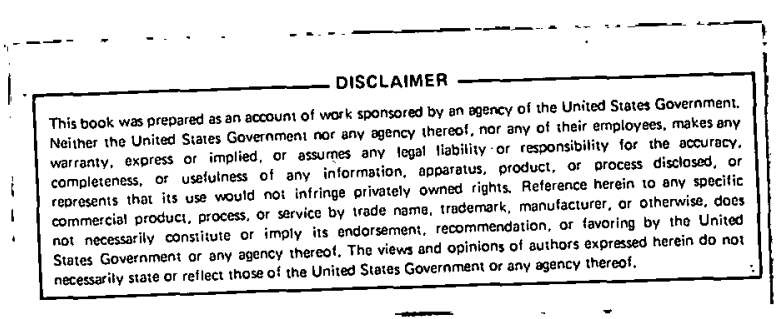




\section{CONTENTS}

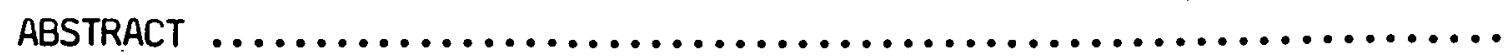

Page

BACKGROUND $\ldots \ldots \ldots \ldots \ldots \ldots \ldots \ldots \ldots \ldots \ldots \ldots \ldots \ldots \ldots \ldots \ldots \ldots \ldots \ldots \ldots \ldots$

CODE DOCUMENTATION $\ldots \ldots \ldots \ldots \ldots \ldots \ldots \ldots \ldots \ldots \ldots \ldots \ldots \ldots \ldots \ldots \ldots \ldots \ldots \ldots \ldots$

SPATIAL DISCRETIZATION $\ldots \ldots \ldots \ldots \ldots \ldots \ldots \ldots \ldots \ldots \ldots \ldots \ldots \ldots \ldots \ldots \ldots \ldots \ldots$

MATERIAL MODELS $\ldots \ldots \ldots \ldots \ldots \ldots \ldots \ldots \ldots \ldots \ldots \ldots \ldots \ldots \ldots \ldots \ldots \ldots \ldots \ldots \ldots$

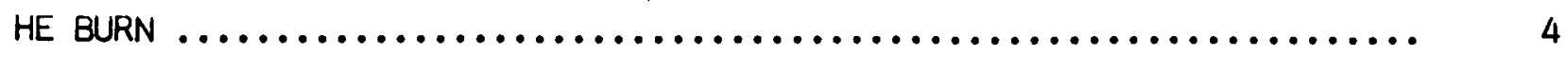

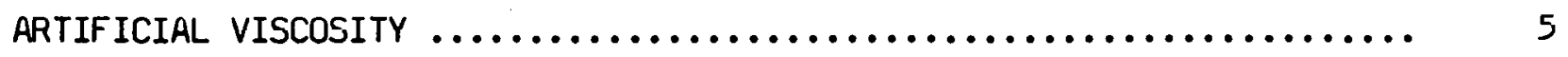

GRAVITY $\ldots \ldots \ldots \ldots \ldots \ldots \ldots \ldots \ldots \ldots \ldots \ldots \ldots \ldots \ldots \ldots \ldots \ldots \ldots \ldots \ldots \ldots \ldots \ldots$

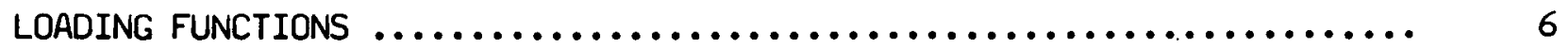

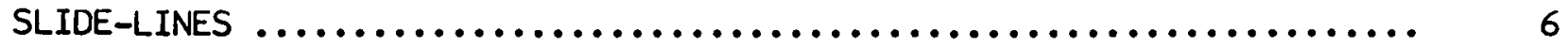

REZONING $\ldots \ldots \ldots \ldots \ldots \ldots \ldots \ldots \ldots \ldots \ldots \ldots \ldots \ldots \ldots \ldots \ldots \ldots \ldots \ldots \ldots \ldots \ldots$

CAPACITY $\ldots \ldots \ldots \ldots \ldots \ldots \ldots \ldots \ldots \ldots \ldots \ldots \ldots \ldots \ldots \ldots \ldots \ldots \ldots \ldots \ldots \ldots \ldots$

CODE ORGANIZATION $\ldots \ldots \ldots \ldots \ldots \ldots \ldots \ldots \ldots \ldots \ldots \ldots \ldots \ldots \ldots \ldots \ldots \ldots \ldots$

SENSE SWITCH CONTROLS $\ldots \ldots \ldots \ldots \ldots \ldots \ldots \ldots \ldots \ldots \ldots \ldots \ldots \ldots \ldots \ldots \ldots \ldots \ldots . \ldots$

EXECUTION $\ldots \ldots \ldots \ldots \ldots \ldots \ldots \ldots \ldots \ldots \ldots \ldots \ldots \ldots \ldots \ldots \ldots \ldots \ldots \ldots \ldots \ldots$

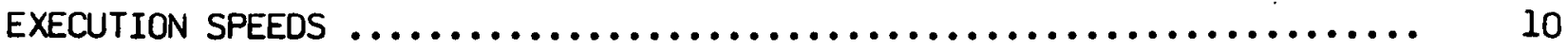

AUTOMATED INPUT GENERATION $\ldots \ldots \ldots \ldots \ldots \ldots \ldots \ldots \ldots \ldots \ldots \ldots \ldots \ldots \ldots \ldots$

POST-PROCESSING $\ldots \ldots \ldots \ldots \ldots \ldots \ldots \ldots \ldots \ldots \ldots \ldots \ldots \ldots \ldots \ldots \ldots \ldots \ldots \ldots \ldots$

DYNAZD User's Guide $\ldots \ldots \ldots \ldots \ldots \ldots \ldots \ldots \ldots \ldots \ldots \ldots \ldots \ldots \ldots \ldots \ldots \ldots \ldots$

1. Title Card ................................... 11

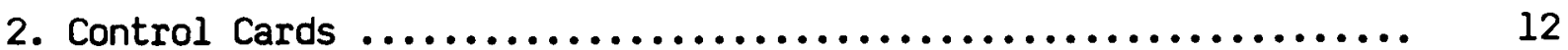

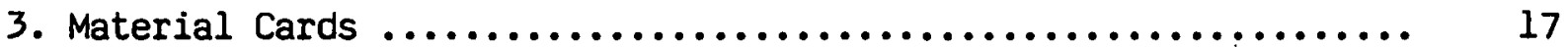

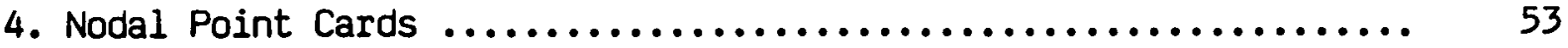

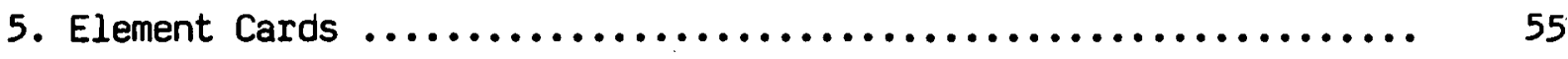

6. High Explosive Burn Definitions ..................... 57

7. Nodal Printout Blocks ............................. 60

8. Element Printout Blocks ........................... 61 
9. Time History Curve Cards $\ldots \ldots \ldots \ldots \ldots \ldots \ldots \ldots \ldots \ldots \ldots \ldots \ldots . \ldots \ldots, 62$

10. Concentrated Nodal Load and Follower Force Cards ............. 63

11. Pressure and Shear Boundary Condition Cards .................. 64

12. Velocity Boundary Condition Cards ........................ 66

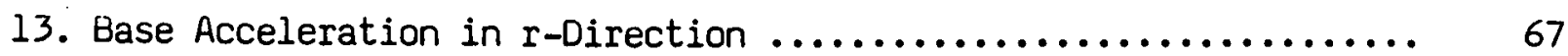

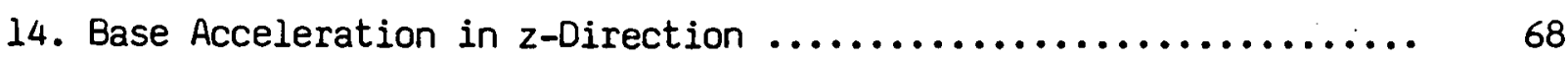

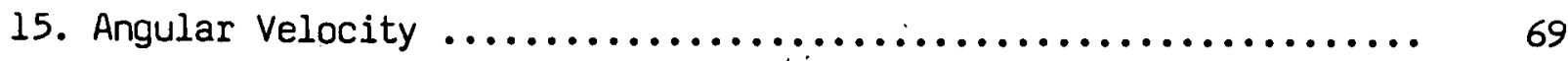

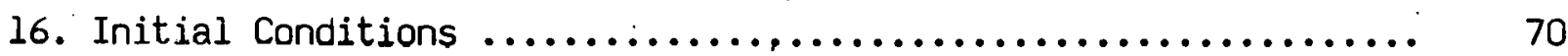

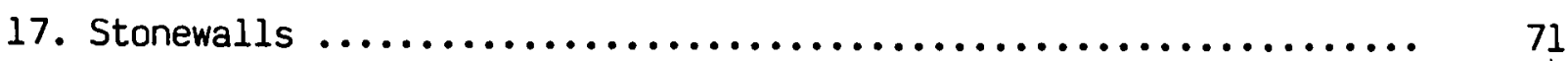

18. Slide-Line Control Cards ............................... 73

19. Sllde-Line Definitions ................................ 74

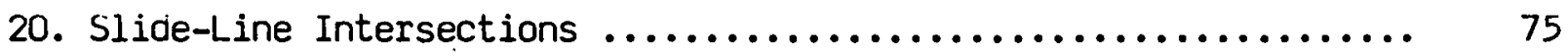

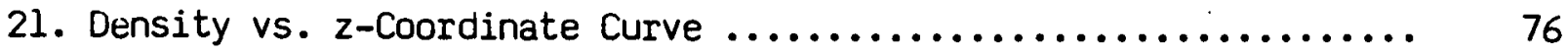

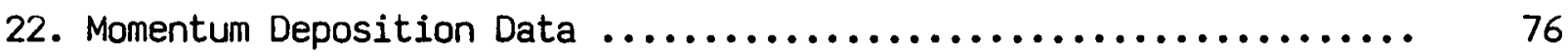

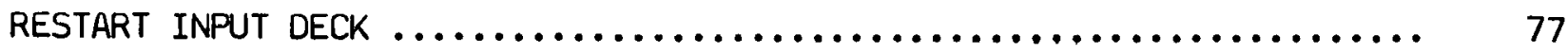

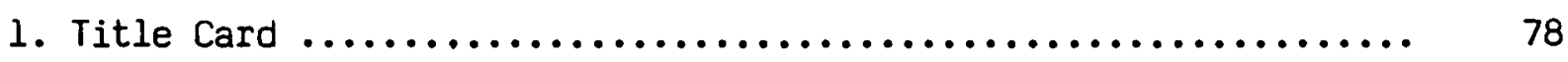

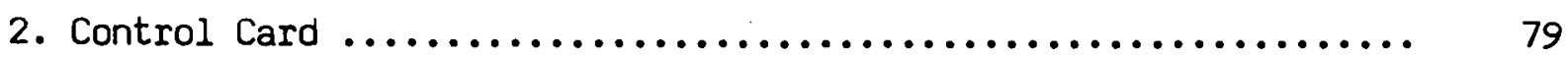

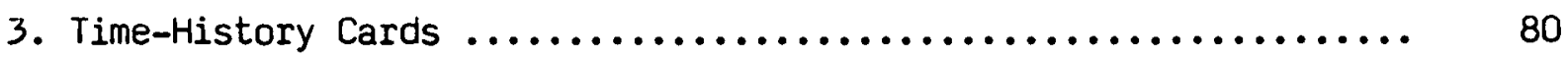

4. Deleted Slide-Lines ................................... 81

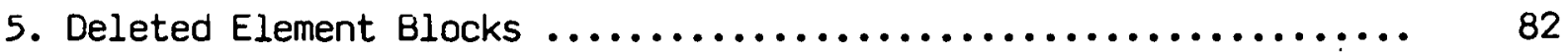

6. Deleted Material Blocks ................................ 83

7. Slide-Line Control Cards ................................ 84

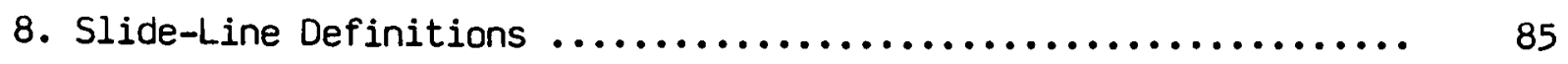

9. Slide-Line Intersections $\ldots \ldots \ldots \ldots \ldots \ldots \ldots \ldots \ldots \ldots \ldots \ldots \ldots, 8 \ldots \ldots \ldots$

COMMANDS FOR REZONING $\ldots \ldots \ldots \ldots \ldots \ldots \ldots \ldots \ldots \ldots \ldots \ldots \ldots \ldots \ldots \ldots,{ }^{2}$

1. Command Definitions ................................. 87

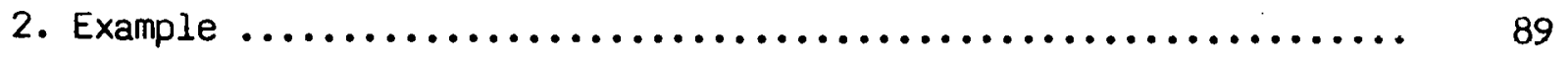

EXAMPLE PROBLEM

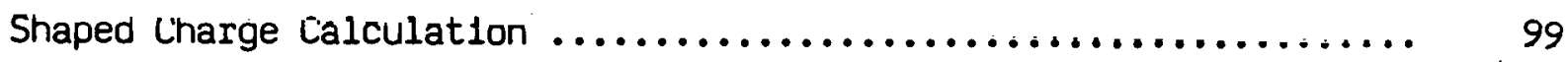

ACKNOWLEDGEMENTS $\ldots \ldots \ldots \ldots \ldots \ldots \ldots \ldots \ldots \ldots \ldots \ldots \ldots \ldots \ldots \ldots \ldots \ldots, 101$

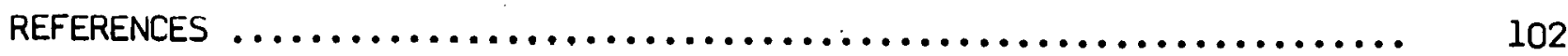

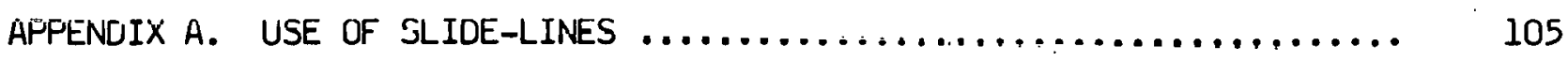




\title{
USER'S MANUAL FOR DYNA2D -- AN EXPLICIT TWO-DIMENSIONAL HYDRODYNAMIC FINITE ELEMENT CODE WITH INTERACTIVE REZONING
}

\begin{abstract}
This revised report provides an updated user's manual for DYNA2D, an explicit two-dimensional axisymmetric and plane strain finite element code for analyzing the large deformation dynamic and hydrodynamic response of inelastic solids. A contact-impact algorithm permits gaps and sliding along material interfaces. By a specialization of this algorithm, such interfaces can be rigidly tied to admit variable zoning without the need of transition regions. Spatial discretization is achieved by the use of 4-node solid elements, and the equations-of-motion are integrated by the central difference method. An interactive rezoner eliminates the need to terminate the calculation when the mesh becomes too distorted. Rather, the mesh can be rezoned and the calculation continued. The command structure for the rezoner is described and illustrated by an example.

\section{BACKGROUND}

DYNA2D [1] was developed over five years ago and has since been applied in the analysis of a large number of problems. Originally, DYNA2D had a variety of elements including nine node Lagrange elements, constant pressure variable node elements with four integration points and constant stress quadrilaterals with single points integration. Three solution schemes were available:

- Finite element (Galerkin).

- Finite element (Petrov-Galerkin).

- Finite difference [2].
\end{abstract}

*Work performed under the auspices of the U.S. Department of Energy by the Lawrence Livermore Laboratory under contract number W-7405-Eng-48. 
The first scheme which included the variable node elements was eliminated because the radial weighting in axisymmetry caused centerline difficulties in large deformation, hydrodynamic calculations. Furthermore, variable node elements proved to be very expensive relative to the constant stress four node elements and, consequently, were seldom exercised. The finite difference scheme was eliminated since the second method gave comparable results with a smaller storage requirement.

Early in the development of DYNA2D, the author, reinforced by conversations with Goudreau [3] and our experiences with the finite difference method, decided to attempt a solution to the axisymmetric axis problems of the Galerkin finite element method by weighting the momentum equations in the discretization by the product of the basis functions and the reciprocal of the radius, $r^{-1}$. The attempt worked so well, the resulting scheme remains as the sole option in DYNA2D. We referred to the method as "area Galerkin" since it eliminated the radial weighting. Later conversations with Hughes [4] lead us to call the method by its proper name, Petrov-Galerkin. Although a time dependent mass vector is obtained, this has proven to be a very small penalty. The method is identical to the finite difference method [2] in plane strain, but in axisymmetric problems, the method is the same only if material strength is neglected.

In the sections that follow, some of the aspects of the current version of DYNA2D are briefly discussed.

\section{Code Documentation}

Presently, no formal (or informal) documentation exists for DYNA2D; however, many of the references cited in this report would be very helpful to those wanting more insight into the techniques employed.

\section{Spatial Discretization}

The elements shown in Fig. 1 are available. One element centered stress state is stored for each element in addition to any material parameters. An hourglass viscosity is used to control the zero energy modes. 


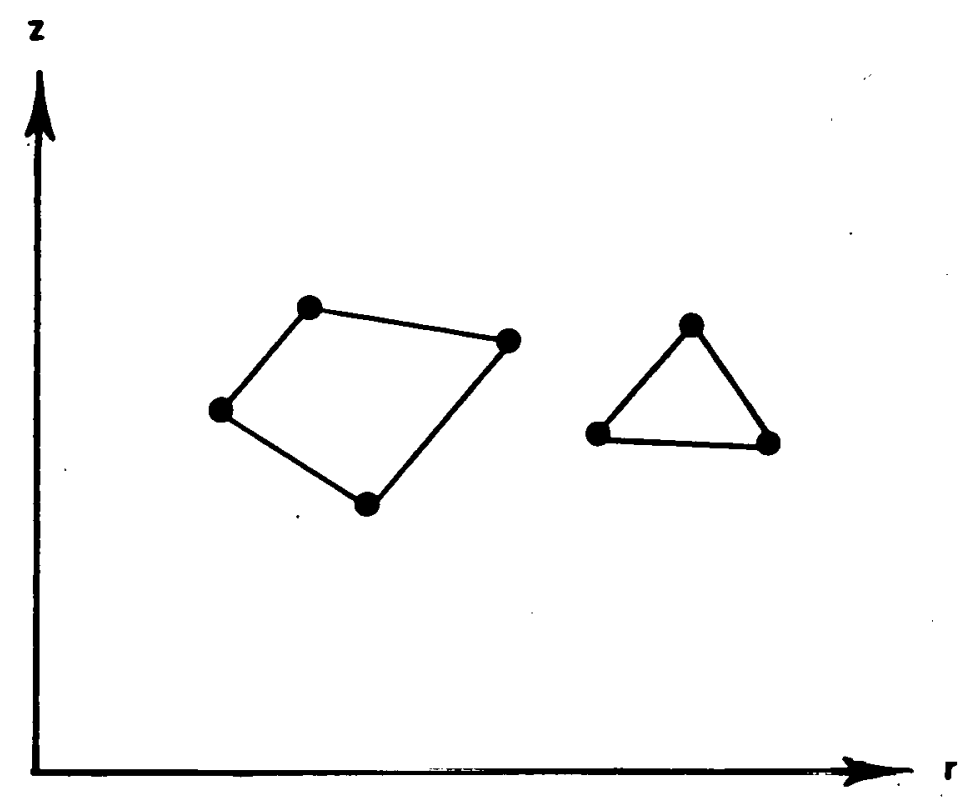

- Fig. 1. Solid elements available in DYNA2D.

\section{Material Models}

The material models presently implemented are:

- elastic,

- orthotropic elastic,

- kinematic/isotropic elastic-plastic [5],

- thermo-elastic-plastic [6],

- soil and crushable foam [7],

- linear viscoelastic [7],

- rubber [7],

- isotropic elastic-plastic,

- temperature dependent elastic-plastic [8].

The latter two models determine only the deviatoric stresses. Pressure is determined by one of nine equations of state including: 
- linear polynomial,

- JWL high explosive,

- Sack "Tuesday" high explosive [9],

- Gruneisen,

- ratio of polynomials

- linear polynomial with energy deposition,

- ignition and growth of reaction in HE $[10,11]$,

- tabulated compaction,

- tabulated.

The soil and crushable foam, the linear viscoelastic, and the rubber subroutines were adapted from HONDO and recoded for vectorization; the ignition and growth EOS was adapted from KOVEC [12]; the other subroutines, programmed by the author, are based in part on the cited references and are nearly 100 percent vectorized. The forms of the first five equations of state are given in the KOVEC user's manual and are retained in the this mannual.

With the exception of the orthotropic elastic and the rubber material subroutines, a Jaumann stress rate formulation is used; these latter two use Green-St. Venant strains to compute second Piola-Kirchoff stresses, which are then subsequently transformed to Cauchy stresses.

OYNA2D is organized to accept new material models and equations of state of any complexity. The organization permits different material and EOS types to have unique storage requirements. All history variables except the stress tensor and the effective plastic strain are packed in a one-dimensional storage vector to ensure that no space is wasted.

\section{HE Burns}

Two burn models are presently available. One is the beta burn model used by KOVEC, and the other is the programmed burn model used by HEMP [13]. Both models permit detonations from points and lines. 


\section{Artificial Viscosities}

The linear-quadratic bulk viscosity is used to smear shock fronts over several elements and to damp numerical oscillations. Two such formulations are implemented

- standard DYNA2D,

- Richards-Wilkins [14,15].

The former differs from the latter in that the strain rate and characteristic length used in the viscosity calculation are the volumetric strain rate and the square root of the area, respectively. In the latter formulation directional properties of the shock wave are considered. For most engineering problems, the less expensive standard DYNA2D formulation is usually sufficient. When DYNA2D is applied to problems where element aspect ratios are poor, the Richards-Wilkins algorithm tends to provide a more stable solution and is recommended.

Three viscosities are available for resisting zero energy deformation modes in constant stress elements. These are the

- standard DYNA2D [3],

- rotational $[16,13]$,

- Flanagan-Belytechko [17].

Hourglass viscosity should always be used to prevent instabilities. All three formulations work well although one sometimes is better than another on a problem by problem basis. The standard DYNA2D formulation is very inexpensive and can be recommended for most problems. 


\section{Gravity}

In soil-structure interaction problems, gravity effects may be significant. Element pressures can be initialized by DYNA2D. In the soil and crushable foam material subroutine, the volumetric strain is initialized as well. Care is taken to insure that an equilibrium state exists at time zero so that no oscillations are caused by the nonzero initial stress state. This option has not been used recently and may not work properly.

\section{Loading Functions}

A variety of loading functions may be used including:

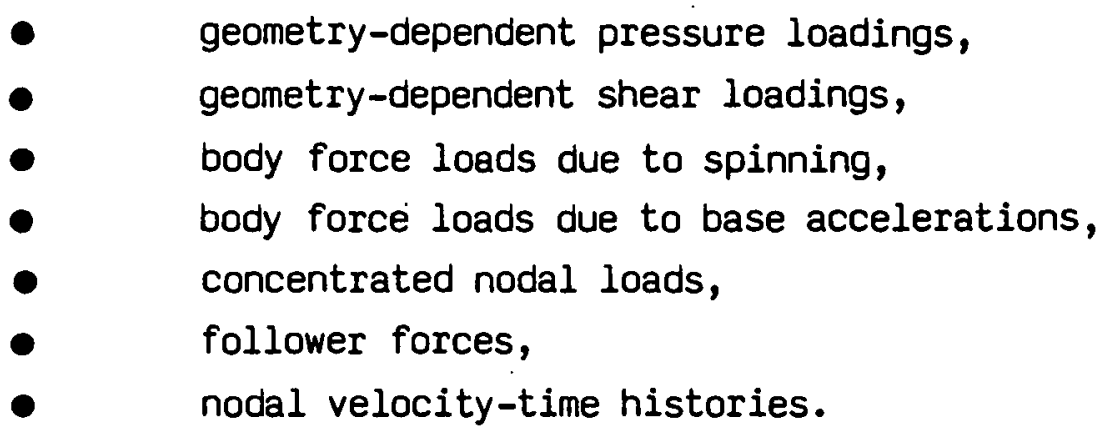

An unlimited number of time histories may be defined and may be referenced by any loading function.

\section{Slide-Lines}

Three slide-line options are available.

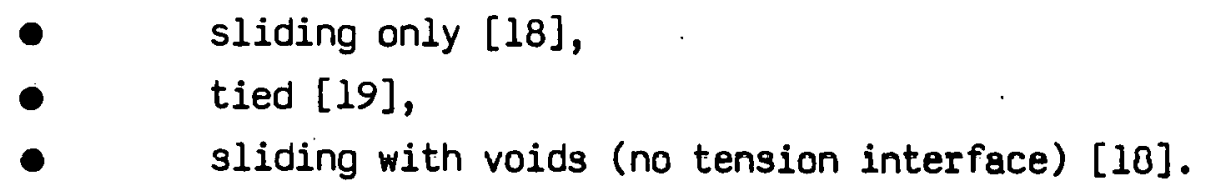

All slide-line types admit arbitrary zoning along interfaces, and, with the exception of the first two options, gaps may exist in the initial configuration. Slide-lines are permitted to intersect. When voids close, momentum is conserved. It should be noted that the current slide-line references are not up-to-date. 


\section{Rezoning}

A rezoner has been embedded in DYNA2D. All element and nodal variables are remapped to a new mesh generated interactively. Internal energy, kinetic energy, r-momentum, z-momentum, and mass are computed and printed for each material before and after rezoning to enable the user to determine if the rezoned mesh is acceptable. A simple example is provided in the input section, but perhaps the best way to learn to use the rezoner is by experimentation.

\section{Capacity}

Presently, the capacity of DYNA2D is limited to approximately 5000 elements on the CDC 7600 and 30000-40000 elements on Cray-1. Storage allocation is dynamic so that the only limit that exists on the number of boundary condition cards, number of material cards, number of pressure cards, etc., is the capacity of the computer.

\section{Code Organization}

DYNA2D consist of one source that compiles under CFT [20] and FTN [21] on the Cray-1 and CDC 7600 computers, respectively. The programming is in FORTRAN IV. DYNA2D has seven overlays in addition to the main code. They are: They are:

$\begin{array}{ll}- & \text { Input. } \\ \text { - } & \text { Restart. } \\ \text { - } & \text { Initialization. } \\ \text { - } & \text { Finite element method. } \\ \text { - } & \text { Rezoning initialization. } \\ & \text { Rezoning mesh redefinition. }\end{array}$

All data are stored in core during execution. 


\section{Sense Switch Controls}

DYNA2D has four teletypewriter sense switch controls that are tabulated below:

Type Response

SWl. A retart file is written and DYNA2D terminates.

SW2. DYNA2D responds with time and cycle numbers.

SW3. A restart file is written and DYNA2D continues.

SW4. Plot state is dumped.

When DYNA2D terminates, all scratch files are destroyed. The restart file, plot files, and high-speed printer files remain on disk. of these, only the restart file is needed to continue the interrupted analysis.

\section{Execution}

DYNA2D is a public file on the CDC 7600 and CRAY-1 computers at LLNL.

The teletypewriter execution line for DYNA2D is as follows:

DYNA2D I=inf $0=\operatorname{otf} G=p t f \quad D=$ dpf $T=$ tpf $F=$ the $C=c f r$

whiere 


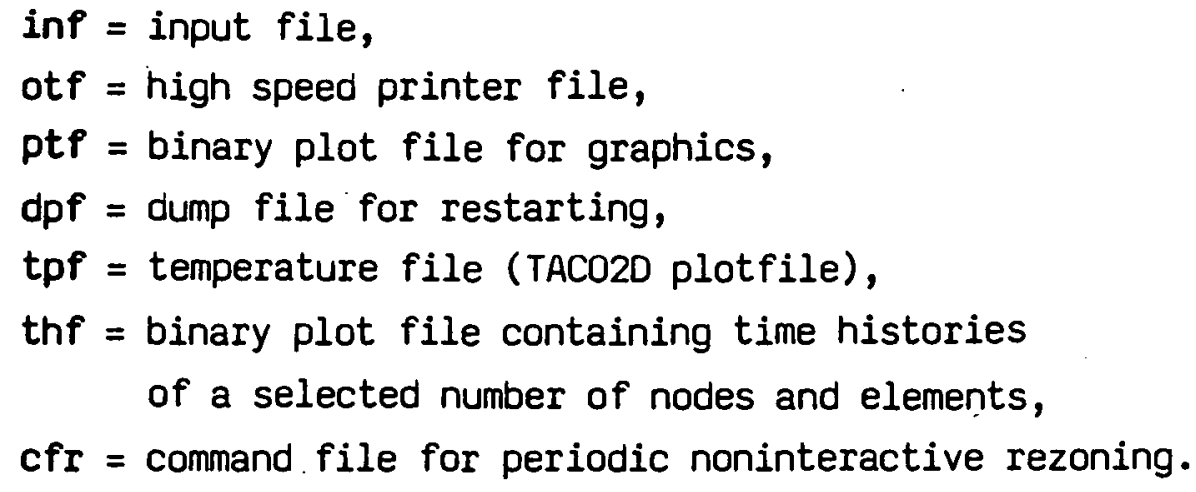

File names must not exceed six characters. If the time history file (thf) is not specified, time history data is written into the high speed printer file.

When restarting from a dump file, the execution line becomes

$$
\text { DYNA2D I=inf } O=\text { otf } G=p t f \quad D=\text { dpf R=rtf }
$$

where

$$
\text { rtf }=\text { restart file. }
$$

When restarting from a dump file with the intent of rezoning, the execution line becomes

$$
\text { DYNA2D Z=REZONE I=inf } O=\text { otf } G=p t f \quad D=\text { dpf } R=\operatorname{rtf} F=\text { thf } T=\text { tpf }
$$

File name dropouts are permitted, for example

$$
\begin{aligned}
& \text { DYNA2D I=inf } \\
& \text { DYNA2D } R=r t f \\
& \text { DYNA2D } Z=\text { REZONE R=rtf }
\end{aligned}
$$

Default names for the output file, binary plot files, and the dump file are DYNOUT, PPDYNA, and DUMPFL, respectively. 


\section{Execution Speeds}

The execution speeds of OYNA2D's various options are tabulated below in CPU minutes per million mesh cycles.

\begin{tabular}{ll} 
Machine & CPU \\
\hline COC 7600 & Minutes $/ 10^{6}$ Mesh Cycles \\
Cray-1 & 3.00 finite element method \\
& $0.30-0.50$ finite element method
\end{tabular}

These timings do not account for the inclusion of sliding interfaces. Presently, the sliding interface logic is not vectorized.

\section{Automated Input Generation}

Complete input files for DYNA2D are generated by MAZE [22]. MAZE input is totally format free and can be inputted interactively, with a command file, or both. MAZE writes an input file in accordance with this user's manual.

\section{Post-Processing}

Post-processors, THOR, [23] and ORION [24] are available. These programs read the binary plot files that DYNA2D generates, and plot contours, time histories, and deformed shapes. Contours of nearly 100 different quantities may be plotted on meshes consisting of triangular and quadrilateral elements. They can compute a variety of strain measures, momentum by material, reaction forces along constrained boundaries, and interface pressures along sliding interfaces. ORION is fully interactive and will eventually replace THOR. 


\section{DYNA2D USER'S GUIDE}

\section{Title Card}

- Columns

$\frac{\text { Quantity }}{\text { Heading to appear on output }}$

Format

$12 A 6$

$-11-$ 


\section{Control Cards}

\section{Card 1}

Columns $1-2$

Input form Quantity

Format A2

EQ."ND": input follows this manual

EQ. "OD"; input follows 1980 manual

3-5 Number of materials (NUMMAT) I3

6-10 Number of nodal points I5

11-15 Number of elements I5

16-20 Number of nodal printout blocks I5

21-25 Number of element printout blocks I5

26-30 Number of load curves I5

31-35 Number of concentrated nodal loads and follower forces I5

36-45 Time to begin periodic noninteractive rezoning El0.0

46-55 Time to end periodic rezoning Elo.0

56-65 Time interval between rezoning El0.0

66-75 Scale factor for computed time step size, SFCT El0.0

(DEFAULT $=.67$ )

Parameters in columns 36-65 apply only if an input file is defined $(\mathrm{C}=\mathrm{cfr}$ ) on the execute line.

\section{Card 2}

Columns

$1-5$

6-10

$11-15$
Quantity

Number of element sides having either pressure or shear loadings applied

Number of velocity boundary condition cards

Base acceleration in $\mathrm{r}$-direction (see Fig. 2)
Format

EQ.0: no r-acceleration

EQ.1: r-acceleration 
Columns

$16-20$

$21-25$

$26-30$

$31-35$

$36-40$

4l-45

46-50

$51-55$
Quantity

Base acceleration in $z$-direction

Format I5

EQ.0: no z-acceleration

EQ.1: z-acceleration

Angular velocity about $z$-axis

EQ.0: no angular velocity

EQ.1: angular velocity

Initial condition parameter

IS

EQ.0: initialize velocities to zero

EQ.1: initial velocities are read in

Number of stonewalls

I5

Number of slide-lines

I5

Number of slide-lines intersections, NUMSI

I5

Analysis type

EQ. 0: axisymmetric

EQ. 1: plane strain

Number of points in density vs. z-coordinate curve, NUMDZ

EQ.0: initịal stress due to gravational loads not considered

Reduction factor, RF, to determine minimum

permissible time step $(<1.0)$

NE.0.0: calculation terminates when

$\mathrm{DT} \leq \mathrm{RF}$ * DT $\mathrm{T}_{i}$ where $\mathrm{DT} \mathrm{T}_{i}$ equals

the initial time-step size 


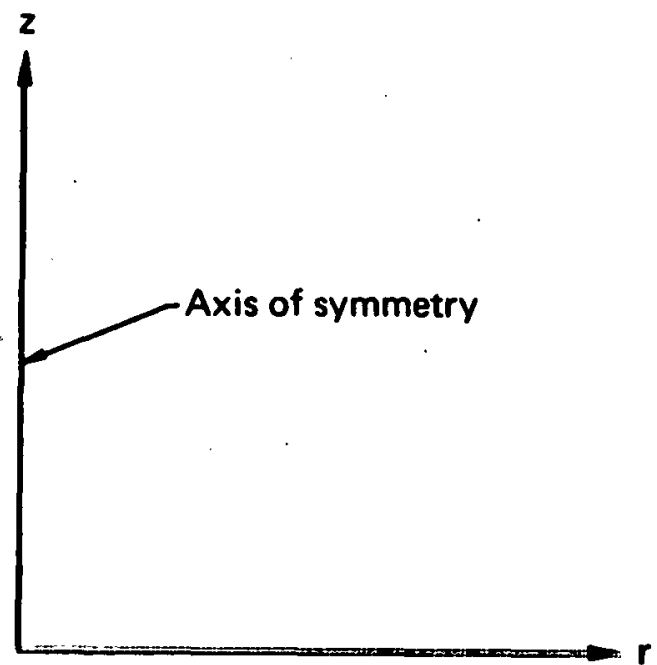

Fig. 2. Coordinate system with

$\therefore \quad$ axis of symmetry about z-axis.

\section{Card 3}

Columns

1-10

$11-20$

$21-30$

$31-40$
Quantity

Termination time

Time interval between high-speed printouts

Time interval between dumps of plot data

Initial time-step size
Format

El0.0

E10.0

El0.0

El0.0

EQ.0.0: an initial time-step size is computed 
EQ.0: beta burn

EQ.1: programmed burn - elements

that are lit at time zero are flagged in

the element data

EQ.2: programmed burn - lighting

is defined in Section 6

EQ.3: volume burn-lighting times are given on element cards

46-50 Number of time steps between restart dumps

EQ.0: restart dump is written when normal termination occurs

51-55 Thermal effects option

EQ.0: no theimal effects

EQ.n: temperature-time history is defined

by load curve $n$

LT.0: nodal temperatures are defined in

TACO2O generated disk files

56-60 Dump option for internal energy

EQ.0: internal energy is not written into data base

EQ.1: internal energy is written into data base

61-65

Special dump option

EQ.1: new defaults are read on next card 


\title{
Card 4 (define if IRQ=1)
}

\author{
Columns \\ $1-5$ \\ Quantity \\ Format \\ Hourglass viscosity type, IHQ \\ EQ.0: default set to "l" \\ EQ.1: standard DYNA2D \\ EQ.2: rotational \\ EQ.3: Flanagan-Belytschko \\ $6-15$ \\ Hourglass viscosity coefficient, $Q H$ (default $=.1$ ) \\ E10.0 \\ IHQ.EQ.1: QH $\leq \cdot 15$ \\ IHQ.EQ.2: QH $\leq \cdot 20$ \\ IHQ.EQ.3: QH $\leq \cdot 40$ \\ 16-20 Bulk viscosity type, IBQ \\ EQ.0: default set to "l" \\ EQ.1: standard DYNA2D \\ EQ.2: Richards-Wilkins \\ $21-30$ \\ Quadratic viscosity coefficients, Q1 (default $=1.5$ ) \\ E10.0 \\ $31-40$ \\ Linear viscosity coefficient, Q2 (default $=.06$ ) \\ ElO.0 \\ These are defaults that can, if desired, be overridden for each material \\ defined below.
}




\section{Material Cards}

Repeat the following cards for each material model:

\section{Card 1}

Columns $1-5$ 6-10

$11-20$

$21-25$
Quantity

Material indentification numer ( $\leq$ NUMMAT)

Material type, MT
Format

I5

I5

EQ. 1: elastic

EQ. 2: orthotropic elastic

EQ. 3: kinematic/isotropic elastic-plastic

EQ. 4: thermo-elastic-plastic

EQ. 5: soil and crushable foam

EQ. 6: linear viscoelastic

$\mathrm{EQ}$. 7: rubber

EQ. 8: high explosive burn

EQ. 9: null material

EQ.10: elastic-plastic hydrodynamic

EQ.11: temperature dependent elastic-plastic

Density

E10.0

Equation-of-state type. Define if MT > 7

EQ.l: linear polynomial

EQ.2: JWL high explosive

EQ.3: Sack "Tuesday" high explosive

EQ.4: Gruneisen

EQ.5: ratio of polynomials

EQ.6: linear polynomial with energy deposition

EQ.7: ignition and growth of reaction in HE

EQ.8: tabulated compaction

EQ.9: tabulated

If not defined, the following quanitities are set to their default values. 
Columns

26-30

$31-40$

4l-45

56-65

Columns $1-72$
Quantity

Hourglass viscosity type, IHQ

Format I5

EQ.1: standard DYNA2D

EQ.2: rotational

EQ.3: Flanagan-Belytschko

Hourglass viscosity coefficient

Bulk viscosity type, IBQ

E10.0

I5

EQ.1: standard DYNAZD

EQ.2: Richards-Wilkins

Quadratic viscosity coefficient, Q1

Linear viscosity coefficient, Q2

\section{Card 2}

Quantity

Material identification
Format $12 A 6$ 


\begin{tabular}{|c|c|c|c|}
\hline & & Cards $3,4,5, \ldots, 8$ & \\
\hline Material & 1 (Elastic & Material & \\
\hline Columns & & Quantity & Format \\
\hline $1-10$ & Card 3 & Young's modulus & E10.0 \\
\hline $1-10$ & Card 4 & Poisson's ratio & E10.0 \\
\hline $1-10$ & Card 5 & Blank & \\
\hline $1-10$ & Card 6 & Blank & \\
\hline $1-10$ & Card 7 & Blank & \\
\hline $1-10$ & Card 8 & Blank & \\
\hline
\end{tabular}


Material Type 2 (Orthotropic Elastic)

Columns

Quantity

Format

1-10

11-20

$21-30$

$1-10$

$11-20$

21-30

$1-10$

$1-10$

$\begin{array}{ll}\text { Card } 3 & E_{a} \text { (see Fig. 3) } \\ & E_{b} \\ & E_{c} \\ \text { Card } 4 & \nu_{a b} \\ & \nu_{a c} \\ & \nu_{b c} \\ \text { Card } 5 & G_{a b} \\ \text { Card } 6 & \text { Material axes option, AOPT }\end{array}$

E10.0

E10.0

E10.0

El0.0

E10.0

E10.0

E10.0

E10.0

EQ.0.0: locally orthotropic with material

axes determined by $\psi$ specified on each

element card and element nodes $n_{1}$ and $n_{2}$

(see Fig. 3)

EQ.1.0: locally orthotropic with material axes

determined by a point in space and global

location of element center

EQ.2.0: globally orthotropic with material

axes determined by $\psi_{G}$

$1-10$

Card

$y_{p}$, define for AOPT $=1.0$

E10.0

$11-20$

$z_{p}$, define for AOPT $=1.0$

E10.0

$1-10$

Card $8 \quad \psi_{G}$ in radians, define for

El0.0

The material law that relates stresses to strains is defined as:

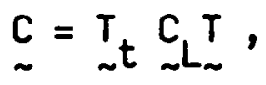

where $I$ is a tranformation matrix, and $C_{L}$ is the constitutive matrix defined in terms of the material constants of the orthogonal material axes, $a$ and $b$ : 

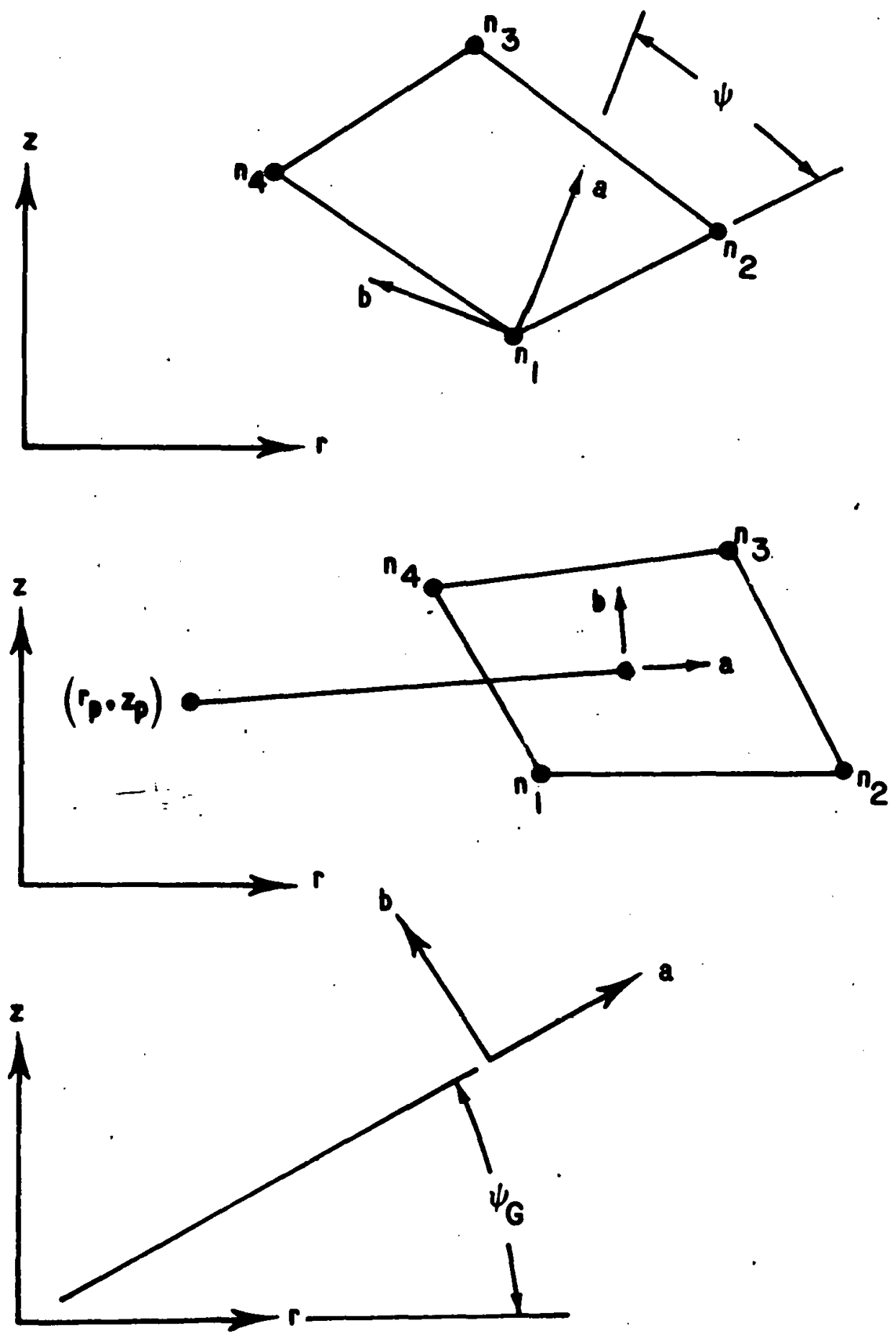

Fig. 3. Options for determining principal material axes: AOPT $=0.0$, (b) $A O P T=1.0$, and $(c)$ AOPT $=2.0$. 


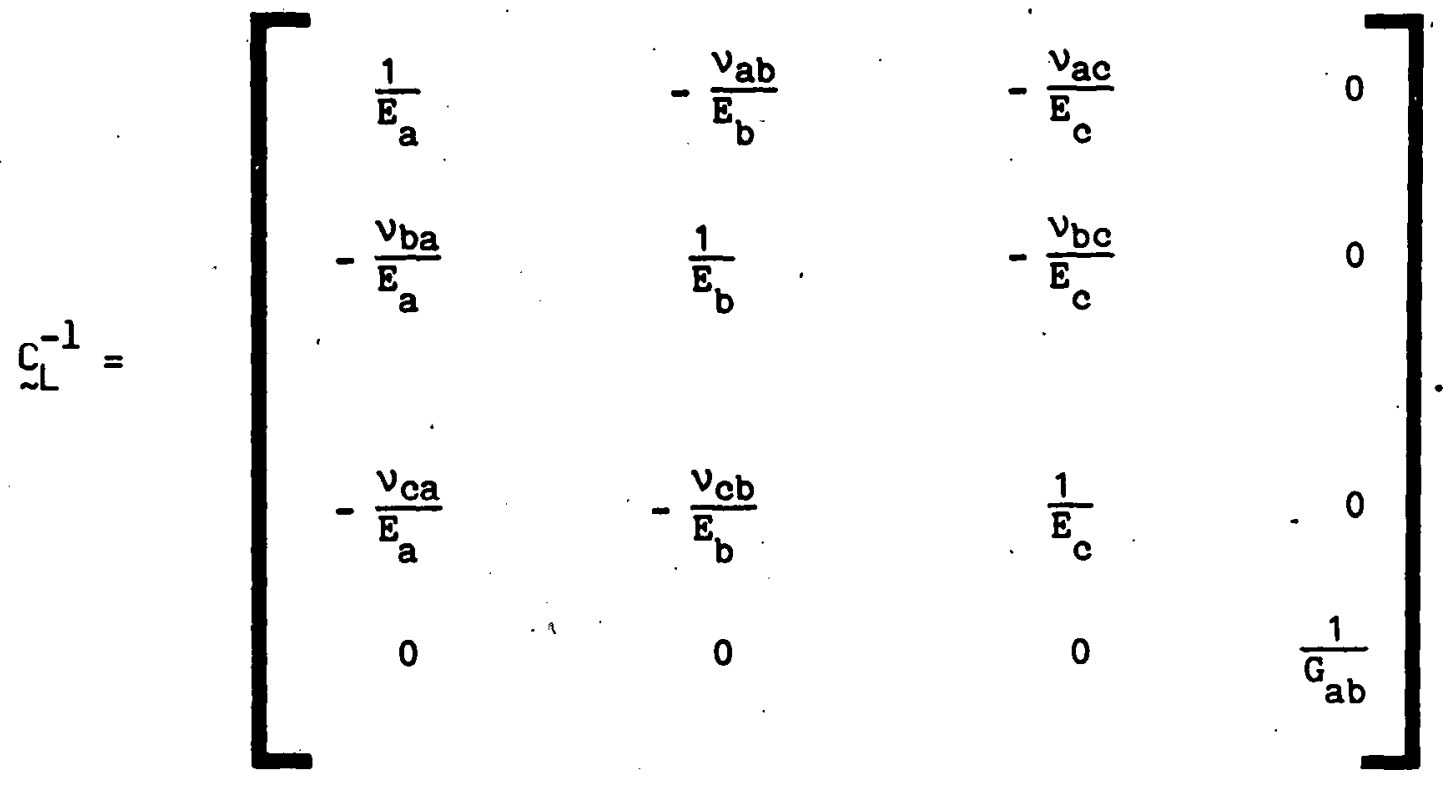

Note that $\nu_{b a} / E_{a}=\nu_{a b} / E_{b}, \nu_{a c} / E_{c}=\nu_{c a} / E_{a}$, and $\nu_{b c} / E_{c}=\nu_{c b} / E_{b}$. 
Material Type 3 (Kinematic/Isotropic Elastic-Plastic)

Columns

$1-10$

$1-10$

$1-10$

$1-10$

$1-10$
Quantity

Card 3 Young's modulus

Card 4 Poisson's ratio

Card 5 Yield stress

Card 6 Hardening modulus, $E_{t}$

Card 7 Hardening parameter, $\beta^{\prime}$

$0<\beta^{\prime}<1$

Card 8 Blank
Format

E10.0

El0.0

ElO.0

El0.0

E10.0

Isotropic; kinematic, or a combination of isotropic and kinematic hardening may be specified by varying $\beta^{\prime}$ and between $l$ and 0 . For $\beta^{\prime}$ equal to 0 and 1 , respectively, kinematic and isotropic hardening are obtained as shown in Fig. 4.

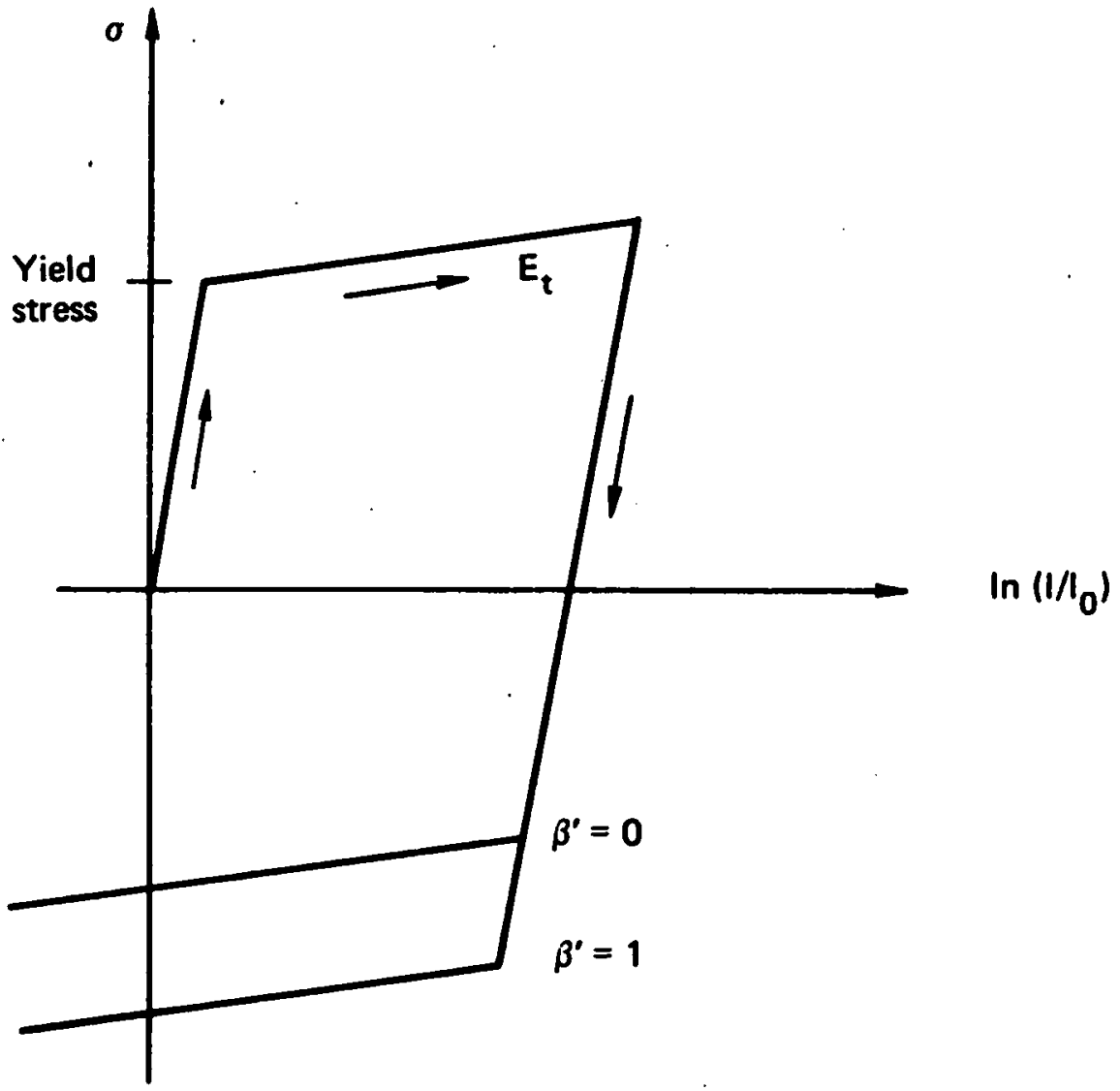

Fig. 4. Elastic-plastic behavior with isotropic and kinematic hardening where $l_{0}$ and 1 are undeformed and deformed lengths of uniaxial tension specimen. 
Material Type 4 (Thermo-Elastic-Plastic)

Columns

1-10

$11-20$

$71-80$

$1-10$

$11-20$

$71-80$

$1-10$

$11-20$

$\cdot$

•

$71-80$

1-10

$11-20$

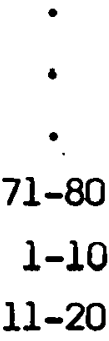

$71-80$

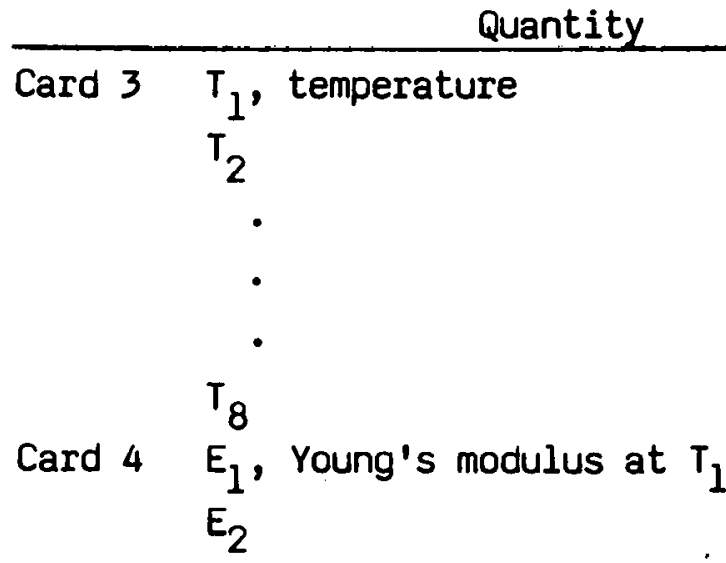

El0.0

El0.0

El0.0

$E_{8}$

Card $5 \quad v_{1}$, Poisson's ratio at $T_{1}$

$v_{2}$

-

$\cdot$

-

$v_{8}$

Card $6 \alpha_{1}$, coefficient of thermal expansion at $T_{1}$

$\alpha_{2}$

$\alpha_{8}$

Card $7, \sigma_{y l}$, yield stress at $T_{1}$

$\sigma_{\mathrm{y} 2}$

•

$\sigma_{\text {y8 }}$
E10.0

E10.0

El0.0

E10.0

El0.0

E10.0

ElO.O

El0.0

E10.0

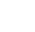

El0.0 
Columns

1-10

11-20

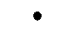

-

71-80
Quantity

Format

Card $8 \quad E_{l}^{p}$, plastic hardening modulus at $T_{1}$

El0.0

El0.0

•

\section{-}

$\dot{E}_{8}^{p}$

At least two temperatures and their corresponding material properties must be defined. The analysis will be terminated if a material temperature falls outside the range defined in the input. If a thermoelastic material is considered, leave cards 7 and 8 blank. The coefficient of thermal expansion is defined with respect to a reference temperature. 
Material Type 5 (Soil and Crushable Foam)

Columns

$1-10$

$11-20$

$21-30$

$31-40$

$41-50$

$51-60$

$1-10$

$11-20$

$21-30$

$31-40$

$1-10$

$11-20$

$21-30$

31-40

$1-10$

$11-20$

$21-30$

$31-40$

\begin{tabular}{|c|c|}
\hline \multirow[t]{6}{*}{ Card 3} & Shear modulus \\
\hline & Bulk unloading mod \\
\hline & Yield function con \\
\hline & Yield function con \\
\hline & Yield function con \\
\hline & Pressure cutoff fo \\
\hline \multirow[t]{4}{*}{ Card 4} & Volumetric strain \\
\hline & Pressure \\
\hline & Volumetric strain \\
\hline & Pressure \\
\hline \multirow[t]{7}{*}{ Card 5} & Volumetric strain \\
\hline & Pressure \\
\hline & volumetric strain \\
\hline & Pressure \\
\hline & - \\
\hline & - \\
\hline & $\cdot$ \\
\hline \multirow[t]{4}{*}{ Card 8} & Volumetric strain \\
\hline & Pressure \\
\hline & Volumetric strain \\
\hline & Pressure \\
\hline
\end{tabular}

Format

El0.0

E10.0

ElO.0

El0.0

ElO:0

ElO.0

ElO.0

Elo.0

El0.0

E10.0

El0.0

E10.0

E10.0

E10.0

El0.0

El0.0

El0.0

E10.0 


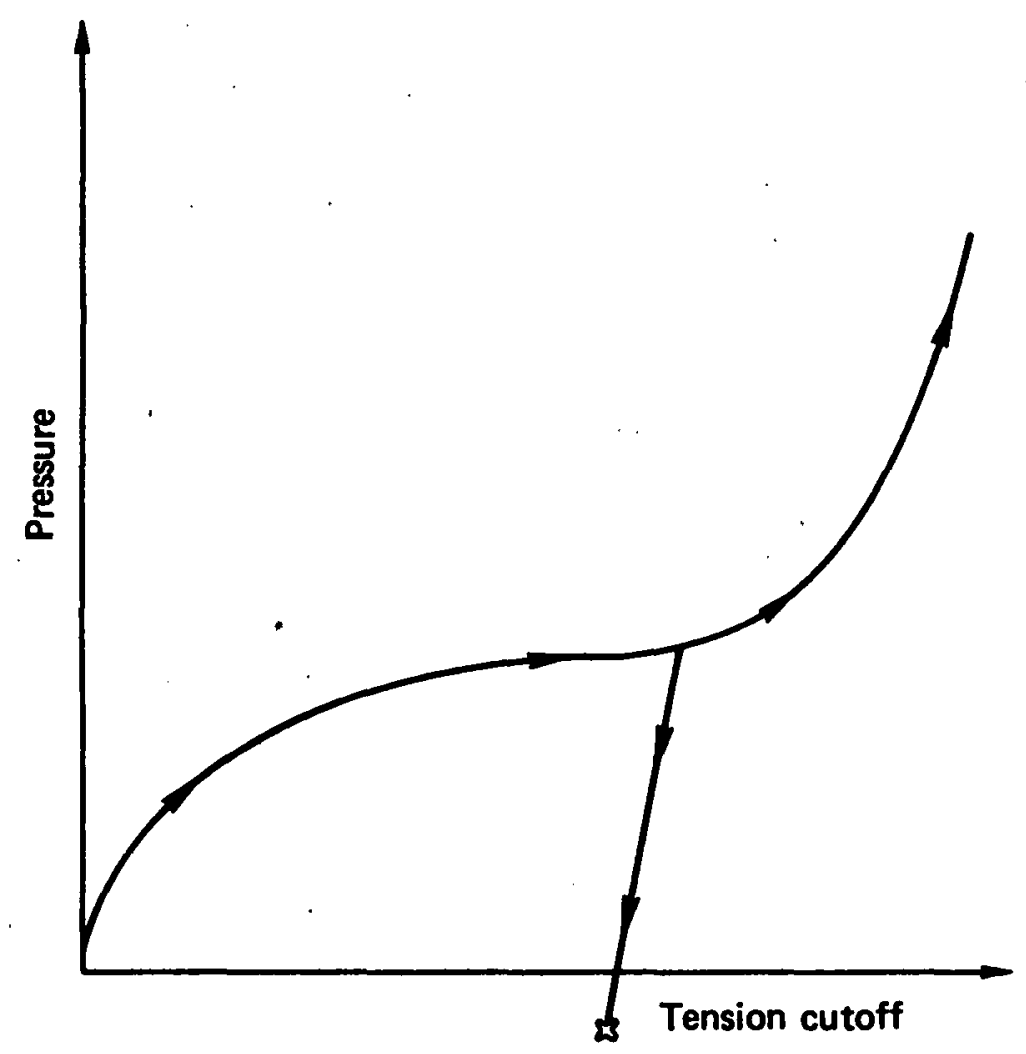

Volumetric strain [- Init)]

Fig. 5. Volumetric strain vs pressure curve for soil and crushable foam model.

The deviatoric yield function, $\phi$, is described in terms of the second invariant $\mathrm{J}_{2}$,

$$
J_{2}=\frac{1}{2} s_{i j} s_{i j}
$$

pressure, $p$, and constants $a_{0}, a_{1}$, and $a_{2}$ as:

$$
\phi=J_{2}-\left[a_{0}+a_{1} p+a_{2} p^{2}\right] \text {. }
$$

The volumetric strain is given by the natural logarithm of the relative volume, $v$.

$-27-$ 


\section{Material Type 6 (Viscoelastic)}

Columns

$1-10$

$1-10$

$1-10$

$1-10$
Quantity

Card 3 Bulk modulus (elastic)

Card 4 Short-time shear modulus, $G_{0}$

Card 5 Long-time shear modulus, $G_{\infty}$

Card 6 Decay constant, $B$

Card 7

Card 8
Format

ElO.0

El0.0

El0.0

El0.0

The shear relaxation behavior as described by:

$$
G(t)=G_{\infty}+\left(G_{0}-G_{\infty}\right) e^{-\beta t}
$$




\section{Material Type 7 (Rubber)}

Columns

$$
\text { 1-10 }
$$

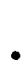$$
\text { - }
$$

Quantity

\begin{tabular}{ll}
\hline Card 3 & Shear modulus \\
Card 4 & $\begin{array}{l}\text { Blank } \\
\end{array}$ \\
& - \\
Card 8 & Blank
\end{tabular}

Format

E10.0 
Material Type 8 (High Explosive Burn)

Columns

Quantity

Format

1-10

Card 3

$D$, Detonation velocity

El0.0

$11-20$

$\mathrm{P}_{\mathrm{CJ}}$, Chapman-Jouget pressure

E10.0

Card 4 Blank

Card 8 Blank 
Material Type 9 (Null);

Columns

$1-10$

\begin{tabular}{cc}
\hline Card 3 & press \\
Card 4 & blank \\
$\cdot$ & - \\
- & - \\
- & .
\end{tabular}

The null material may be used with an equation-of-state. No deviatoric stress is permitted with this material type. 
Material Type 10 (Isotropic-Elastic-Plastic-Hydrodynamics)

Columns

$1-10$

$11-20$

$21-20$

$31-40$

$41-50$

$51-60$

$1-10$

Card 4

Card 5

$\varepsilon_{1}$

$\varepsilon_{2}$

$\varepsilon_{3}$

$\varepsilon_{4}$

$41-50$

$71-80$

$1-10$

$71-80$

1-10

Card
Quantity

Format

El0.0

El0.0

ElO.0

E10.0

E10.0

E10.0

Elo.0

El0.0

ElO.0

E10.0

El0.0

41-50

$\sigma_{8}$ 
Columns

$1-10$

$31-80$
Format

Card 8

$\sigma_{9}$

El0.0

E10.0

Whenever Cards 5-8 are blank, the yield stress and plastic hardening modulus are taken from Card 3 . In this case assuming $a_{1}=a_{2}=0$, the bilinear stress-strain curve shown in Fig. 4 is obtained with $\beta=1$. The yield strength is calculated as

$$
\sigma_{y}=\sigma_{0}+E_{h} \bar{\varepsilon}^{-p}+\left(a_{1}+a_{2} p\right) \max (0, p)
$$

where $p$ is the pressure. The quantity $E_{h}$ is the plastic hardening modulus defined in terms of Young's modulus, $E$, and the tangent modulus, $E_{t}$, as follows

$$
E_{h}=\frac{E_{t} E}{E-E_{t}}
$$

If cards 5-8 are used, a curve like that shown in Fig. 6 may be defined. In this latter case, the yield stress and plastic haroiening modulus, $a_{1}$ and $a_{2}$ on Card 3 are ignored. Effective stress is defined in terms of the deviatoric stress tensor, $s_{i j}$, as:

$$
\bar{\sigma}=\left(\frac{3}{2} s_{i j} s_{i j}\right)^{1 / 2}
$$

and effective plastic strain by:

$$
\bar{\varepsilon}^{p}=\int_{0}^{t}\left(\frac{2}{3} D_{i j}^{p} D_{i j}^{P}\right)^{1 / 2} d t,
$$


where $t$ denotes time and $D_{i j}^{P}$ is the plastic component of the rate of deformation tensor.

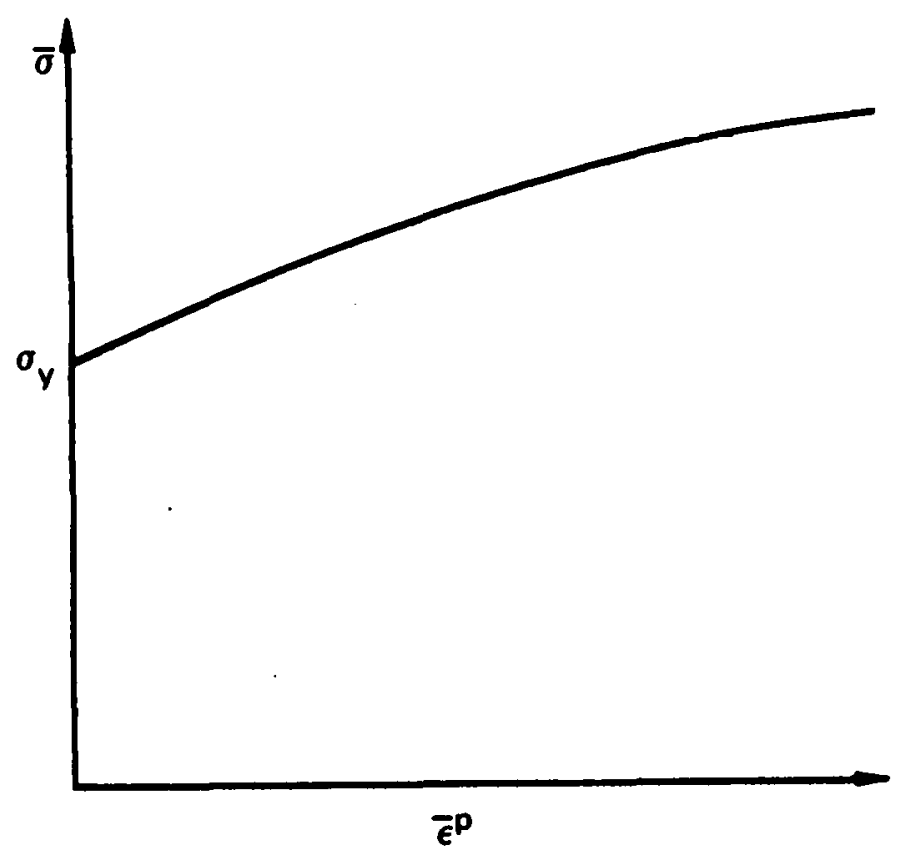

Fig. 6. Effective stress vs effective plastic strain curve. 
Material Type 11 (Temperature Dependent, Elastic-Plastic,|Hydrodynamic)

Columns

$1-10$

$11-20$

$21-30$

$31-40$

41-50

$1-10$

$11-20$

$21-30$

$31-40$

41-50

$1-10$

$11-20$

$21-30$

$31-40$

41-50

Card 6

Card 3

$G_{0}$

Format

E10.0

E10.0

E10.0

E10.0

E10.0

Card $4 \quad \sigma_{m}$

E10.0

E10.0

E10.0

E10.0

E10.0

E10.0

El0.0

E10.0

E10.0

El0.0

$P_{\min }$ or failure stress, $\sigma_{f}$

E10.0

EQ.0.0: default set to "2.0"

EQ.1.0: $p \geq P_{\min }$

EQ.2.0: if $\sigma_{\max } \geq \sigma_{f}$ element spalls and tension, $p<0$, is never allowed

EQ.3.0: if $p<p_{\text {min }}$ element spalls and tension, $p<0$, is never allowed

$1-16$

Card 5

$E C_{0}$

El6.0

$17-32$

$\mathrm{EC}_{1}$

El6.0

$33-48$

$\mathrm{EC}_{\text {? }}$

El6.0

$49-64$

$\mathrm{EC}_{3}$

El6.0

$65-80$

$\mathrm{EC}_{4}$

El6.0 
Columns

1-16

17-32

$33-48$

49-64

65-80
Quantity

Format

Card $6 . \mathrm{EC}_{5}$

$\mathrm{EC}_{6}$

E16.0

E16.0

E16.0

$\mathrm{EC}_{8}$

E16.0

Users, who have an interest in this model, are encouraged to study the paper by Steinberg and Guinan which provides the theoretical basis. Another useful reference is the KOVEC user's manual.

In terms of the foregoing input parameters, we define the shear modulus, $G$, before the material melts as:

$$
G=G_{0}\left[1+b p v^{1 / 3}-h\left(\frac{E_{i}-E_{c}}{3 R^{\prime}}-300\right)\right] e^{-\frac{f E}{E_{m}-E_{i}}}
$$

where $p$ is the pressure, $v$ is the relative volume, $E_{c}$ is the cold compression energy:

$$
\begin{aligned}
& E_{c}(x)=\int_{0}^{x} p d x-\frac{900 R^{\prime} \exp (a x)}{(1-x)^{2\left(\gamma_{0}-a-1 / 2\right)}}, \\
& x=1-V,
\end{aligned}
$$

and $E_{m}$ is the melting energy:

$$
E_{m}(x)=E_{c}(x)+3 R \cdot T_{m}(x)
$$

which is in terms of the melting temperature $T_{m}(x)$ : 


$$
T_{m}(x)=\frac{T_{m 0} \exp (2 a x)}{v^{2\left(\gamma_{0}-a-1 / 3\right)}}
$$

and the melting temperature at $\rho=\rho_{o}, T_{m o}$.

In the above equation, $\mathrm{R}^{\prime}$ is defined by

$$
R^{\prime}=R \rho / A
$$

where $R$ is the gas constant and $A$ is the atomic weight.

The yield strength $\sigma_{y}$ is given by:

$$
\sigma_{y}=\sigma_{0}^{\prime}\left[1+b p^{1 / 3}-h\left(\frac{E_{i}-E_{c}}{3 R^{\prime \prime}}-300\right)\right] e^{-\frac{f E}{E_{m}-E_{i}}}
$$

if $E_{m}$ exceeds $E_{i}$. Here, $\sigma_{0}^{\prime}$ is given by:

$$
\sigma_{0}^{\prime}=\sigma_{0}\left[1+\beta\left(\gamma_{i}+\varepsilon^{-p}\right)\right]^{n}
$$

where $\gamma_{i}$ is the initial plastic strain. Whenever $\sigma_{0}{ }^{\prime}$ exceeds $\sigma_{m}, \sigma_{0}^{\prime}$ is set equal to $\sigma_{m}$. After the material melts, $\sigma_{y}$ and $G$ are set to zero.

If the coefficients ECO,...,EC9 are not defined above, DYNA2D will fit the cold compression energy to the ten term polynomial expansion:

$$
E_{c}=\sum_{i=0}^{9} E C_{i} n^{i}
$$

where $E C_{i}$ is the ith coefficient and $n=\rho / \rho_{0}$. The least squares method is used to perform the fit. 
Define equation-of-state cards only if MT $>7$.

\section{Card 9}

Columns

Quantity

Format

$1-72$

Equation-of-state identification

$12 A 6$ 
Cards 10,...

Equation-of-State Form 1 (Linear Polynomial)

Columns

$1-10$

$10-20$

$21-30$

$31-40$

41-50

$51-60$

$61-70$

$71-80$

$1-10$

Card $10 \mathrm{c}$

Card $11 \mathrm{v}_{0}$, initial relative volume

“Quantity
Format

El0.0

E10.0

E10.0

E10.0

E10.0

E10.0

E10.0

E10.0

E10.0

The linear polynomial equation-of-state is linear in internal energy. The pressure is given by:

$$
p=c_{\phi}+c_{1} \mu+c_{2} \mu^{2}+c_{3} \mu^{3}+\left(c_{4}+c_{5} \mu+c_{6} \mu^{2}\right) E \text {. }
$$

where terms $\mathrm{C}_{2} \mu^{2}$ and $\mathrm{C}_{6} \mu^{2}$ are set to zero if $\mu<0, \mu=\rho / \rho_{0}-1$, and $\rho / \rho_{0}$ is the ratio of current density over initial density. 
Equation-of-State Form 2 (JUL)

Columns

$1-10$
$11-20$
$21-30$
$31-40$
$41-50$
$51-60$
$61-70$
Quantity

$\begin{array}{ll}\text { Card } & A \\ B & \\ R 1 \\ R 2 \\ \omega \\ E_{0} \text {, initial internal energy }\end{array}$

$v_{0}$, initial relative volume
Format

E10.0.

E10.0

E10.0

E10.0

E10.0

E10.0

E10.0

The JWL equation-of-state defines the pressure as

- $P=A\left(1-\frac{\omega}{R_{1} V}\right) e^{-R_{1} V}+B\left(1-\frac{\omega}{R_{2} V}\right) e^{-R_{2} V}+\frac{\omega E}{V}$,

and is usually used for detonation products of high explosives.

$-40-$ 
Equation-of-State Form 3 (Sack) ,

$\frac{\text { Columns }}{1-10}$
$11-20$
$21-30$
$31-40$
$41-50$
$51-60$
$61-70$

\begin{tabular}{|c|c|c|}
\hline \multirow{2}{*}{ Card 10 } & Quantity & \multirow{2}{*}{$\frac{\text { Format }}{\text { Elo.0 }}$} \\
\hline & $A_{1}$ & \\
\hline & $A_{2}$ & Elo. 0 \\
\hline & $\mathrm{A}_{3}$ & E10.0 \\
\hline & $B_{1}$ & Elo.0 \\
\hline & $\mathrm{B}_{2}$ & E10.0 \\
\hline & $E_{0}$, initial internal energy & El0.0 \\
\hline & $\mathrm{v}_{0}$, initial relative volume & $\mathrm{E} 10.0$ \\
\hline
\end{tabular}

The Sack equation-of-state defines pressure as

$$
p=\frac{A_{3}}{V^{A}} e^{-A_{2} V}\left(1-\frac{B_{1}}{V}\right)+\frac{B_{2}}{V} E
$$

and is used for detonation products of high explosives. 
Equation-of-State Form 4 (Gruneisen)

$\frac{\text { Columns }}{1-10}$
$11-20$
$21-30$
$31-40$
$41-50$
$51-60$
$61-70$
$71-80$

\begin{tabular}{clc}
\multicolumn{1}{c}{ Quantity } & Format \\
\hline Card 10 & $C$ & El0.0 \\
& $S_{1}$ & $E 10.0$ \\
$S_{2}$ & $E 10.0$ \\
$S_{3}$ & $E 10.0$ \\
$\gamma_{0}$ & $E 10.0$ \\
$a$ & $E 10.0$ \\
$E_{0}$, initial internal energy & $E 10.0$ \\
$V_{0}$, initial relative volume & $E 10.0$
\end{tabular}

The Gruneisen equation-of-state with cubic shock velocity-particle velocity defines pressure for compressed materials as

$$
p=\frac{\rho_{0} c^{2} \mu\left[1+\left(1-\frac{\gamma_{0}}{2}\right) \mu-\frac{a}{2} \mu^{2}\right.}{\left[1-\left(S_{1}-1\right) \mu-S_{2} \frac{\mu^{2}}{\mu+1}-S_{3} \frac{\mu^{3}}{(\mu+1)^{2}}\right]^{2}}+\left(\gamma_{0}+a \mu\right) E .
$$

and for expanded materials as

$$
p=\rho_{0} c^{2} \mu+\left(\gamma_{0}+a \mu\right) E
$$

where $C$ is the intercept of the $u_{s}-u_{p}$ curve; $s_{1}, s_{2}$, and $s_{3}$ are the coefficients of the slope of the $u_{s}-u_{p}$ curve; $\gamma_{0}$ is the Gruneisen gamma; and $a$ is the first order volume correction to $\gamma_{0}$. 
Equation-of-State Form 5 (Ratio of Polynomials)

\begin{tabular}{|c|c|c|c|c|}
\hline Columns & & & & Format \\
\hline $1-16$ & Card 10 & Alo & & El6.0 \\
\hline $17-32$ & & All. & & El6.0 \\
\hline $33-48$ & 1 & Al2 & & El6.0 \\
\hline $49-64$ & & Al3 & & El6.0 \\
\hline $1-16$ & Card 11 & $A 20$ & $\cdot$ & El6.0 \\
\hline $17-32$ & & $A 21$ & & El6.0 \\
\hline $33-48$ & & $A 22$ & & El6.0 \\
\hline $49-64$ & & $A 23$ & & El6.0 \\
\hline $1-16$ & Card 12 & A30 & & El6.0 \\
\hline $17-32$ & . & $A 31$ & & El6.0 \\
\hline $33-48$ & & A32 & & El6.0 \\
\hline $49-64$ & & A33 & & El6.0 \\
\hline $1-16$ & Card 13 & A40 & & El6.0 \\
\hline $17-32$ & & A4l & & E16.0 \\
\hline $33-48$ & & A42 & & El6.0 \\
\hline $49-64$ & & A43 & . & E16.0 \\
\hline $1-16$ & Card 14 & $A 50$ & & t16.0 \\
\hline $17-32$ & & $A 51$ & & El6.0 \\
\hline $33-48$ & & A52 & & El6.0 \\
\hline $49-64$ & & A53 & & El6.0 \\
\hline $1-16$ & Card 15 & $A 60$ & & El6.0 \\
\hline $17-32$ & & A61 & & El6.0 \\
\hline $33-48$ & & $A 62$ & & E16.0 \\
\hline $49-64$ & & $A 63$ & & El6.0 \\
\hline
\end{tabular}


Columns

1-16

17-32

$33-48$

$49-64$

$1-16$

17-32

$33-48$

$49-64$

$1-16$

17-32

\section{Card $16 \quad$ A70}

El6.0

A71

E16.0

A72

El6.0

A73

El6.0

Card $18 \alpha$

E16.0

E16.0

E16.0

E16.0

El6.0

Card $19 E_{0}$, initial internal energy

El6.0

The ratio of polynomials equation-of-state defines the pressure as

$$
p=\frac{F_{1}+F_{2} E+F_{3} E^{2}+F_{4} E^{2}}{F_{5}+F_{6} E+F_{7} E^{2}}(1+\alpha \mu)
$$

where

$$
\begin{array}{ll}
F_{i}=\sum_{j=0}^{n} A_{i j} \mu^{j} . & n=4 \text { if } i<3 \\
\mu=\rho / \rho_{0}-1 & n=3 \text { if } i \geq 3
\end{array}
$$

In expanded zones $F_{1}$ is replaced by $F_{1}^{\prime}=F_{1}+\beta \mu^{2}$ 
Equation-of-State Form 6 (Linear Polynomial with Energy Leak)

Columns

$1-10$

$10-20$

$21-30$

$31-40$

$41-50$

51-60

$61-70$

$71-80$

$1-10$

$11-20$
Quantity

Format

El0.0

El0.0

El0.0

E10.0

E10.0

El0.0

El0.0

E10.0

E10.0

El0.0

$\mathrm{CN}$, number of time history curve that gives energy deposition rate. 
Equation-of-State Form 7 (Ignition and Growth of Reaction in HE) ,

\begin{tabular}{|c|c|c|c|}
\hline Columns & & Quantity & Format \\
\hline $1-10$ & Card 10 & $A_{p}$ & ElO.0 \\
\hline $11-20$ & & $B_{p}$ & E10.0 \\
\hline $21-30$ & & $\mathrm{Rl}_{\mathrm{p}}$ & El0.0 \\
\hline $31-40$ & & $R 2 p$ & E10.0 \\
\hline $41-50$ & & G, second ignition coefficient & ElO.0 \\
\hline $1-10$ & Card 11 & $\omega_{p} c_{p}$ & $\mathrm{E} 10.0$ \\
\hline $11-20$ & & $A_{e}$ & El0.0 \\
\hline $21-30$ & & $\mathrm{~B}_{\mathrm{e}}$ & Elo.0 \\
\hline $31-40$ & . & $\omega_{e} c_{e}$ & E10.0 \\
\hline $41-50$ & & $\mathrm{Rl}_{\mathrm{e}}$ & El0.0 \\
\hline $1-10$ & Card 12 & $\mathrm{R}_{\mathrm{e}}$ & E10.0 \\
\hline $11-20$ & & FCRIT, critial fraction reacted (usually $=1.0$ ) & $E 10.0$ \\
\hline $21-30$ & & I, first ignition coefficient & E10.0 \\
\hline $31-40$ & & $H$, growth coefficient & E10.0 \\
\hline $41-50$ & & $z$, pressure exponent & E10.0 \\
\hline $1-10$ & Card 13 & $x$ & E10.0 \\
\hline $11-20$ & & $y \quad$ & ElO.0 \\
\hline $21-30$ & & $c_{p}$, heat capacity of reaction products & Elo.0 \\
\hline $31-40$ & & $c_{e}$, heat capacity of unreacted $\mathrm{HE}$ & E10.0 \\
\hline $1-10$ & Card 14 & m (generally $=0$ ) & E10.0 \\
\hline $11-20$ & & $E_{0}$, initial energy of $\mathrm{HE}$ per unit volume & El0.0 \\
\hline $21-30$ & & $T_{0}$, initial temperature $\left({ }^{O} \mathrm{~K}\right)$ & Elo.0 \\
\hline & Card 15 & Blank & \\
\hline
\end{tabular}


A JWL equation-of-state defines the pressure in the unreacted HE as

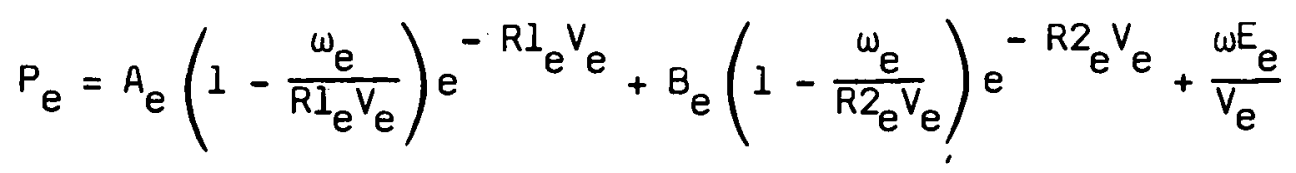

where $V_{e}$ is the relative volume, $E_{e}$ is the internal energy, and the constants $A_{e}, B_{e}, \omega_{e}, R l_{e}$, and $R 2$ are input constants.

Similarily, the pressure in the reaction products is defined by another JWL form

$$
P_{p}=A_{p}\left(1-\frac{\omega_{p}}{R I_{p} V_{p}}\right) e^{-R 1_{p} V_{p}}+B_{p}\left(1-\frac{\omega_{p}}{R 2_{p} V_{p}}\right) e^{-R 2_{p} V_{p}}+\frac{\omega E_{p}}{V_{p}}
$$

The mixture of unreacted explosive and reaction products is defined by the fraction reacted $F(F=0 \rightarrow$ no reaction, $F=1 \rightarrow$ complete conversion from explosive to products). The pressures and temperature are assumed to be in equilibrium and the volumes are assumed to be additive.

$$
V=(1-F) V_{e}+F V_{p}
$$

The rate of reaction for material type 13 is

$$
\frac{\partial F}{\partial t}=I(F C R I T-F)^{y}\left(V_{e}^{-1}-1\right)^{3}\left[1+G\left(V_{e}^{-1}-1\right)\right]+H(1-F)^{y} F^{x} P^{z}\left(V_{p}^{-1}-1\right)^{m}
$$

where $I, G, H, x, y, z$, and $m$ (generally $m=0$ ) are input constants.

The JWL equations of state and the reaction rates have been fitted to one- and two-dimensional shock initiation and detonation data for four explosives: PBX-9404, RX-03-BB, PETN, and cast TNT. The details of the calculational method are described by Cochran and Chan [11]. The detailed one-dimensional calculations and parameters for the four explosives are given by Lee and Tarver [10]. 
Equation-of-State Form 8 (Tabulated-Compaction)

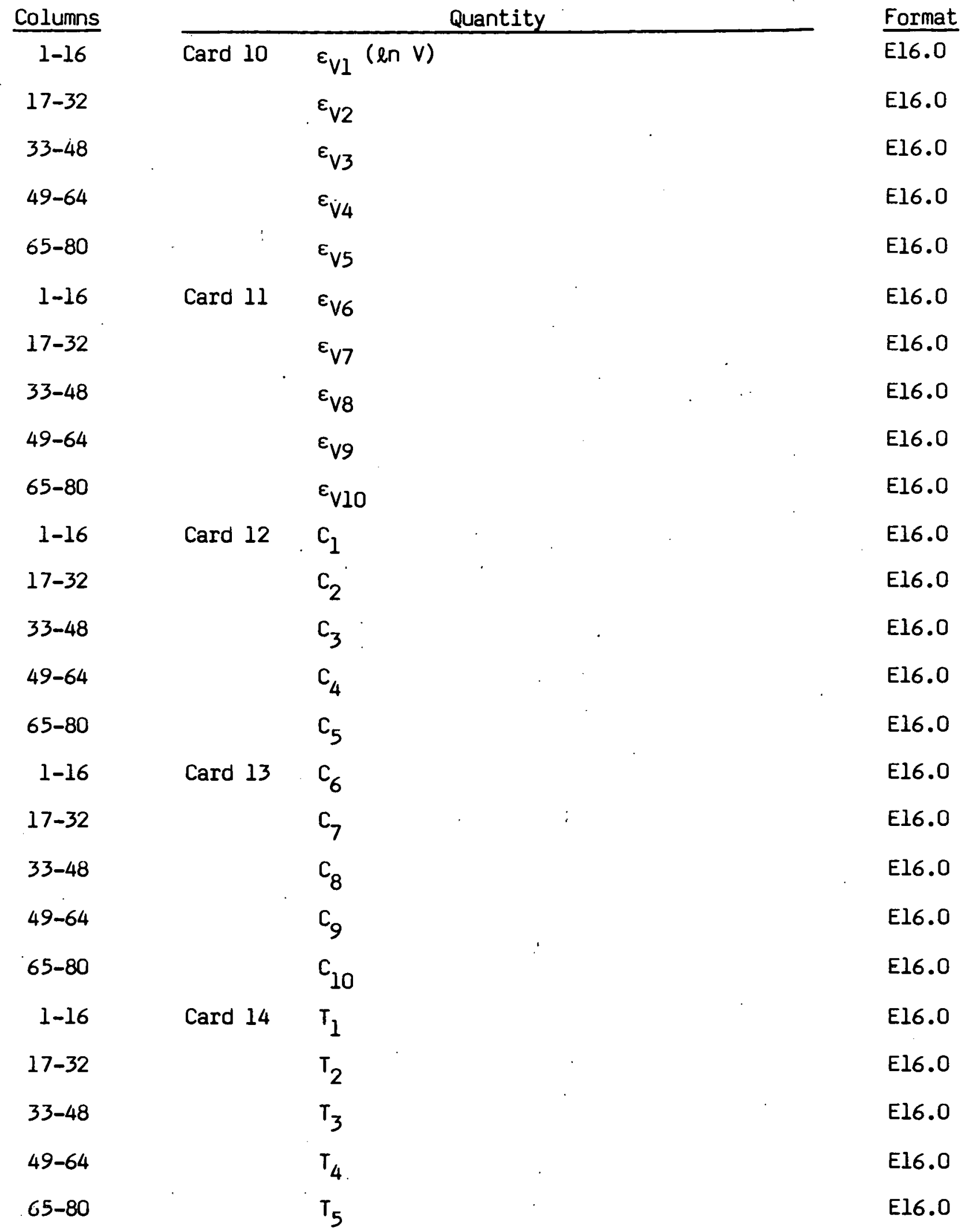


Columns

$$
\text { 1-16 }
$$

17-32

$33-48$

49-64

65-80

1-16

$17-32$

$33-48$

49-64

65-80

$1-16$

17-32

$33-48$

49-64

65-80

1-16

$17-32$

$33-48$
Quantity

Format Card $15 \quad T_{6}$

$T_{7}$

$\mathrm{T}_{8}$

$\mathrm{T}_{9}$

$\mathrm{T}_{10}$

Card $16 \quad \mathrm{k}_{\mathrm{l}}$

$\mathrm{K}_{2}$

$\mathrm{K}_{3}$

$\mathrm{K}_{4}$

$\mathrm{K}_{5}$

Card $17 \quad K_{6}$

$k_{7}$

$\mathrm{k}_{8}$

$\mathrm{K}_{9}$

$\mathrm{k}_{10}$

Card $18 \quad \gamma$

$E_{0}$, initial internal energy

$v_{0}$, initial relative volume
El6.0

El6.0

E16.0

E16.0

E16.0

El6.0

El6.0

El6.0

El6.0

E16.0

E16.0

El6.0

El6.0

El6.0

E16.0

E16.0

E16.0

E16.0

The tabulated compaction model is linear in internal energy. Pressure is defined by

$$
p=C\left(\varepsilon_{V}\right)+\gamma^{T}\left(\varepsilon_{V}\right) E
$$

in the loading phase. The volumetric strain, $\varepsilon_{\mathrm{V}}$, is given by the natural logarithm of the relative volume. Unloading occurs along the unloading bulk modulus to the pressure cutoff. Reloading always follows the unloading path 
to the point where unloading began, and continues on the loading path. See Fig. 7. Up to 10 points and as few as 2 may be used when defining the tabulated functions, DYNA2D will extrapolate to find the pressure if necessary.

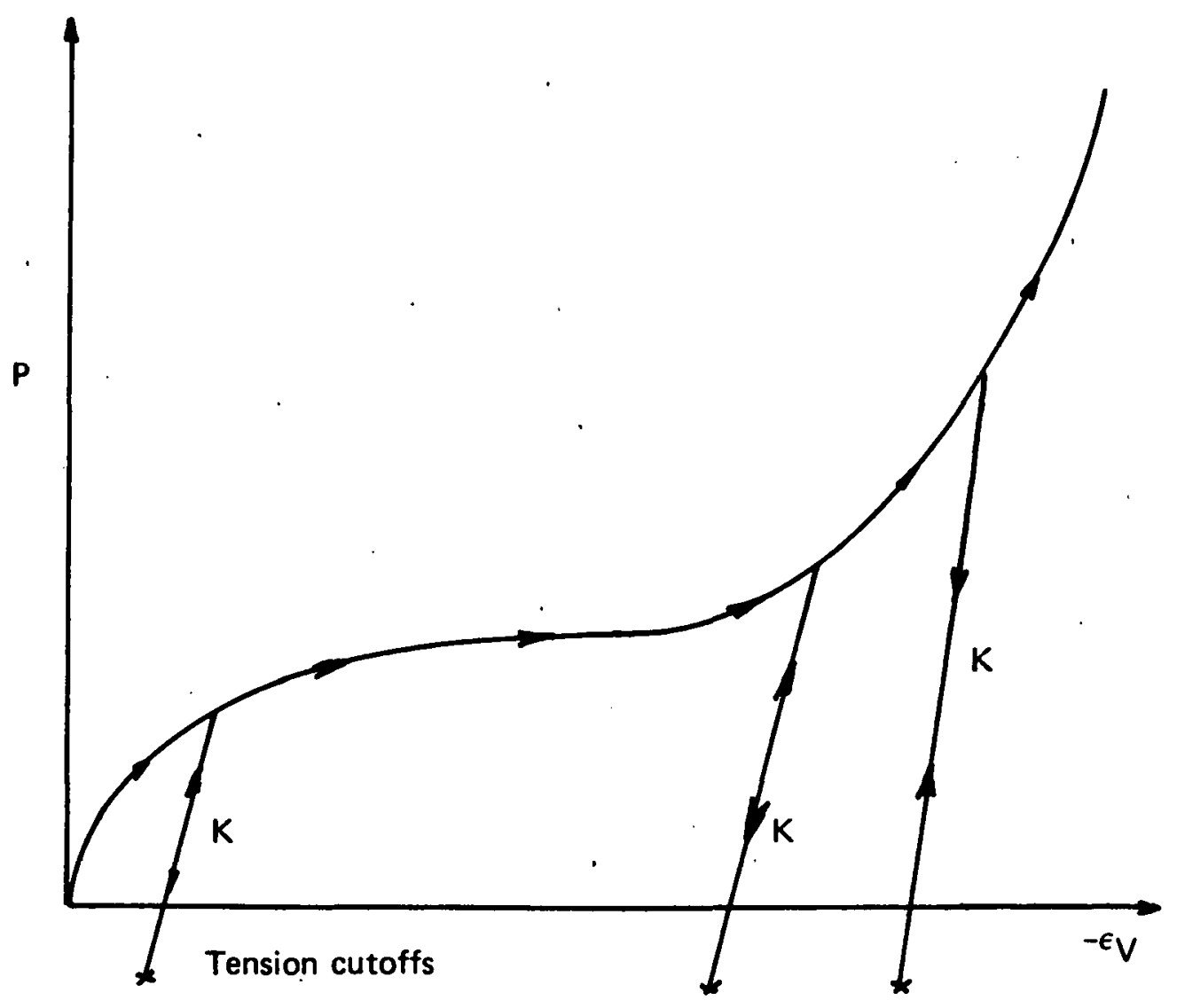

Fig. 7. Pressure versus volumetric strain curve for equation-of-state form 8 with compaction. In the compacted states the bulk unloading modulus depends on the peak volumetric strain. . 


\section{Equation-of-State Form 9 (Tabulated)}

Columns

$1-16$

$17-32$

$33-48$

$49-64$

$65-80$

$1-16$

$17-32$

$33-48$

$49-64$

$65-80$

$1-16$

$17-32$

$33-48$

$49-64$

$65-80$

1-16

$17-32$

$33-48$

49-64

$65-80$

$1-16$

$17-32$

$33-48$

49-64

$65-80$

Card $10 \varepsilon_{V_{1}}(\ln V)$

Quantity

Format

E16.0

El6.0

El6.0

El6.0

El6.0

El6.0

Card $11 \quad E_{V 6}$

$\varepsilon_{V 7}$

El6.0

El6.0

E16.0

El6.0

El6.0

El6.0

El6.0

El6.0

E16.0

El6.0

E16.0

El6.0

E16.0

E16.0

E16.0

El6.0

El6.0

E16.0

El6.0 
Columns

$$
1-16
$$

$17-32$

$33-48$

49-64

$65-80$

$1-16$

$17-32$

$33-48$
Quantity

Format

El6.0

El6.0

El6.0

El6.0

El6.0

El6.0

Card $16 \gamma$

El6.0

El6.0

The tabulated equation-of-state model is linear in internal energy. Pressure is defined by

$$
P=C\left(\varepsilon_{V}\right)+\gamma T\left(\varepsilon_{V}\right) E
$$

The volumetric strain, $\varepsilon_{v}$, is given by the natural logarithm of the relative volume. Up to 10 points and as few as 2 may be used when defining the tabulated functions. DYNA2D will extrapolate to find the pressure if necessary. 


\section{Nodal Point Cards}

Supply one card for each nodal point with the following information:

Columns

$1-5$

6-io

Quantity

Nodal point number, $n^{i}$

Boundary condition code, $\mathrm{BCC}^{\mathrm{i}}$

Format

F5.0

EQ.0.0: no constraint

EQ.1.0: r-constraint

EQ.2.0: z-constraint

$E Q$.3.0: $r$ and $z$ constraints

If $\mathrm{BCC}^{i}$ is not any of the above, it is assumed to be the angle in degrees between the positive $r$-axis and the direction of the motion along a sliding boundary (see Fig. 8)

$11-20$

$21-30$

31-35

$r^{i}$ - global coordinate

E10.0

$z^{i}$ - global coordinate

E10.0

Generation interval $\mathrm{KN}$

\section{EQ.0: default set to "l"}

Nodal point cards do not need to be in order; however, the highest nodal point number must terminate the nodal data. When nodal data are missing, node numbers are generated according to the sequence:

$$
n^{i}, n^{i}+k N, n^{i}+2 k N, \ldots, n^{j}
$$

where $n^{i}$ and $n^{j}$ are the nodal numbers defined on two consecutive cards, and $K N$ is taken from the first card. Linear interpolation is used to obtain the coordinates of the generated nodes. The boundary conditions code of generated data is set to zero whenever BCCi $\neq B C C j$; otherwise, the code 


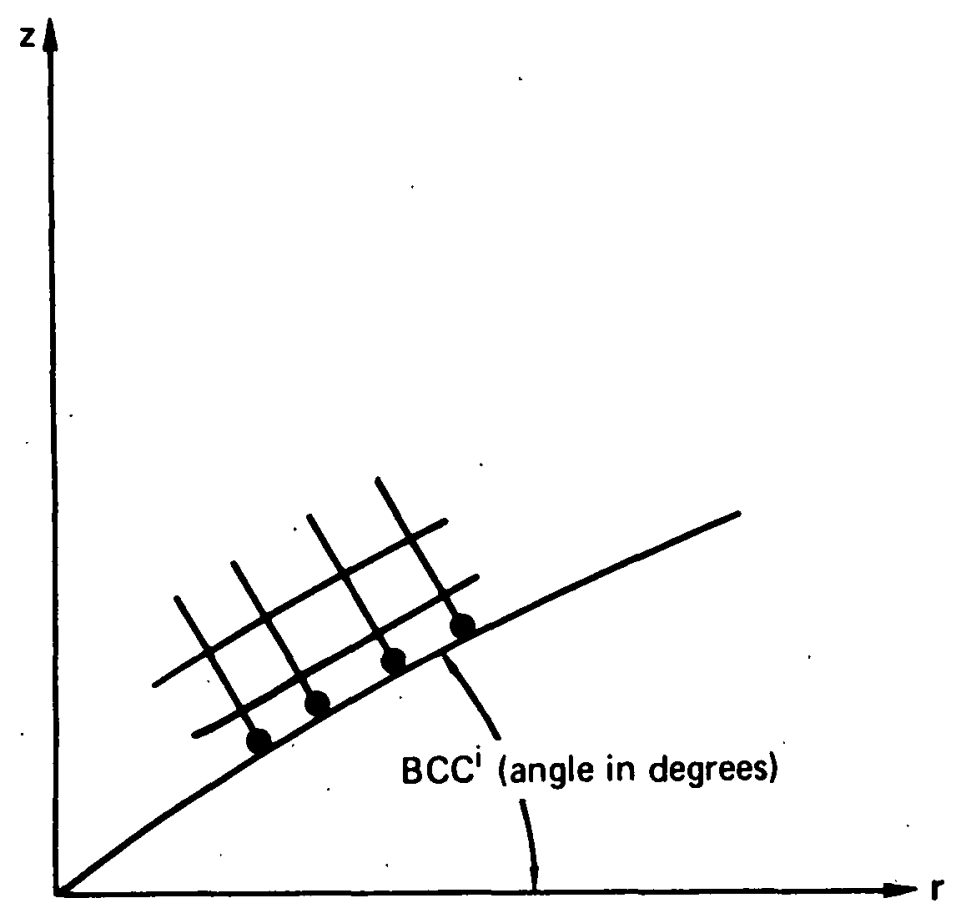

Fig. 8. Roller boundary condition that is obtained if $\mathrm{BCC}^{i}$ is , not equal to $0,1,2$, or 3 .

is assumed to be the same. Unconstrained nodes can be generated between constrained nodes that have the same boundary condition by making the code on the second card (node $n^{j}$ ) negative. After the data are generated, the code is reset. 


\section{Element Cards}

Supply one card for each element with the following information:

$\frac{\text { Columns }}{1-5}$
$6-10$
$11-15$
$16-20$
$21-25$
$26-30$
$31-35$
$36-45$

Quantity

$$
\begin{aligned}
& \text { Element number } \\
& \text { Node } n_{1} \\
& \text { Node } n_{2} \\
& \text { Node } n_{3} \\
& \text { Node } n_{4} \\
& \text { Material number } \\
& \text { Generation increment, KN } \\
& \text { Material dependent parameter } \\
& \text { MT.EQ.2: angle } \psi \text { in degrees } \\
& \text { MT.EQ.8 or MT.EQ.9: input "l.0" if } \\
& \text { element is lit at time zero } \\
& \text { MT.GE.10: initial internal energy }
\end{aligned}
$$

Format

I5

I5

I5

I5

I5

I5

I5

E10.0

Element cards are assumed to be in element number sequence with the last element terminating the data. Omitted data are automatically generated with respect to the first card prior to the omitted data as follows:

$$
n_{j}^{i+1}=n_{j}^{i}+k N
$$

The material properties, the mesh generation parameter, print code, and $\psi$ are taken from the first card. The convention for numbering nodal points is shown in Fig. 9 where $n_{1}, n_{2}, \ldots, n_{4}$ stand for global node numbers. Triangular zones are defined by setting node $n_{4}=n_{3}$. 

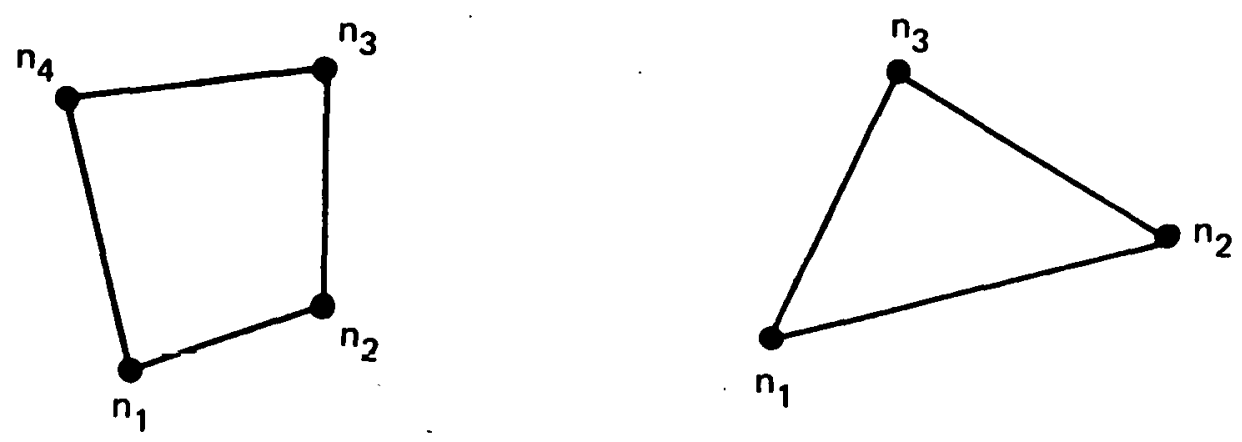

Fig. 9. Plane strain and axisymmetric elements available in DYNA2D.

$-56-$ 


\section{High Explosive Burn Definition}

Skip this section if IHE (Card 3, Section 2) is not equal to 2. Three options are available (see Fig. 10): they are the multiple point detonation, the line detonation, and Huygen detonation.

\section{Card 1}

Columns $1-5$

Detonation type, IBTYP

Quantity

Format

I5

EQ.0: multiple point detonation

EQ.1: line detonation

EQ.2: Huygens detonation

6-10 NUMPTS

I5

IBTYP.NE.1: NUMPTS is the number of detonation points

IBTYP.EQ.1: NUMPTS is the number of points in detonation line

Repeat the following set of cards NUMPTS times:

\section{Card 2}

Columns

$1-5$

Quantity

Format

Nodal point number

I5

IBTYP.NE.1: lying at detonation point

IBTYP.EQ.l: lying on detonation line

6-15

Lighting time

E10.0

EQ.0.0: if IBTYP $=1$

16-20 Material number of HE to be lit (IBTYP $=0$ only) 


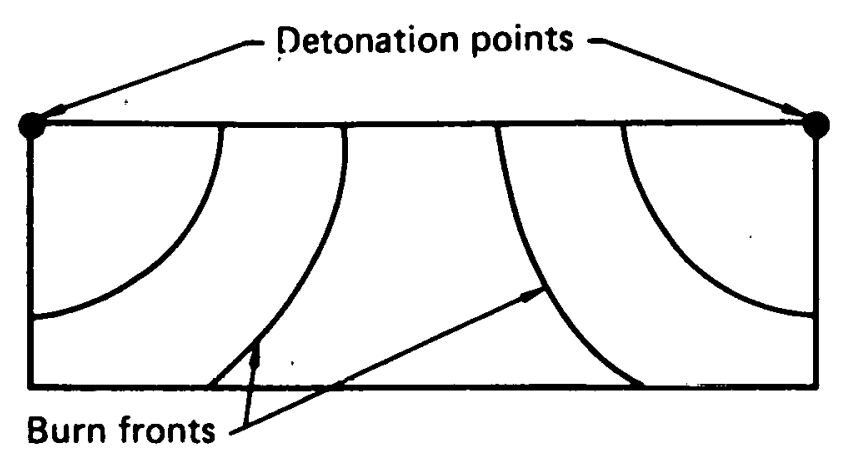

(a)

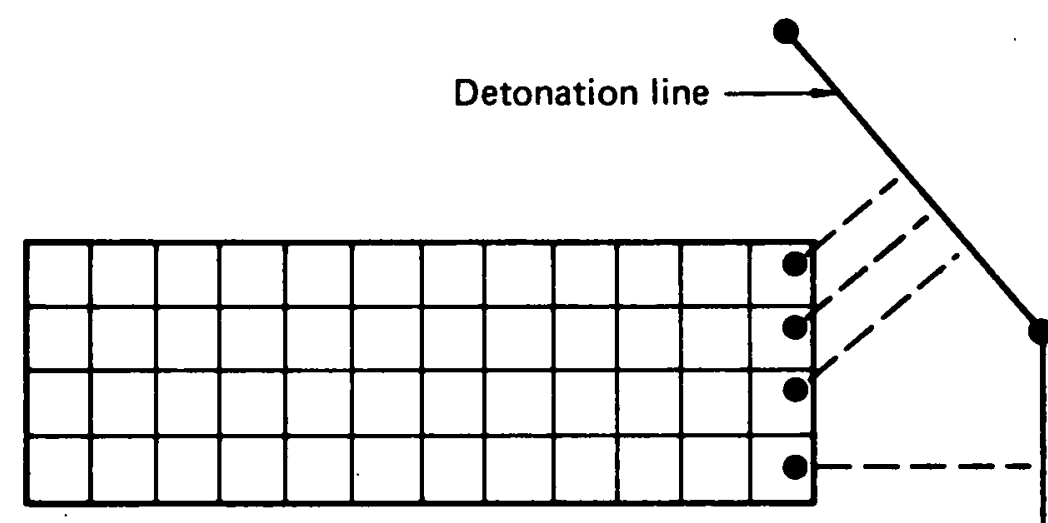

(b)

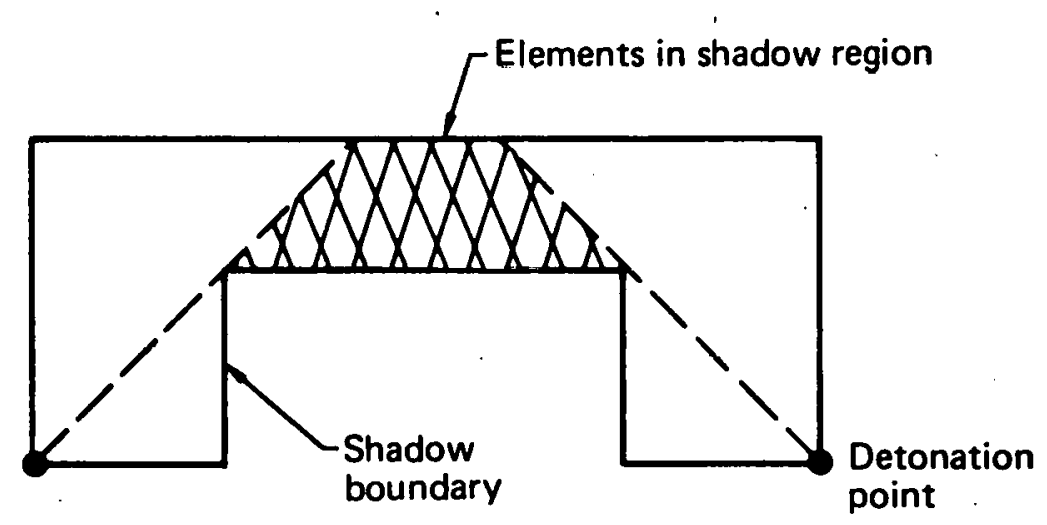

(c)

Fig. 10. Burn options: (a) multiple point, (b) line, and (c) Huygens. $-58-$ 
Columns

$21-30$

Quantity

Format

$31-40$

Detonation velocity outside shadowed HE (optional input)

E10.0

Detonation velocity in shadowed HE (optional input)

E10.0

\section{Card 3}

Include the following card only if IBTYP $=2$

Columns

Quantity

Format

$1-5$

NPSS, number of nodal points defining shadow boundary

\section{Card $4,5, \ldots$, NPSS +3}

Include the following cards only if IBTYP $=2$

$\frac{\text { Columns }}{1-5}$

Shadow point number
Nodal point number

Quantity

Format

A line detonation must be defined by at least two points. Nodal points that define a line must be given in the order in which they appear as one moves along the line.

In a Huygens detonation, a shadow boundary must be given for each detonation point. The first point on the shadow boundary must be closest to the detonation point - if it is not the detonation point. The shadow points must be defined in the order in which they are encountered as one moves along the boundary. Omitted data are automatically generated by incrementing the nodal point numbers by:

$$
\left(n_{i}-n_{j}\right) /\left(s n_{i}-s n_{j}\right)
$$

where $s n_{i}, s n_{j}$ are the shadow point numbers on two successive cards and $n_{i}$ and $n_{j}$ are their corresponding code numbers. 


\section{Nodal Printout Blocks}

Skip this section if the number of nodal printout blocks (Card 1, Section 2) is zero. Otherwise, insert one card with the following information (up to eight printout blocks may be defined):

\begin{tabular}{clc}
$\frac{1}{\text { Columns }}$ & \multicolumn{1}{c}{ Quantity } & Format \\
\cline { 2 - 3 } $1-5$ & First node of first printout block & I5 \\
$6-10$ & Last node of first printout block & I5 \\
$11-15$ & First node of second printout block & I5 \\
$16-20$ & Last node of second printout block &
\end{tabular}




\section{Element Printout Blocks}

Skip this section if the number of element printout blocks (Card l, Section 2) is zero. Otherwise, insert one card with the following information (up to eight printout blocks may be defined):

Columns

$1-5$

6-10

$11-15$

$16-20$
Quantity

First element of first printout block Last element of first printout block

First element of second printout block

Last element of. second printout block
Format

I5

I5

I5

I5 


\section{Time History Curve Cards}

Define the number of load curve sets specified in columns 26-30 of Card 1 in Section 2. Repeat the following cards for each set: Define the number of load curve sets specified in columns $26-30$ of Card 1 in Section 2. Repeat the following cards for each set:

\section{Card 1}

\begin{tabular}{lll}
$\frac{1}{\text { Columns }}$ & \multicolumn{1}{c}{ Quantity } & Format \\
\cline { 2 - 3 } $1-5$ & Load curve number & I5 \\
$6-10$ & Number of points in load curve (NPTS) & I5
\end{tabular}

\section{Card 2,...,NPTS+1}

\begin{tabular}{|c|c|c|}
\hline Columns & Quantity & Format \\
\hline $1-10$ & Time & ElO.0 \\
\hline $11-20$ & Load value & ElO.0 \\
\hline
\end{tabular}




\section{Concentrated Nodal Load and Follower Force, Cards}

Define the number of concentrated nodal point loads specified in columns 31-35 of Card 1 in Section 2.

\begin{tabular}{|c|c|c|}
\hline Columns & Quantity & Format \\
\hline $1-5$ & Nodal point number $(m)$ on which this load acts & I5 \\
\hline \multirow[t]{4}{*}{$6-10$} & Direction in which load acts & I5 \\
\hline & EQ.1: and IFW.EQ.0: r-direction & \\
\hline & EQ.2: and IFW.EQ.O: z-direction & \\
\hline & $\begin{array}{l}\text { EQ. } n \text { : and IFW.EQ.I: } n \text { is a node number } \\
\text { that defines a plane beginning at } m \text { and } \\
\text { ending at } n \text { (the force points to the } \\
\text { right as one moves along the surface } \\
\text { from } m \text { to } n \text { ) }\end{array}$ & \\
\hline $11-15$ & Load curve number & I5 \\
\hline \multirow[t]{2}{*}{$16-25$} & Scale factor & E10.0 \\
\hline & EQ.0.0: default set at "l.0" & \\
\hline \multirow[t]{2}{*}{$26-30$} & IFW, follower force flag & I5 \\
\hline & $\begin{array}{l}\text { EQ.0: concentrated force acts in } \\
\text { either } r \text { or } z \text { direction } \\
\text { EQ.1: follower force considered }\end{array}$ & \\
\hline
\end{tabular}




\section{Pressure and Shear Boundary Condition Cards}

Define the number of cards specified in Columns $1-5$ of Card 2 in Section 2.

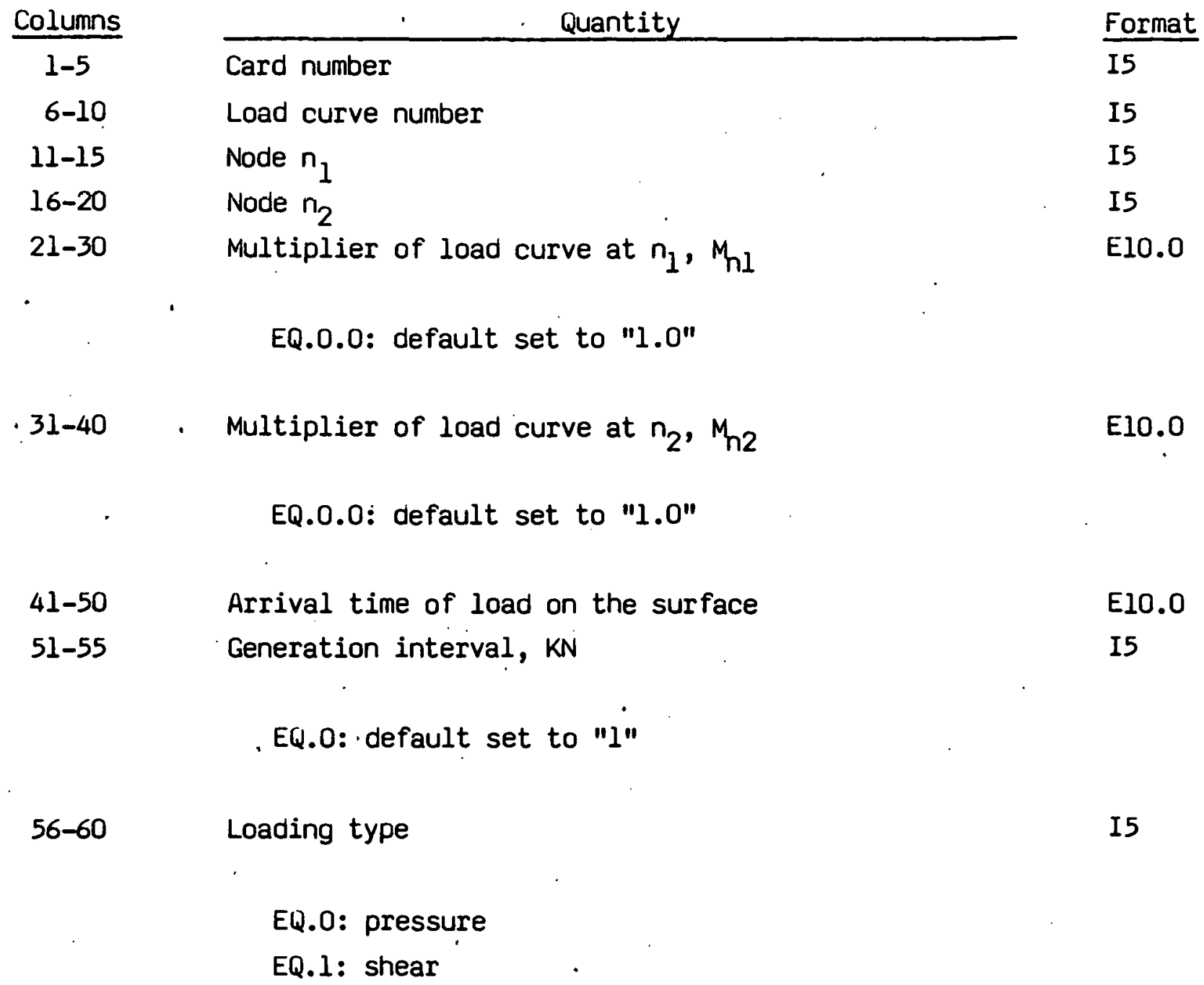

The start times, multipliers, and generation interval are taken from the first card. The interior is kept to the left as one progresses from node $n_{1}$ to $\mathrm{n}_{2}$ (see Fig. 11). Traction loads are always evaluated with respect to the deformed geometry. 

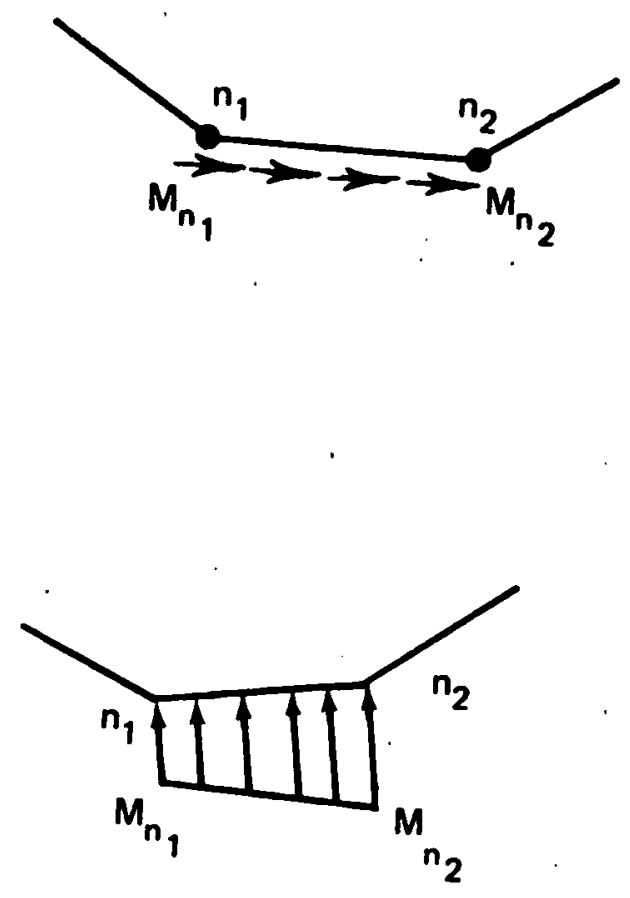

Fig. 11. Definition of nodes $n_{1}$ and $n_{2}$ for traction boundary conditions on bilinear elements. 


\section{Velocity Boundary Condition Cards}

Define the number of cards specified in columns 6-10 of Card 2 in Section 2.

\begin{tabular}{|c|c|c|}
\hline Columns & Quantity & Format \\
\hline $1-5$ & Nodal point number to which this velocity is applied & $\overline{\mathrm{I} 5}$ \\
\hline $6-10$ & Load curve number & I5 \\
\hline \multirow[t]{4}{*}{$11-15$} & Direction in which the node is displaced & E5.0 \\
\hline & EQ.1.0: r-direction & \\
\hline & EQ.2.0: z-direction & \\
\hline & $\begin{array}{l}\text { NE. } 1.0 \text { and NE.2.0: the angle in degrees } \\
\text { between the r-axis and the direction of the } \\
\text { prescribed velocity vector }\end{array}$ & \\
\hline $16-25$ & Scale factor & $E 10.0$ \\
\hline
\end{tabular}




\section{Base Acceleration in r-Direction}

Skip this card if columns 11-15 of Card 2 in Section 2 are blank.

\begin{tabular}{ccc}
$\frac{\text { Columns }}{1-5}$ & Quantity & Format \\
\cline { 2 - 3 } & $\begin{array}{l}\text { Load curve number } \\
\text { Scale factor on I-acceleration }\end{array}$ & I5 \\
EQ.0.0: default set at "l.0" & El0.0
\end{tabular}

This card applied only to plane strain geometries. 


\section{Base Acceleration in z-Direction}

Skip this card if columns $16-20$ of Card 2 in Section 2 are blank.

Columns $1-5$ 6-10

Load curve number

Scale factor on z-acceleration

EQ.0.0: default set to "1.0"
Format

I5

E10.0 


\section{Angular Velocity}

Skip this card if columns $21-25$ of Card 2 in Section 2 are blank.

Columns

$1-5$

6-10
Quantity

Load çurve number

Scale factor on angular velocity

EQ.0.0: default set to "1.0"
Format

I5

E10.0

Nodal loads due to the angular velocity are always calculated with respect to the deformed configuration. Angular velocity is assumed to have the units of radians per unit time. 


\section{Initial Conditions}

Skip this section if the initial condition parameter, in columns 26-30 of Card 2 in Section 2 is zero.

Columns

$1-5$

6-15

$16-25$

$26-35$
Quantity

$$
\text { Nodal point number }
$$

Initial velocity in r-direction

Initial velocity in z-direction

Nodal point increment
Format

I5

E10.0

E10.0

I5

EQ.0: default set to "l"

Initial velocity must be defined for each nodal point. These cards do not need to be in order; however, the highest nodal point number must terminate the data. Missing data are generated as described in Section 4. 


\section{Stonewall}

Skip this section if the number of stonewalls specified in columns $31-35$ of Card 2 in Section 2 is zero. Repeat the following sets of cards for each stonewall.

\section{Card 1}

Columns $1-5$ Quantity

Format

6-15

Number of slave nodes

I5

$r$-coordinate of tail of any outward drawn normal

El0.0 vector originating on wall (tail) and terminating in space (head)

$16-25$ $z$-coordinate of tail E10.0

26-35

$r$-coordinate of head E10.0

$36-45$ $z$-coordinate of head E10.0

Cards 2,3...,etc.

Columns

$$
1-5
$$

6-10

Quantity

Slave number

Format I5 Nodal point number

A stonewall extends to infinity and is defined by a normal vector of arbitrary magnitude drawn outward from the wall. Nodes that are designated as slave nodes cannot penetrate a stonewall: other nodes can penetrate.

Omitted slave nodes are automatically generated by incrementing the nodal point numbers by 


$$
\frac{n_{i}-n_{j}}{s n_{i} s n_{j}}
$$

where $s n_{i}$ and $s n_{j}$ are slave numbers on two successive cards and $n_{i}$ and $n_{j}$ are their corresponding node numbers.

Sections $18-20$ will be skipped if the number of slide-lines is zero. 


\section{Slide-Line Control Cards}

Define a control card for each slide-line. A discussion about the proper use of the slide-line capability is provided in Appendix A.

\begin{tabular}{|c|c|c|}
\hline Columns & Quantity & Format \\
\hline $1-5$ & Number of slave nodes in slide-line (NSN) & I5. \\
\hline $6-10$ & Number of master nodes in slide-line (NMN) & I5 \\
\hline \multirow[t]{2}{*}{$11-15$} & Slide-line type number, ISLT & I5 \\
\hline & $\begin{array}{l}\text { EQ.1: sliding only } \\
\text { EQ.2: tied sliding } \\
\text { EQ.3: sliding with voids }\end{array}$ & \\
\hline \multirow[t]{2}{*}{$16-25$} & SLFAC, tolerance for determining initial gaps & El0.0 \\
\hline & EQ.0.0: SLFAC $=0.001$ & \\
\hline \multirow[t]{2}{*}{$26-35$} & $\begin{array}{l}\theta_{1} \text {, angle in degrees of slide-line extension at } \\
\text { first master node }\end{array}$ & E10.0 \\
\hline & $\begin{array}{l}\text { EQ.0.0: extension remains tangent to first } \\
\text { master segment }\end{array}$ & \\
\hline $36-45$ & $\begin{array}{l}{ }_{2} \text {, angle in degrees of slide-line extension } \\
\text { at last master node. } \\
\text { EQ.0.0: extension remains tangent to last } \\
\text { master segment }\end{array}$ & El0.0 \\
\hline
\end{tabular}

Angles $\theta_{1}$ and $\theta_{2}$ are measured counterclockwise from the $r$-axis and remain constant. If $\theta_{1}$ and $\theta_{2}$ are zero, the extensions are made tangent to the first and last master segments and remain so throughout the calculation. The force exerted by a slave node lying on an extension of the master node at the origin of the extension diminishes to zero as the slave node moves away a distance equal to the length of one slave segment. 


\section{Slide-Line Definitions}

Repeat the following cards for each slide-line.

\section{Card 1}

$\frac{\text { Columns }}{1-72}$

Quantity

Format

Any suitable identification

\section{Cards 2,3,...,NSN+1 ,}

Columns

Quantity

Format

6-10

Slave number I5

Nodal point number

I5

Omitted data are automatically generated by incrementing the nodal point numbers by:

$$
\left(n_{i}-n_{j}\right) /\left(s n_{i}-s n_{j}\right),
$$

where $s n_{i}, s n_{j}$ are the slave numbers on two successive cards and $n_{i}$ and $n_{j}$ are their corresponding numbers.

\section{Cards NSN+2,...,NSN+NMN+1}

Columns

$1-5$

Quantity

Format

6-10

Master number

Nodal point number

Omitted data areigenerated as described above. The master and slave nodes must be given in the order in which they appear as one moves along the surface. The slave surface must be to the left of the master surface. 


\section{Slide-Line Intersections}

If no slide-lines intersect (NUMSI.EQ.0) skip this section; otherwise, define NUMSI cards.

\section{Cards 1,2,...,NUMSI}

Columns

Quantity

Format

$1-5$

Number of slide-line that is intersected

I5

6-10

Number of slide-line that intersects the above line

I5 


\section{Density v8. z-Coordinate Curve}

Skip this section of the number of points in the density versus z-coordinte curve (Card 2, Section 2) is zero; otherwise supply NUMDZ+l cards.

\begin{tabular}{ccc} 
Columns & $\begin{array}{c}\text { Card } \\
\text { Quantity }\end{array}$ & Format \\
\cline { 2 - 3 } & Gravitational acceleration & $\cdots$
\end{tabular}

Cards 2,3,...,NUMDZ+1

Columns Quantity

Format

$1-10$

Density

El0.0

$11-20$

z-Coordinate

E10.0

\section{Momentum Deposition Data}

Skip this section if the number of elements for momentum deposition is zero (Card 3, Section 2). Otherwise enter one card as follows for each element receiving momentum deposition.

\begin{tabular}{cll} 
Columns & \multicolumn{1}{c}{ Quantity } & Format \\
\cline { 2 - 3 } $1-5$ & Element number & I5 \\
$6-15$ & r-momentum per unit radian & Elo.0 \\
$16-25$ & z-momentum per unit radian & El0.0 \\
$26-35$ & Deposition time & El0.0 \\
& & El0.0
\end{tabular}




\section{RESTART INPUT DECK}

An input deck is generally not needed to restart DYNA20. It may be used, however, to reset the following parameters:
- Termination time
- Output printing interval
- Output plotting interval
- Viscosity coefficients
- Time histories

In addition, slide-lines and blocks of elements may be eliminated from the calculations. All changes made when restarting will be reflected in subsequent restart dumps. 


\section{Title Card}

Columns $1-66$
Quantity

Any suitable title
Format

$12 A 6$ 


\section{Control Cards}

Columns

1-10

$\therefore$

$11-20$

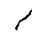

$21-30$

$31-32$

$33-35$

$36-40$

41-45

46-50

$51-55$

$56-60$
Quantity

Termination time

Format

El0.0

ElO.0

Output printing interval

EQ.0.0: output printing interval remains unchanged

Output plotting interval

E10.0

EQ.0.0: output plotting interval remains unchanged

Input form

A2

EQ. "ND": input follows this manual

EQ. "OD": input follows 1980 manual

Number of time histories to be redefined (NTHRD)

I5

Number of slide-lines to be eliminated from

I5

calculation

Number of element blocks to be eliminated from calculation

Number of material blocks to be eliminated from calculation

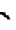

Number of slide-lines to be defined

Number of slide-line intersections, NUMSI

If the number of slide-lines to be defined is nonzero, each slide-line used in the subsequent calculation must be defined - even if it already exists in the restart file. The total number of slide-lines to be defined must not exceed the number used in the original input deck. 


\section{Time-History Cards}

Skip these cards if NTHRD equals zero; otherwise, define NTHRD card sets.

\section{Card 1}

$\frac{\text { Columns }}{1-5} \quad \frac{\text { Quantity }}{\begin{array}{l}\text { Number associated with time history curve to be } \\ \text { redefined }\end{array}} \quad \frac{\text { Format }}{\text { I5 }}$

\section{Cards 2,...,NPTS+1}

\begin{tabular}{|c|c|c|}
\hline Columns & Quantity & Format \\
\hline $1-10$ & Time & El0.0 \\
\hline $11-20$ & Function value & Elo. \\
\hline
\end{tabular}

The number of points in the load curve, NPTS, may not change from the original input. 


\section{Deleted Slide-Lines}

Skip this section if the number of slide-lines to be deleted is zero.

Columns 1-5

6-10
Quantity

Number of first slide-line to be deleted

Number of second slide-line to be deleted
Format I5

I5 


\section{Deleted Element Blocks}

Skip this section if the number of element blocks to be deleted is zero.

Columns

$1-5$

6-10

$11-15$

$16-20$
Quantity

First element of first block to be eliminated Last element of first block to be eliminated

First element of second block to be eliminated

Last element of second block to be eliminated
Format

I5

I5

I5

I5 


\section{Deleted Material Blocks}

Skip this section if the number of material blocks to be deleted is zero.

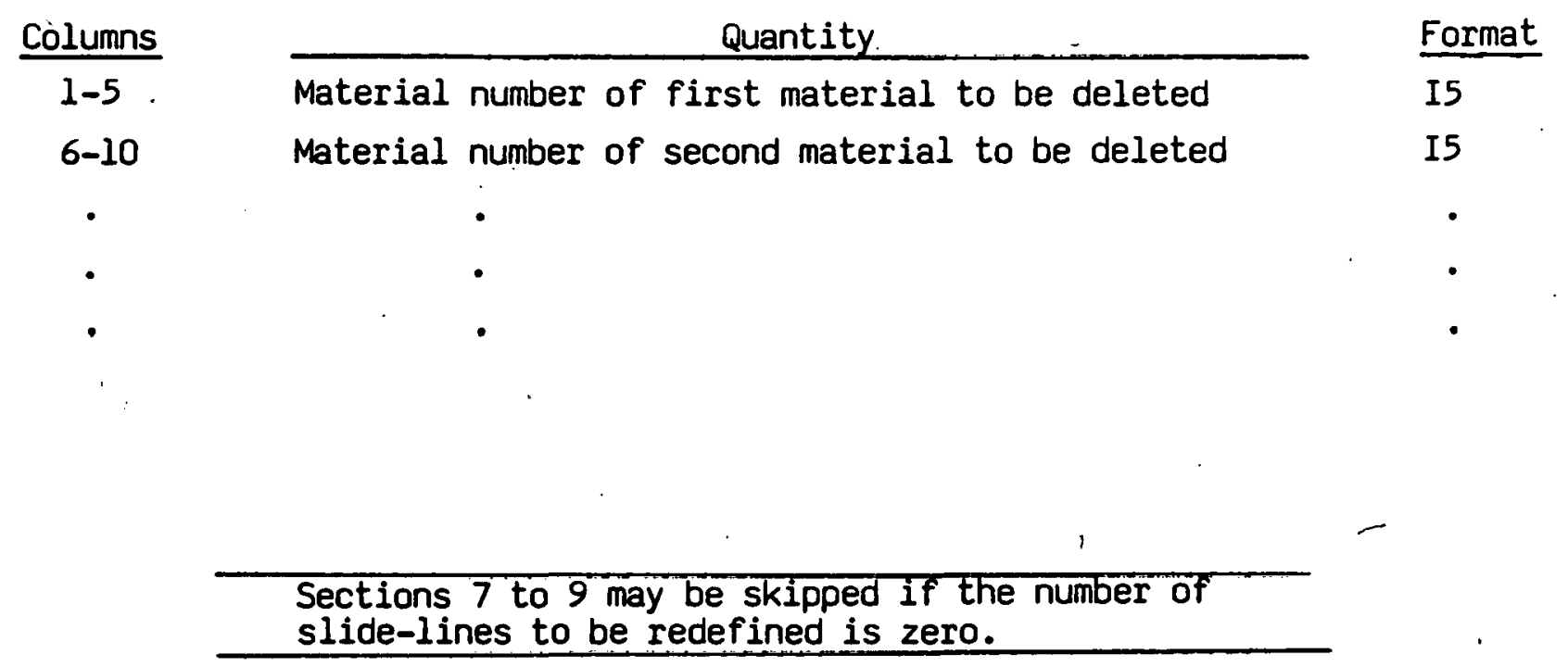




\section{Slide-Line Control Cards}

Define a control card for each slide-line.

Columns

$1-5$

6-10

11-15

$16-25$

$26-35$

$36-45$
Number of slave nodes in slid
Number of master nodes in slidiche type number, ISLT
Slide-line
EQ.1: sliding only
EQ.2: tied sliding
EQ.3: sliding with voids

SLFAC, tolerance for determining initial gaps

EQ.0.0: $S L F A C=0.001$

$\theta$, angle in degrees of slide-line extension at first master node

EQ.0.0: extension remains tangent to first master segment

$\theta_{2}$ angle in degrees of slide-line extension at last master node

EQ.0.0: extension remains tangent to last master segment
Format I5 I5

I5

E10.0

E10.0

ElO.0 


\section{Slide-Line Definitions}

Repeat the following cards for each slide-line:

\section{Card 1}

Columns

Quantity

Format

$1-72$

Any suitable identification

$12 A 6$

Cards 2,3,...,NSN+1

Columns

1-5

Quantity

Format

6-10

Slave number

I5

Nodal point number

I5

\section{Cards NSN+2,...,NSN + NMN+1}

Columns

$1-5$

Quantity

Format

Master number

I5

6-10

Nodal point number

I5 


\section{Slide-Line Intersections}

If there are no slide-line intersections (NUMSI.EQ.0) skip this section.

\section{Cards 1,2,...,NUMSI}

Columns

$1-5$

Quantity

6-10

Number of slide-line which is intersected

Format

Number of slide-line which intersects the above line

I5

I5 


\section{COMMANDS FOR REZONING}

General commands include:

$$
T V, T, F, F R, G, A, S N, S C, S D, M N, M C, M D, Z, R, T R
$$

General commands will not result in a material being rezoned; therefore, materials whose boundaries are changed by the SC, SD, MC, MD commands must be rezoned.

Commands for' rezoning material (may be used with above commands):

$$
M, V, B, S, T N, C N
$$

Commands that are available for adjusting boundary nodes following the "B" command:

$$
E R ; E Z, E S, V S, B D
$$

The "B". command is available if and only if a material has been designated for

\begin{tabular}{|c|c|c|}
\hline TV $n$ & - & Use TMDS where $n$ is the monitor number. \\
\hline G & - & Display complete mesh with material numbers. \\
\hline$T$ & - & Terminate without remap. \\
\hline $\mathbf{F}$ & - & $\begin{array}{l}\text { Terminate interactive phase, remap, continue in execution } \\
\text { phase. }\end{array}$ \\
\hline FR & - & $\begin{array}{l}\text { Terminate interactive phase, remap, write restart dump, } \\
\text { and call exit. }\end{array}$ \\
\hline A & - & $\begin{array}{l}\text { Display all slide-lines. Slave sides are plotted as } \\
\text { dashed or dotted lines. }\end{array}$ \\
\hline
\end{tabular}
rezoning.

\section{Command Definitions}

SN n $\quad$. - $\quad$ Display slide-line $n$ with slave node numbers. 
1. Command Definitions, (cont'd.)

SC $n \quad-\quad$ Check slave nodes of slide-line $n$ and put any nodes that have penetrated through the master surface back on the master surface.

SU $n \quad$ - Dekink slave side of slide-line $n$ - after using this command, the SC or MC command is sometimes advisable.

MN $n \quad$ - Display slide-line $n$ with master node numbers.

MC $n \quad$ - Check master nodes of slide-line $n$ and put any nodes that have penetrated through the slave surface back on the slave surface.

MD $n \quad$ - Dekink master side of slide-line $n$. After using this command, the SC or MC command is sometimes advisable.

Z r z $\Delta l \quad-\quad$ Zoom in at point $(r, z)$ with window $\Delta l$.

$R \quad$ - Restore original mesh.

$M n \quad$ - Material $n$ is to be rezoned.

$\checkmark \quad$ - Display material $n$ on TMDS.

$\mathrm{S} \quad$ - Smooth mesh of material $\mathrm{n}$.

TN $\mathrm{r} z \Delta l \quad-\quad$ Type node numbers and coordinates of all nodes within window ( $\mathrm{r} \pm \Delta \ell / 2, \mathrm{z} \pm \Delta \ell / 2$ ).

CN m I z - Node $m$ has new coordinate $(r, z)$.

B $\quad$ - $\quad$ Determine boundary nodes of material $n$ and display boundary with nodes on TMDS.

ER $m n \quad-\quad$ Equal space in $r$-direction boundary nodes $m$ to $n$ (counterclockwise).

EZ $m \quad$ - Equal space in z-direction boundary nodes $m$ to $n$ (counterclockwise).

ES $m n \quad$ - Equal space along boundary, boundary nodes $m$ to $n$ (counterclockwise).

VS $m \mathrm{n} \quad$ - Vary the spacing of boundary nodes $m$ to $n$ such that $r$ is the ratio of the first segment length to the last segment length.

$\mathrm{BD} m \mathrm{~m} \quad$ - $\quad$ Dekink boundary from boundary node $m$ to boundary node $n$ (counterclockwise).

TR $t \quad-\quad$ At time $t$ DYNA2D will stop and enter interactive rezoning phase. 
Use of the rezoner is demonstrated in the example which follows. In order to minimize the size of the graphics segment of DYNA2D. No graphics files are created. A special version of DYNA2D was compiled to obtain the figures that follow. In the table below, teletypewriter lines are correlated to the figures.

\section{Example}

\begin{tabular}{|c|c|c|}
\hline DYNA2D & User Response & $\begin{array}{l}\text { Resulting } \\
\text { TMDS Figure }\end{array}$ \\
\hline ;TMDS; ? & $1625 \mathrm{G}$ & 12 \\
\hline ;OK-M; ? & Z 2128 & 13 \\
\hline ;OK-M; ? & A & 14 \\
\hline ;OK-M; ? & $M 3 \mathrm{~V}$ & 15 \\
\hline ;OK-M; ? & $\mathrm{B}$ & 16 \\
\hline ;OK-M; ? & ES 758773 VS 7731093.5 ES 10931078 MC 1 V & 17 \\
\hline ;OK-M; ? & $S V$ & 18 \\
\hline ;OK-M; ? & BD 7731093 MC 1 S V & 19 \\
\hline ;OK-M; ? & $\mathrm{G}$ & 20 \\
\hline ;OK-M; ? & FR & \\
\hline
\end{tabular}

Table 1. DYNA2D prompts, user response, and resulting TMDS displays for a typical problem. 


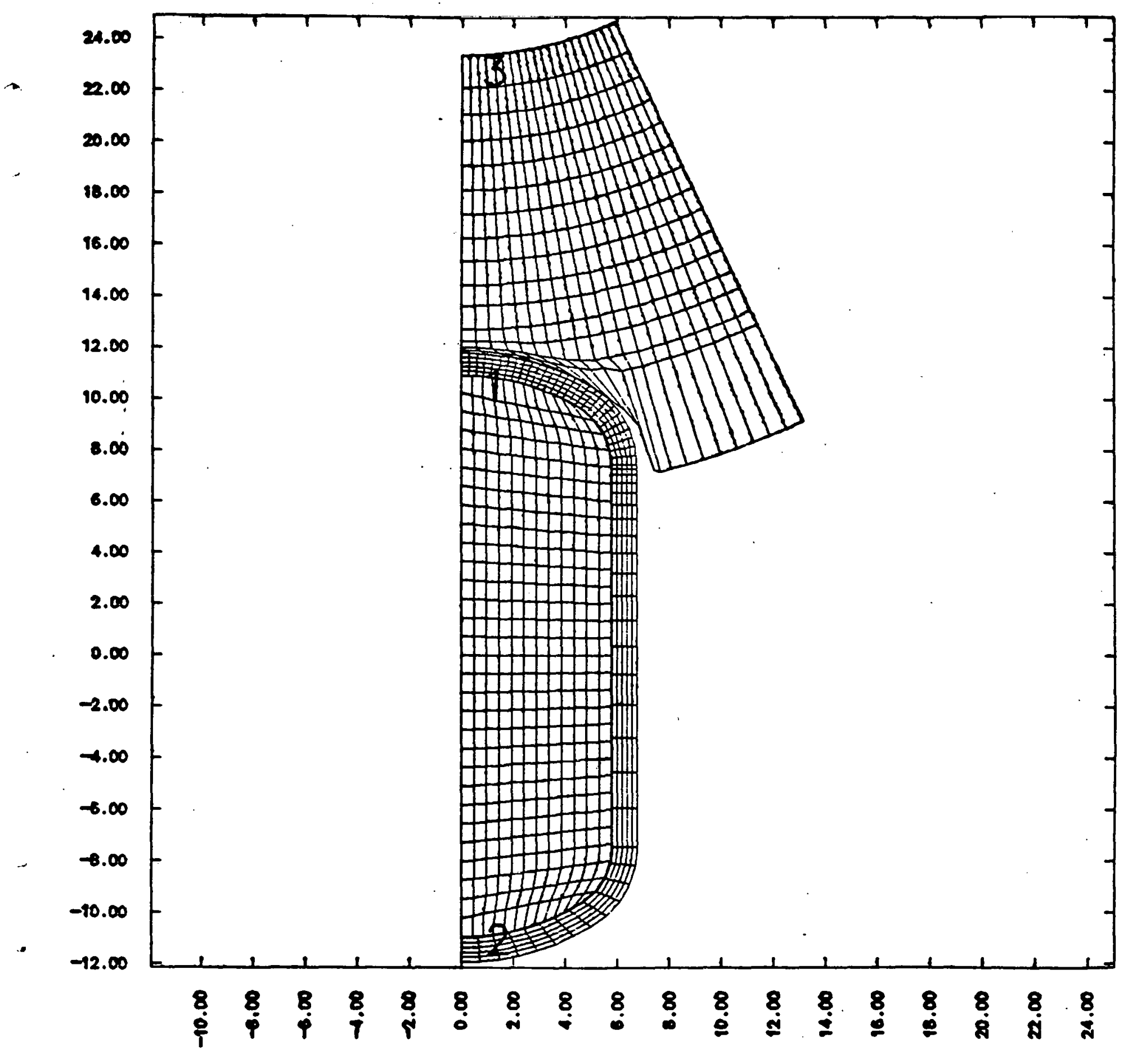

Fig. 12. 


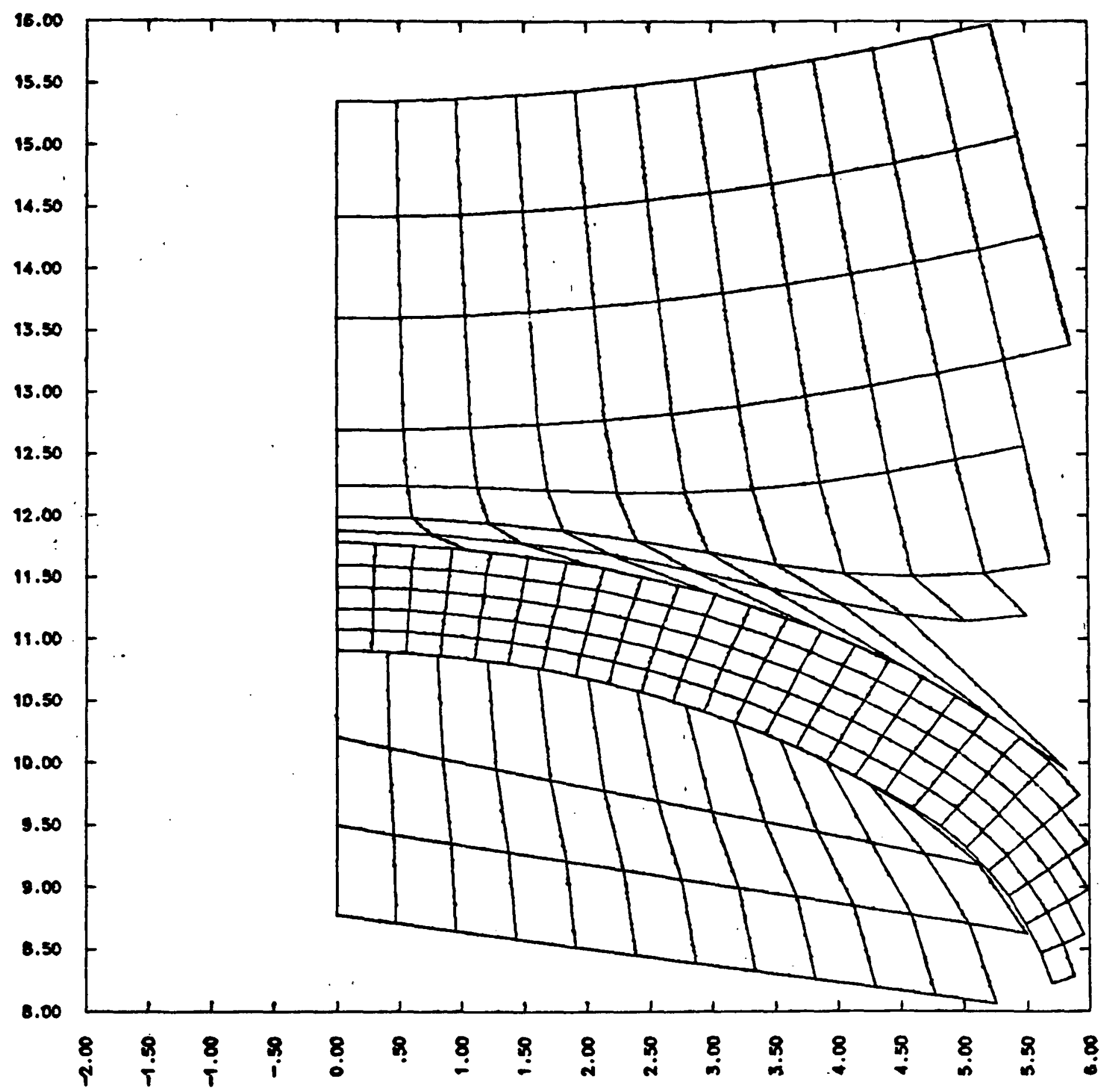

Fig. 13. 


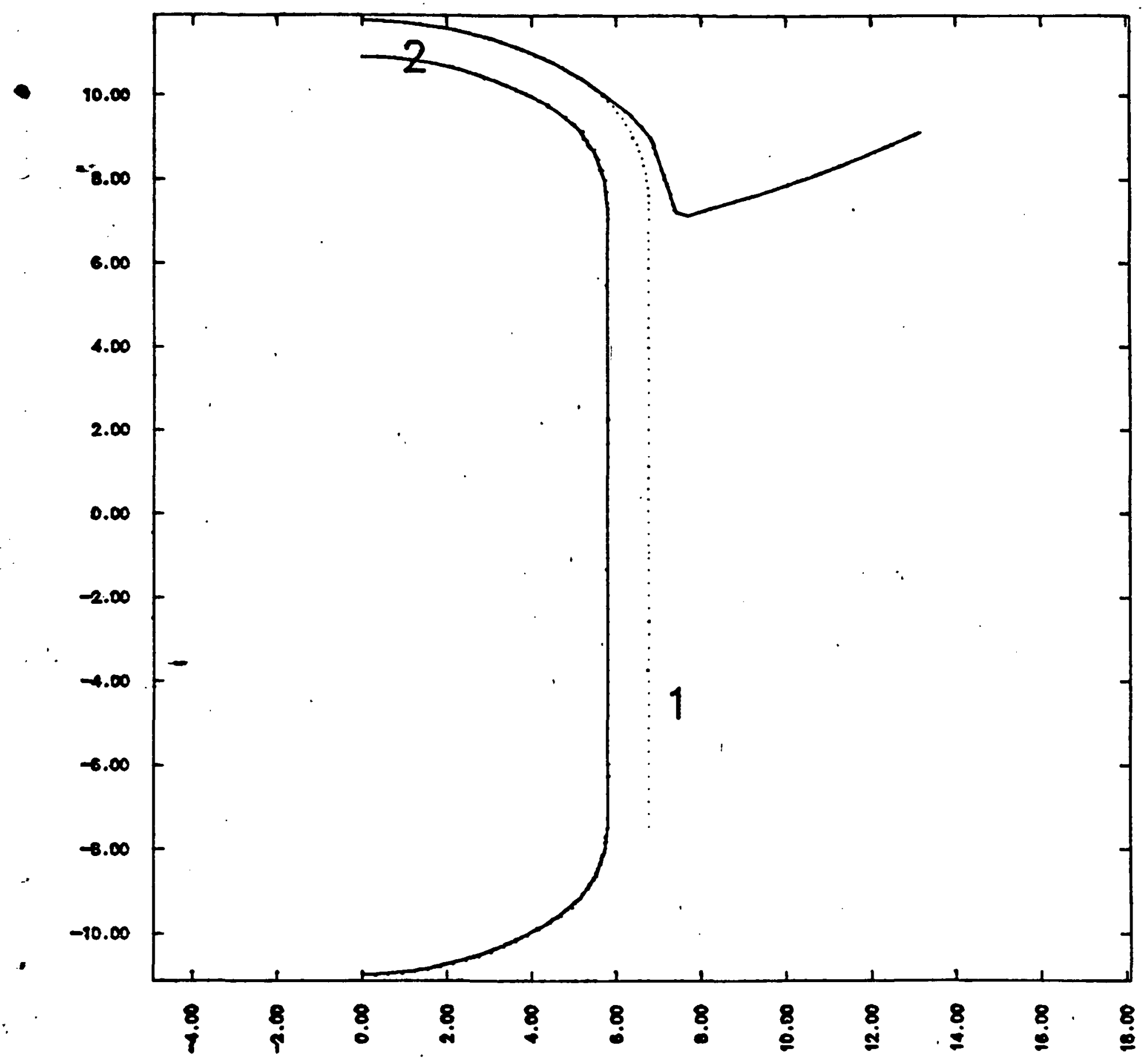

Fig. 14. 


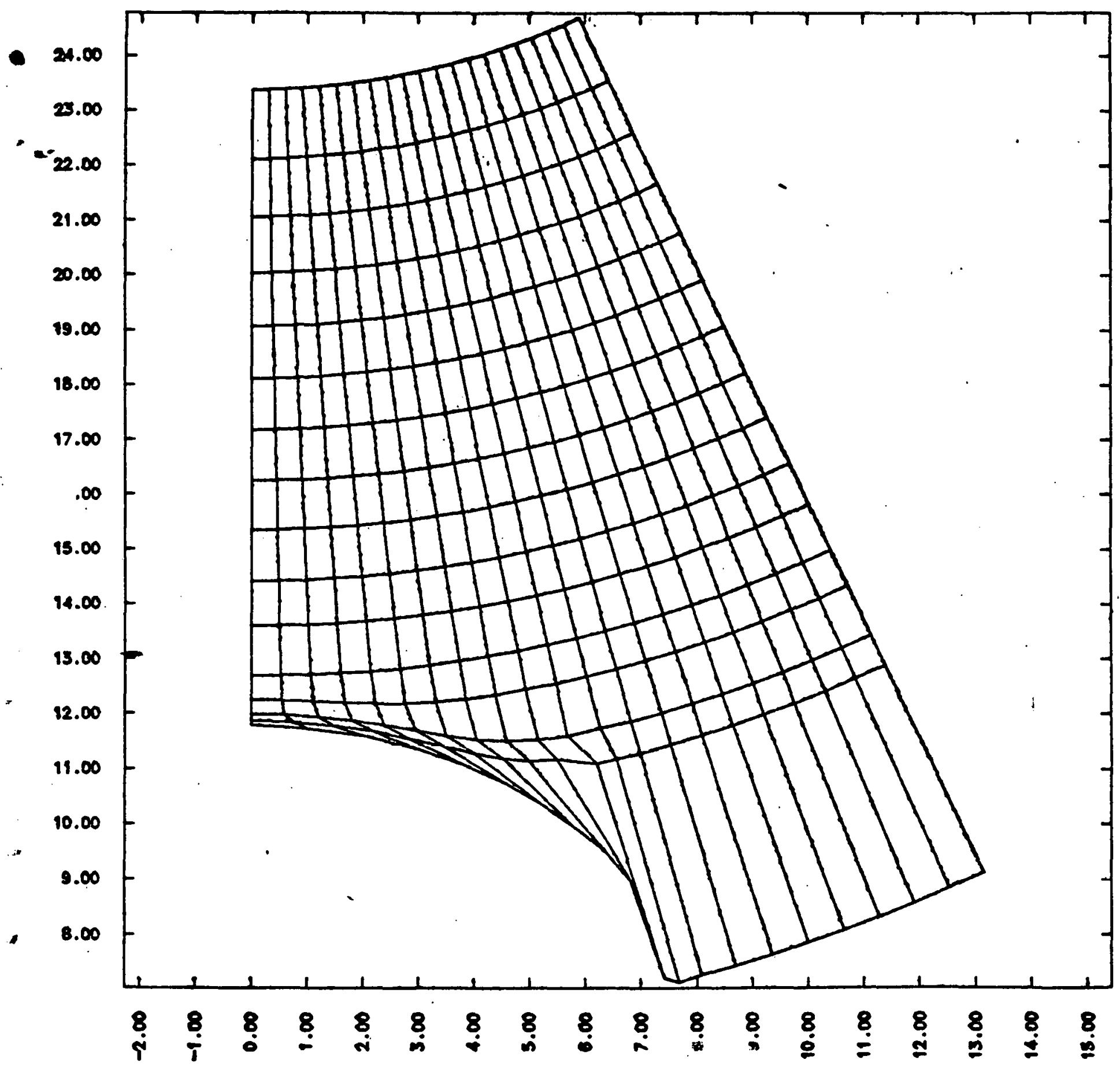

Fig. 15. 


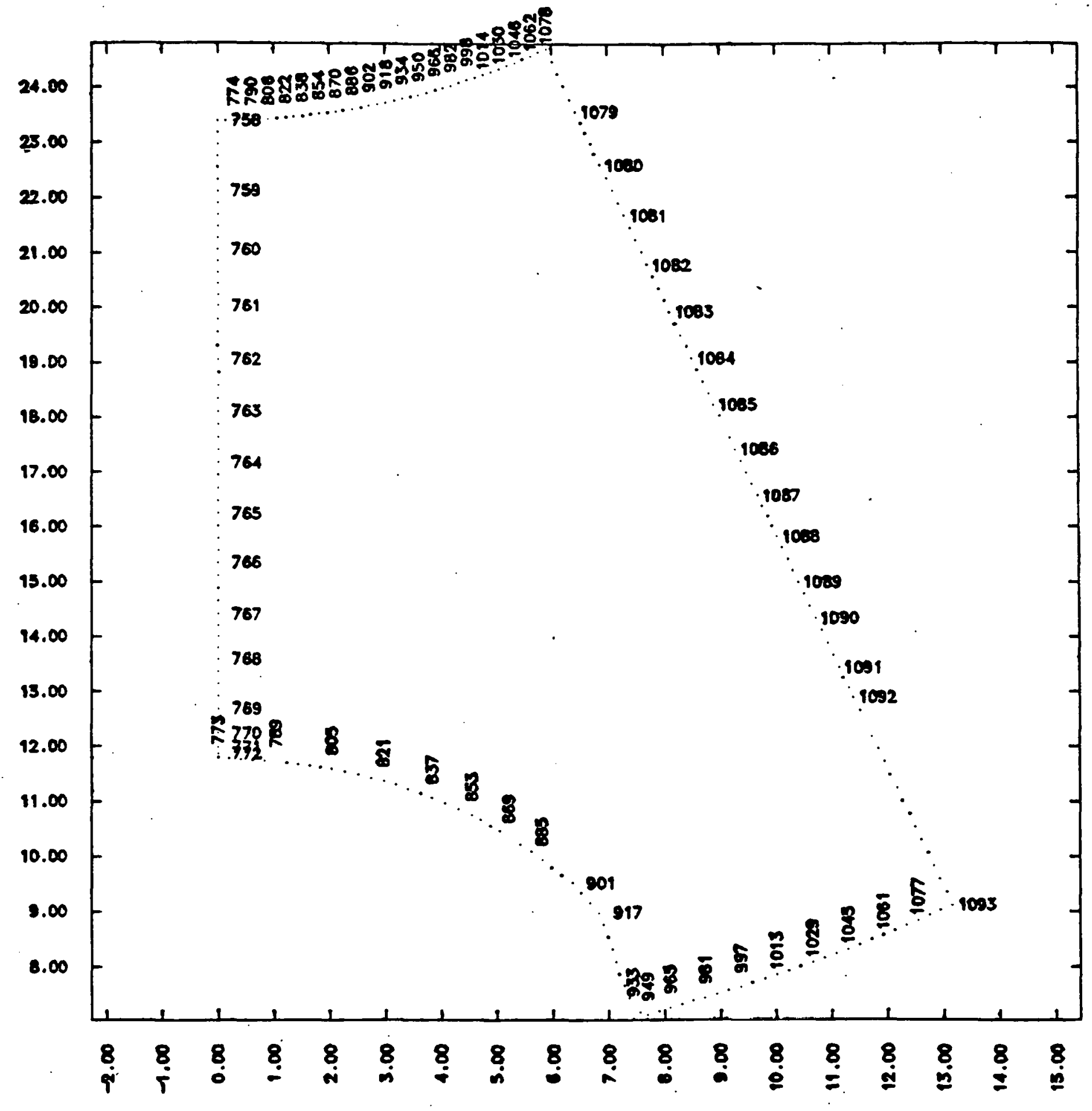

Fig. 16. 


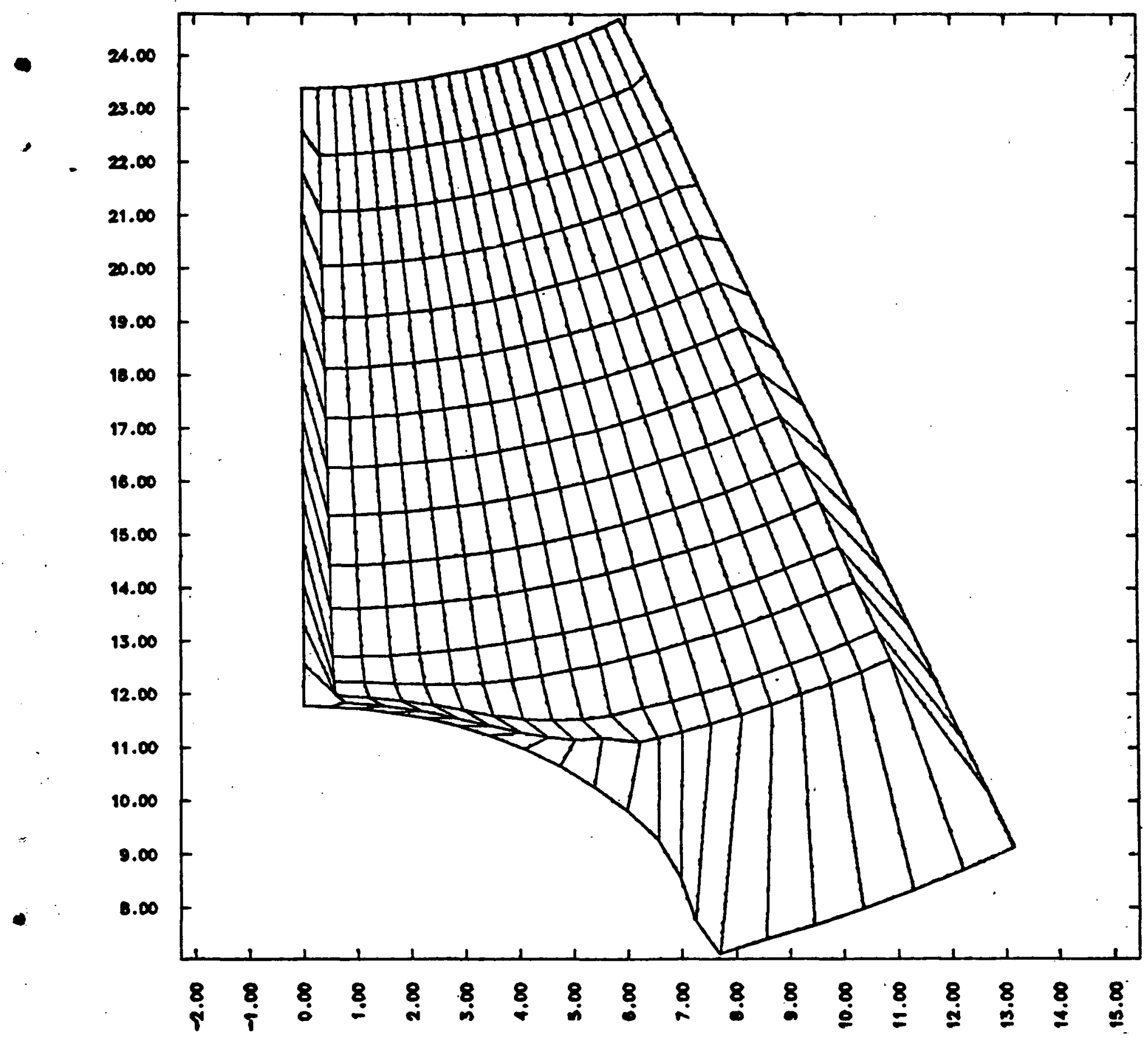

Fig. 17. 


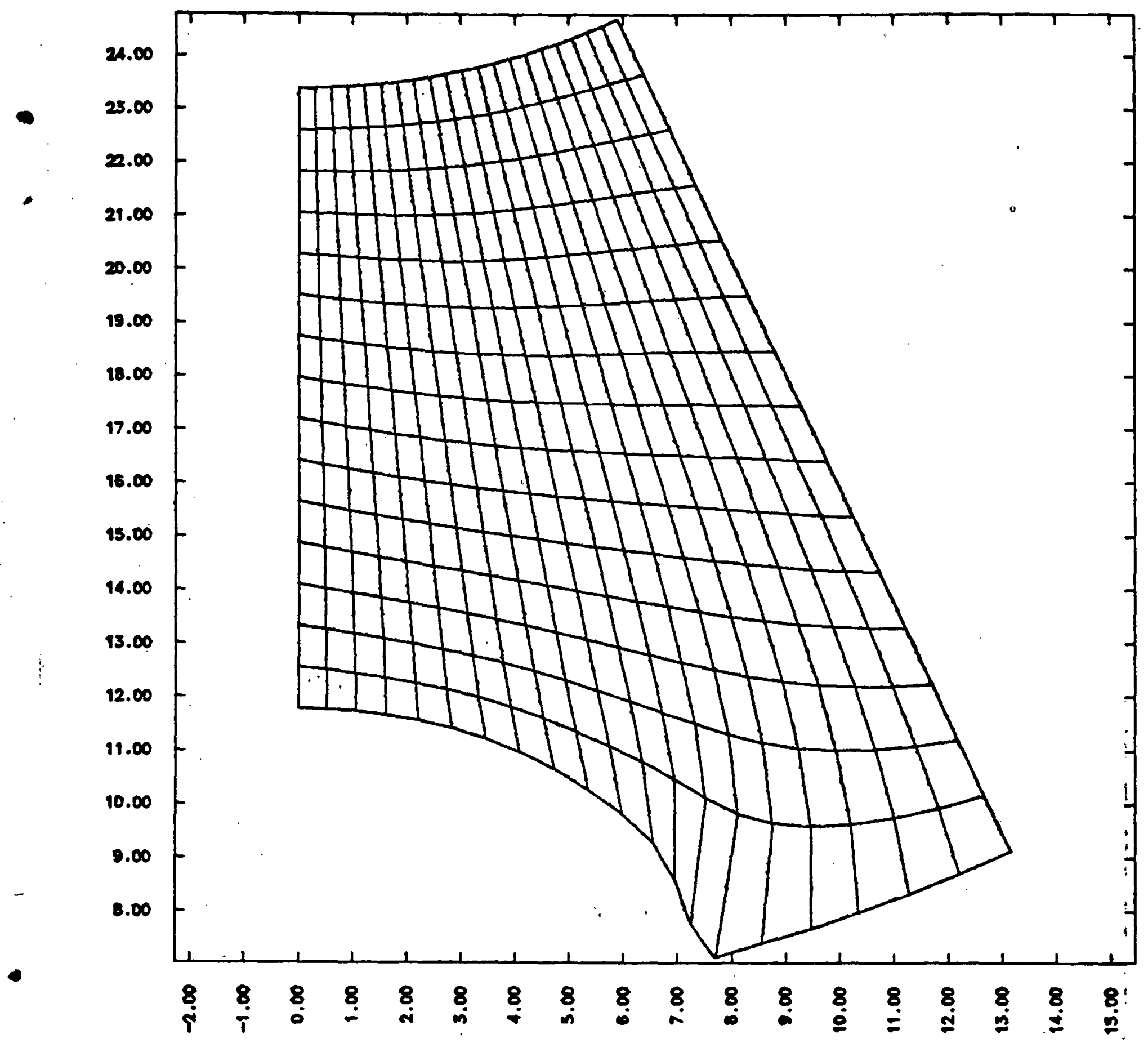

Fig. 18. 


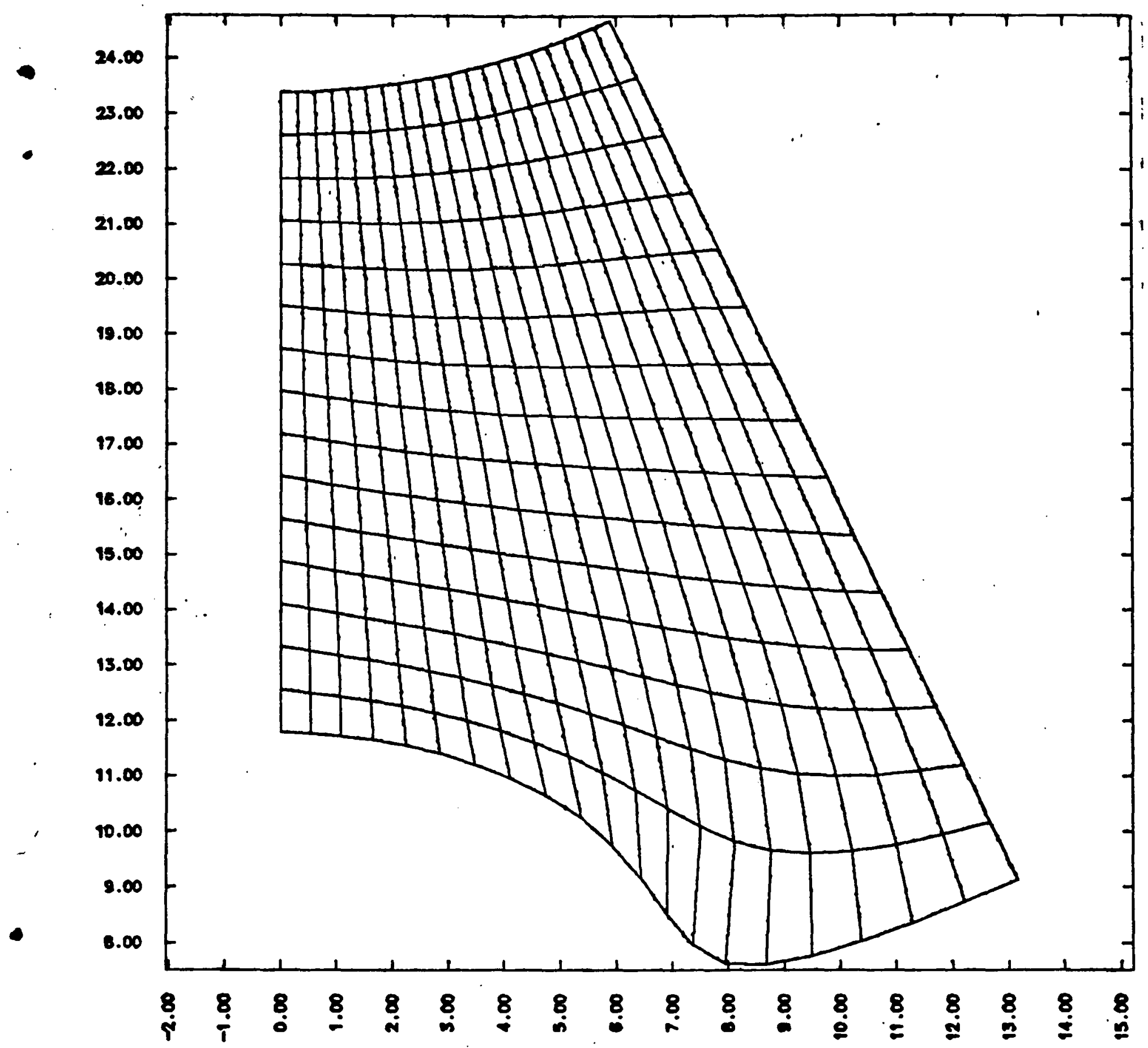

Fig. 19. 


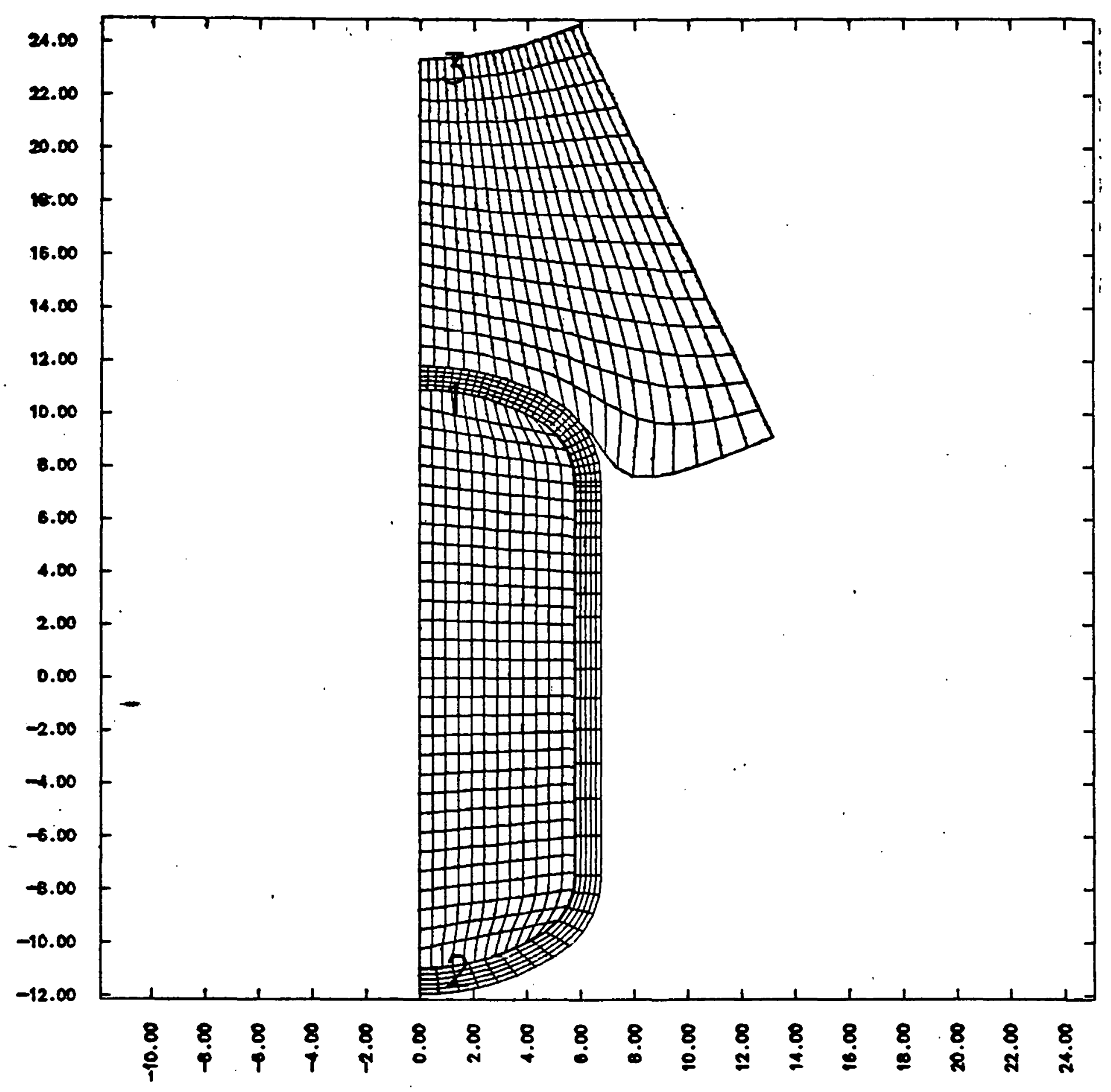

Fig. 20. 


\section{EXAMPLE PROBLEM}

\section{Shaped Charge Calculation}

In Fig. 21, a finite element mesh of 600 elements models a type of shaped charge called a self-forging fragment [25]. Calculations were carried out to compute the formation of the fragment produced by the upper plate. Slide-lines

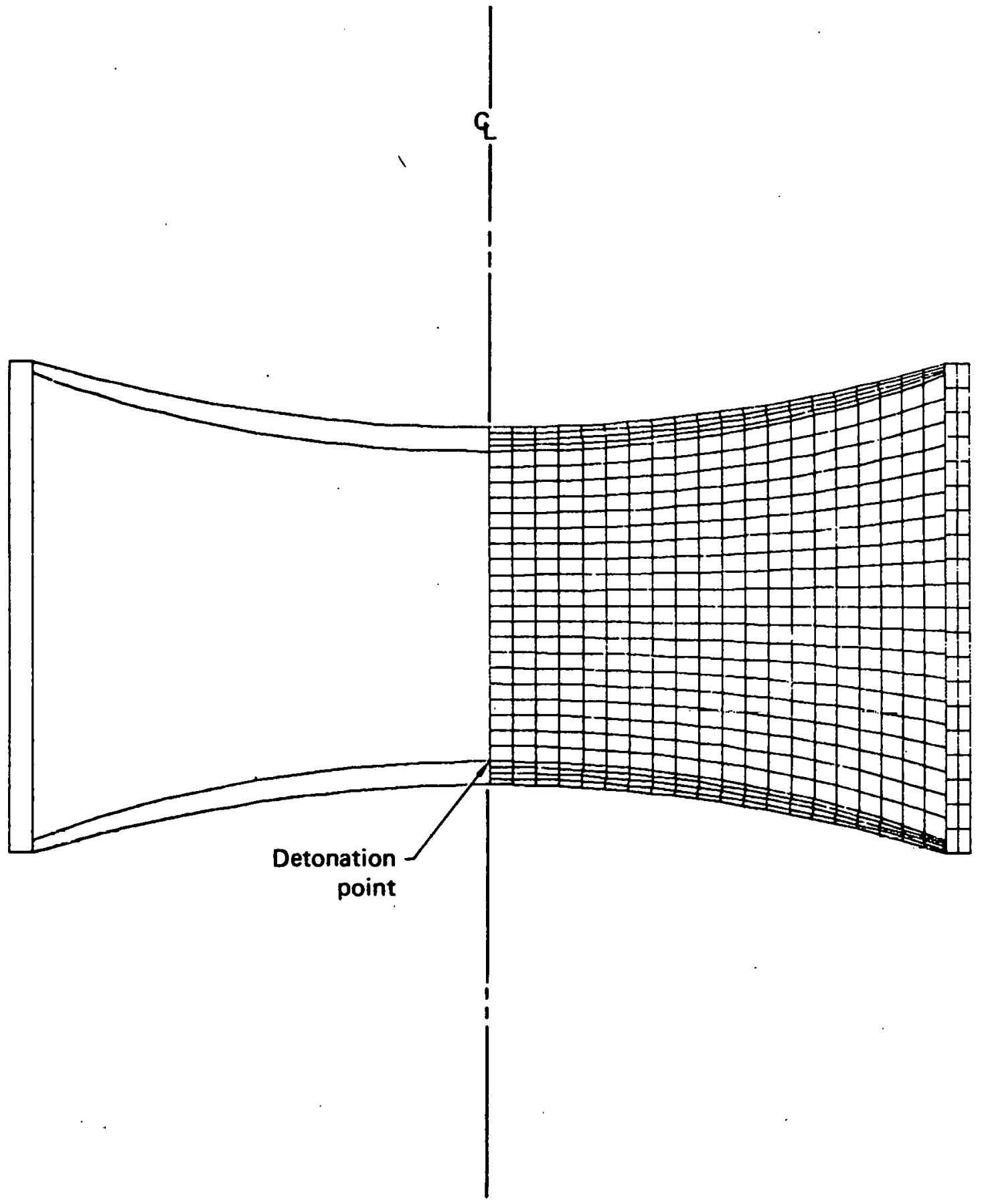

Fig. 21. Finite difference mesh used in shaped charge calculation. -99- 
are initially placed between the plate-HE and cyliner-HE interfaces. By $10 \mu \mathrm{s}$ the HE has burned, and by $50 \mu \mathrm{s}$ the pressure in the HE has dropped to negligible levels. At $50 \mu \mathrm{s}$, therefore, all elements but those in the upper plate are eliminated from the calculation. Between 12 and $50 \mu \mathrm{s}$, zones at the outer edges of the plate become elongated and cause a significant decrease in the time-step size. These latter elements are eliminated prior to $50 \mu \mathrm{s}$. Before the calculation is continued at $50 \mu \mathrm{s}$, a new slide-line is defined along the upper surface to prevent the plate from penetrating through itself as it folds.

Figure 22 shows a view of the deformed shape at $50 \mu \mathrm{s}$. The formation of the fragment is depicted in Fig. 23, which contains a sequence of deformed shapes at $20 \mu \mathrm{s}$ intervals. To verify DYNA2D's accuracy, an additional. calculation was performed with the HE tied along the outer case and compared to a similar calculation with HEMP. As expected, excellent agreement was obtained.

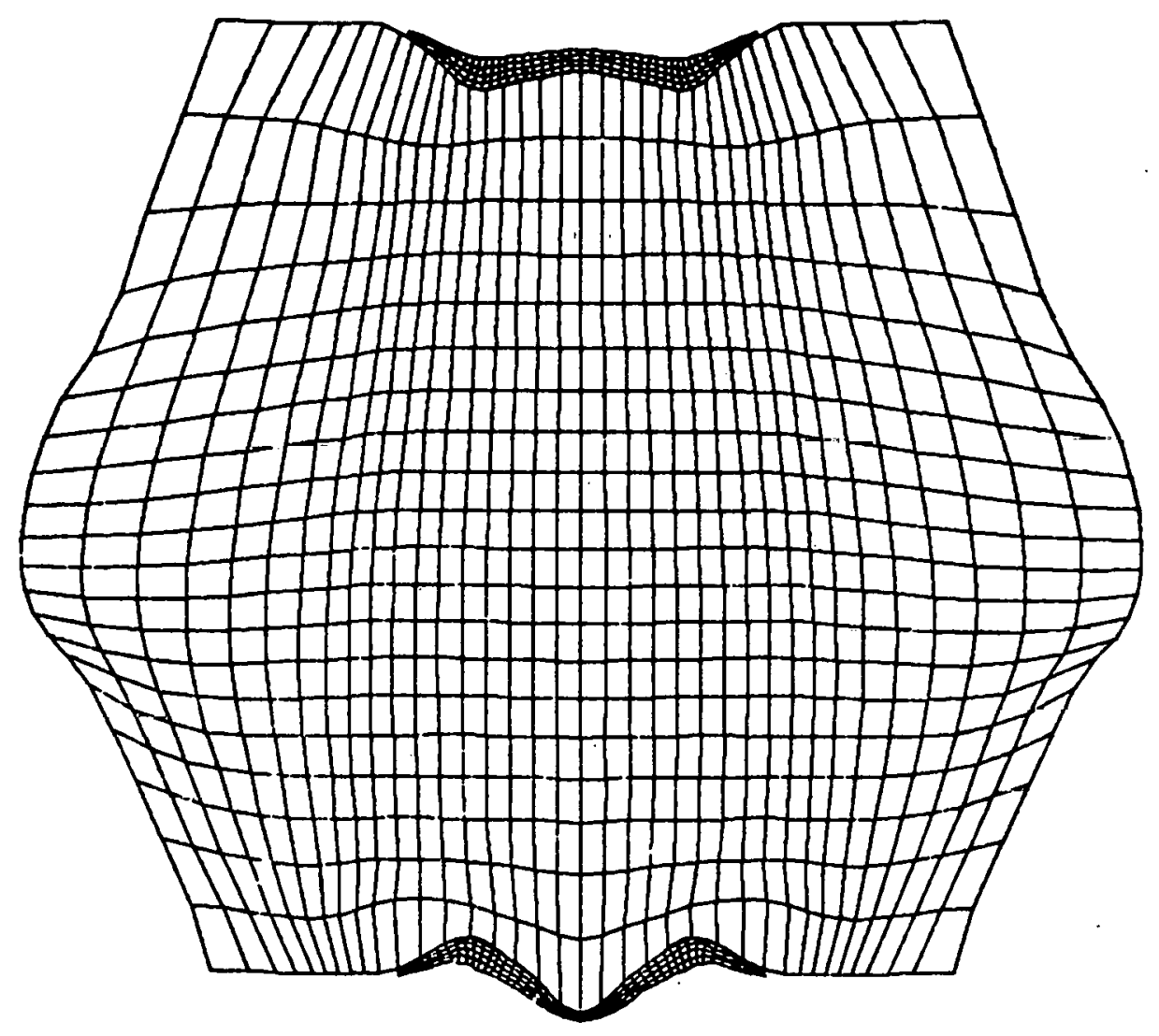

Fig. 22. Deformed shape at $50 \mu s$. -100 - 

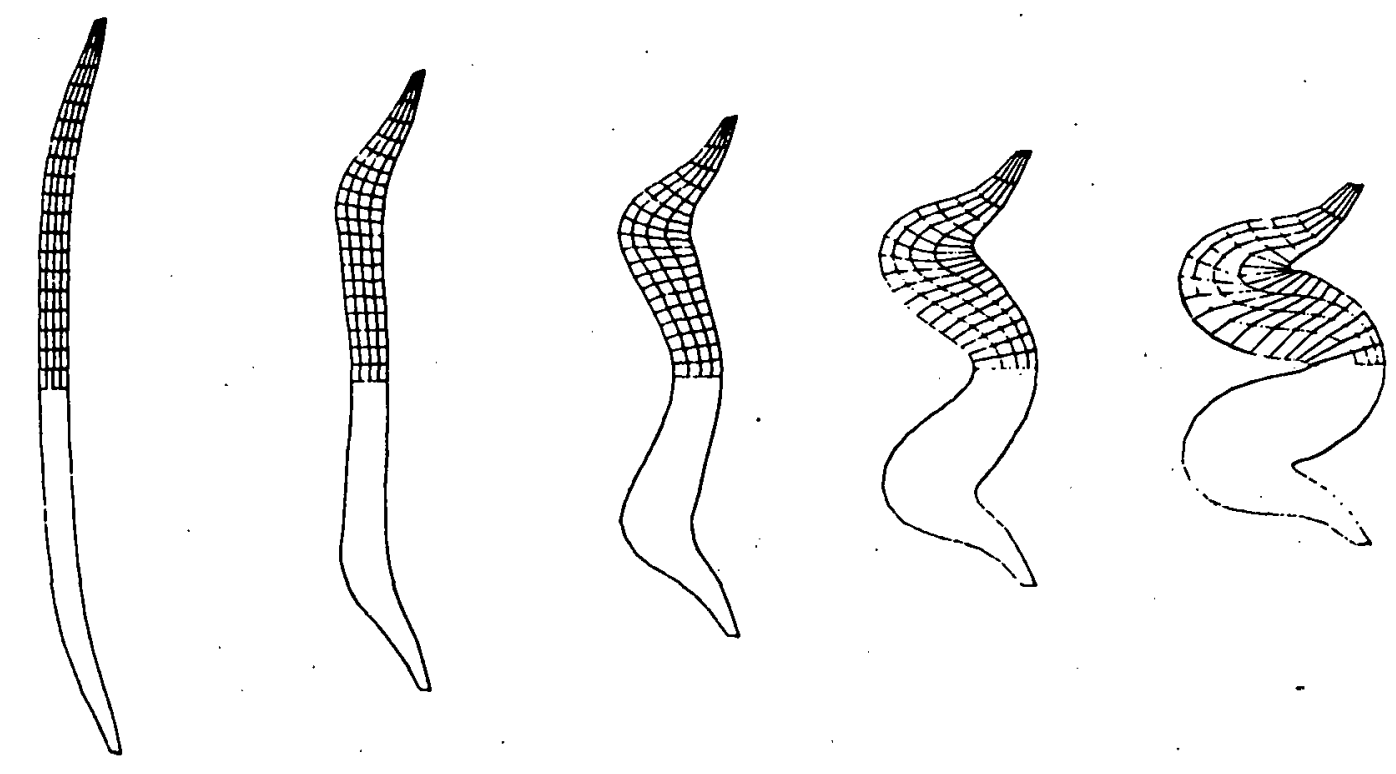

$20 \mu \mathrm{s}$

$40 \mu \mathrm{s}$

$60 \mu \mathrm{s}$

$80 \mu \mathrm{s}$

$100 \mu \mathrm{s}$

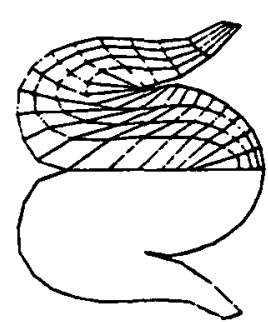

$120 \mu \mathrm{s}$

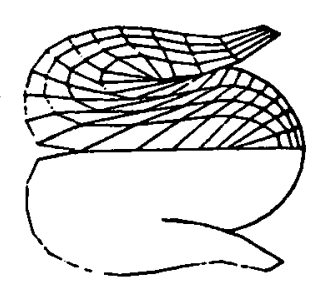

$140 \mu \mathrm{s}$

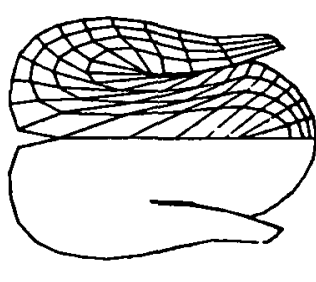

$160 \mu \mathrm{s}$

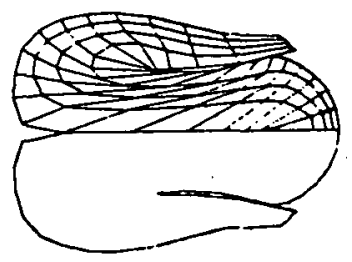

$180 \mu \mathrm{s}$

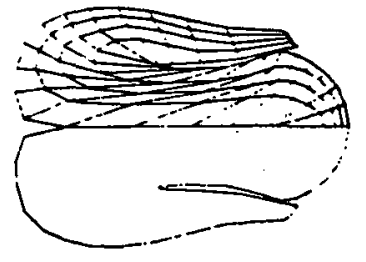

$200 \mu \mathrm{s}$

Fig. 23. Formation of fragment.

\section{ACKNOWLEDGEMENTS}

With respect to the rezoner, Bruce Eric Brown contributed several terminal I/O utility subroutines that are essential for interactivity, and Mark Blair's graphics expertise made the transition from FTNTV80 on the 7600's to GRAFCORE on Cray-l a trivial exercise. Many thanks to Nikki Falco who typed this report. 


\section{REFERENCES}

1. J. O. Hallquist, "OYNA2D - An Explicit Finite Element and Finite Difference Code for Axisymmetric and Plane Strain Calculations, (User's Guide)", University of California, Lawrence Livermore National Laboratory, Rept. UCRL-52429 (1978).

2. M. L. Wilkins, "Calculation of Elastic-Plastic Flow," University of California, Lawrence Livermore National Laboratory, Rept. UCRL-7322, Rev. I (1969).

3. G. L. Goudreau and J. O. Hallquist, "Recent Developments in Large Scale Finite Element Lagrangian Hydrocode Technology, presented at the Second International Conference on Finite Elements in Nonlinear Mechanics," Stuttgart, W. Germany, soon to be published in the Journal, Computer Methods in Applied Mechanics and Engineering, (1981).

4. T.R.J. Hughes, private communication, Lawrence Livermore National Laboratory (1980).

5. R. D. Krieg and S. W. Key, Implementation of a Time Dependent Plasticity Theory into Structural Computer Programs, Vol. 20 of Constitutive Equations in Viscoplasticity: Computational and Engineering Aspects (American Society of Mechanical Engineers, New York, N.Y., 1976), pp. 125-137.

6. J. 0. Hallquist, "NIKE2D: An Implicit, Finite-Deformation, Finite-Element Code for Analyzing the Static and Dynamic Response of Two-Dimensional Solids", University of California, Lawrence Livermore National Laboratory, Rept. UCRL-52678 (1979).

7. S. W. Key, "HONDO - A Finite Element Computer Program for the Large Deformation Dynamic Response of Axisymmetric Solids", Sandia National. Laboratories, Albuquerque, N.M., Rept. 74-0039 (1974).

8. D. J. Steinberg and M. W. Guinan, "A High-Strain-Rate Constitutive Model for Metals", University of California, Lawrence Livermore National Laboratory, Rept. UCRL-80465 (1978).

9. B. M. Dobratz, "LLNL Explosives Handbook, Properties of Chemical Explosives and Explosive Simulants," University of California, Lawrence Livermore National Laboratory, Rept. UCRL-52997 (1981). 
10. E. L. Lee and C. M. Tarver, "A Phenomenological Model of Shock Initiation in Heterogenous Explosives", University of California, Lawrence Livermore National Laboratory, Rept. UCRL-83618 (1979).

11. S. G. Cochran and J. Chan, "Shock Initiation and Detonation Models in One and Two Dimensions", University of California, Lawrence Livermore National Laboratory, Rept. UCID-18024 (1979).

12. J. P. Woodruff, "KOVEC User's Manual", University of California, Lawrence Livermore National Laboratory, Rept. UCID-17306 (1976).

13. E. D. Giroux, "HEMP User's Manual", University of California, Lawrence Livermore National Laboratory, Rept. UCRL-51079 (1973).

14. G. T. Richards, "Derivation of a Generalized Von Neuman Rsuedo-Viscosity with Directional Properties, " University of California, Lawrence Livermore National Laboratory, Rept. UCRL-14244 (1965).

15. M. L. Wilkins, "The Use of Artificial Viscosity in Multidimensional Fluid Dynamics Calculations, "University of California, Lawrence Livermore National Laboratory, Rept. UCRL-78348 (1976).

16. G. Maenchen and S. Sack, "The Tensor Code," in Methods in Computational Physics, Vol. 3, Academic Press, New York (1964).

17. D. P. Flanagan and T. Belytschko, A Uniform Strain Hexahedron and Quadrilateral and Orthogonal Hourglass Control, International J. Numer. Meths. Engr., 17 679-706 (1981).

18. J. O. Hallquist, "A Numerical Treatment of Sliding Interfaces and Impact", in: K. C. Park and D. K. Gartling (eds.), Computational Techniques for Interface Problems, AMD Vol. 30, ASME, New York (1978).

19. J. 0. Hallquist, "A Procedure for the Solution of Finite Deformation Contact-Impact Problems by the Finite Element Method", University of California, Lawrence Livermore National Laboratory, Rept. UCRL-52066 (1976).

20. Cray-1 Computer System CFT Reference Manual, Cray Research Incorporated, Bloomington, MN, Publication No. 2240009 (1978).

21. FORTRAN Extended Version 4, Reference Manual, Control Data Corporation, Sunnyvale, CA, Publication No. 60497800, Revision B (1977).

22. J. 0. Hallquist, "MAZE - An Input Generator for DYNA2D and NIKE2D," University of California, Lawrence Livermore National Laboratory, Rept. UC.TD-19029 (198]) 
23. J. 0. Hallquist, "THOR: A Post-Processor for Two-Dimensional Analysis Codes", University of California, Lawrence Livermore National Laboratory, Rept. UCRL-52852 (1980).

24. J. O. Hallquist, "ORION: An Interactive Post-Processor for Analysis Codes NIKE2D, DYNA2D, and TACO2D," University of California, Lawrence Livermore National Laboratory, Rept. UCID-17980, (1982).

25. G. Randers-Pehrson and I. P. Juriaes, Computer Aided Self-Forging Fragment Design, U.S. Army Science Conference Proceedings, west Point, N.Y. (1968). 


\section{APPENDIX A}

\section{Use of Slide-Lines}

The purpose of this appendix is to describe briefly the proper use of slide-lines.

Consider two surfaces in contact. In DYNA2D it is necessary to designate one as a slave surface and the other as a master surface. Nodal points defining the slave surface are called slave nodes, and similarly, nodes defining the master surface are called master nodes. Each slave-master surface combination is referred to as a slide-line.

Many potential problems with the algorithm can be avoided by observing the following precautions:

- If one surface is more finely zoned, it should be used as the slave surface.

- A slave node may have more than one master segment, and may be included as a member of a master segment if a slide-line intersection is defined.

- Angles in the master side of a slide-line that approach 90 deg must be avoided. Whenever such angles exist in a master surface, two or more slide-lines should be defined. This procedure is illustrated in Fig. Al. An exception for the foregoing rule arises if the surfaces are tied. In this case, only one slide-line is needed.

- Rigid walls are defined by a series of fixed master nodes (boundary condition code 3.0), which outline the desired profile. For best results, the spacing of these nodes should be approximately the same as that of the slave nodes. If very large spacing is used, errors may occur during the initialization phase.

- Whenever two surfaces are in contact, the smaller of the two surfaces should be used as the slave surface. For example, in modeling a missile impactiny a wall, the contact surface on the missile should be used as the slave surface.

- Care should be used when defining a master surface to prevent the extension from interfering with the solution. In Figs. A2 and A3, slide-line extensions are shown.

- Whenever slide-lines intersect as shown in Fig. A4, an intersection should be defined to insure proper treatment of the intersection. 


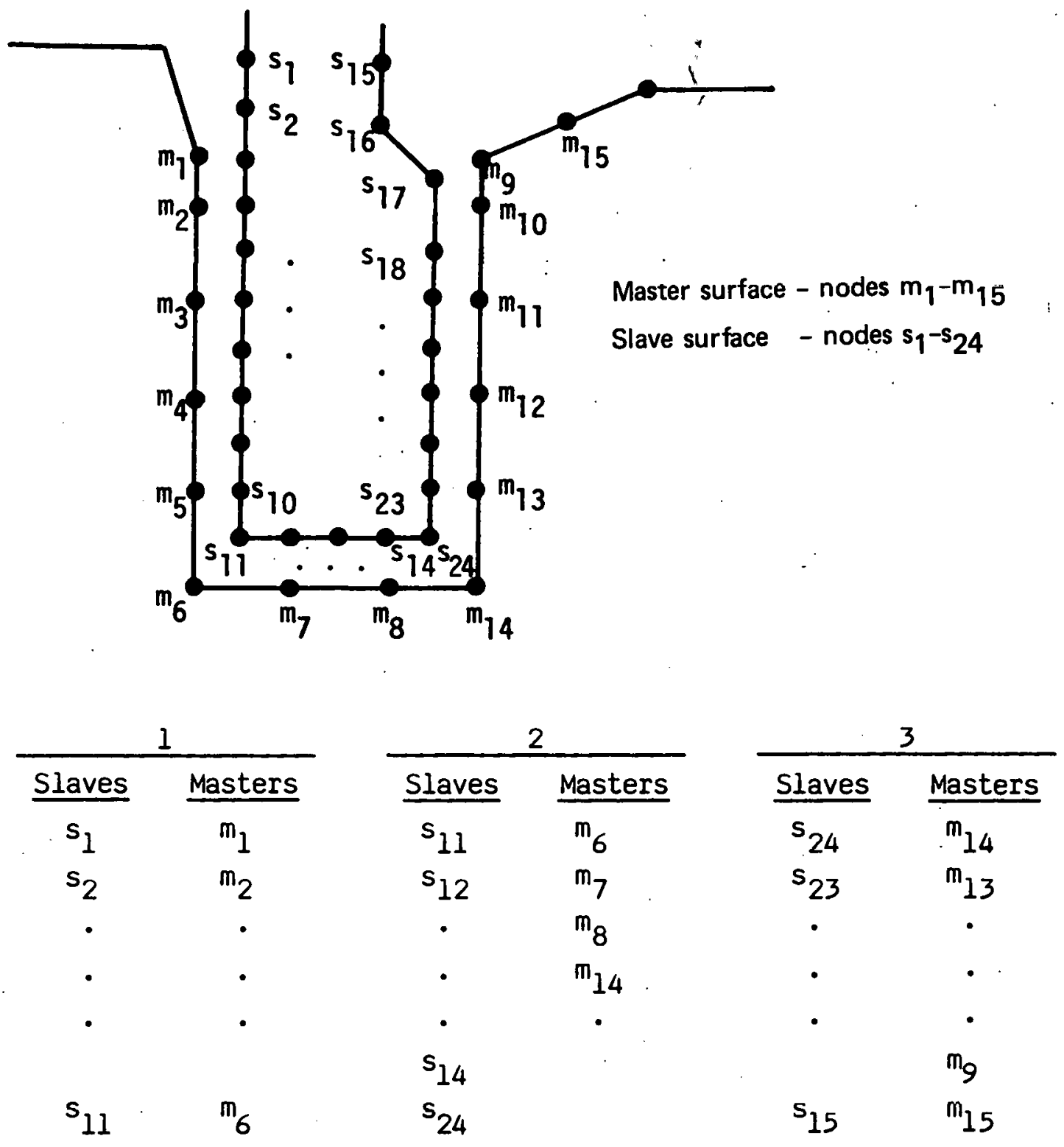

Fig. Al. Proper definition of illustrated slave-master surface requires three slide-lines (note that slave surface is to left of master surface as one moves along master nodes in order of definition). 


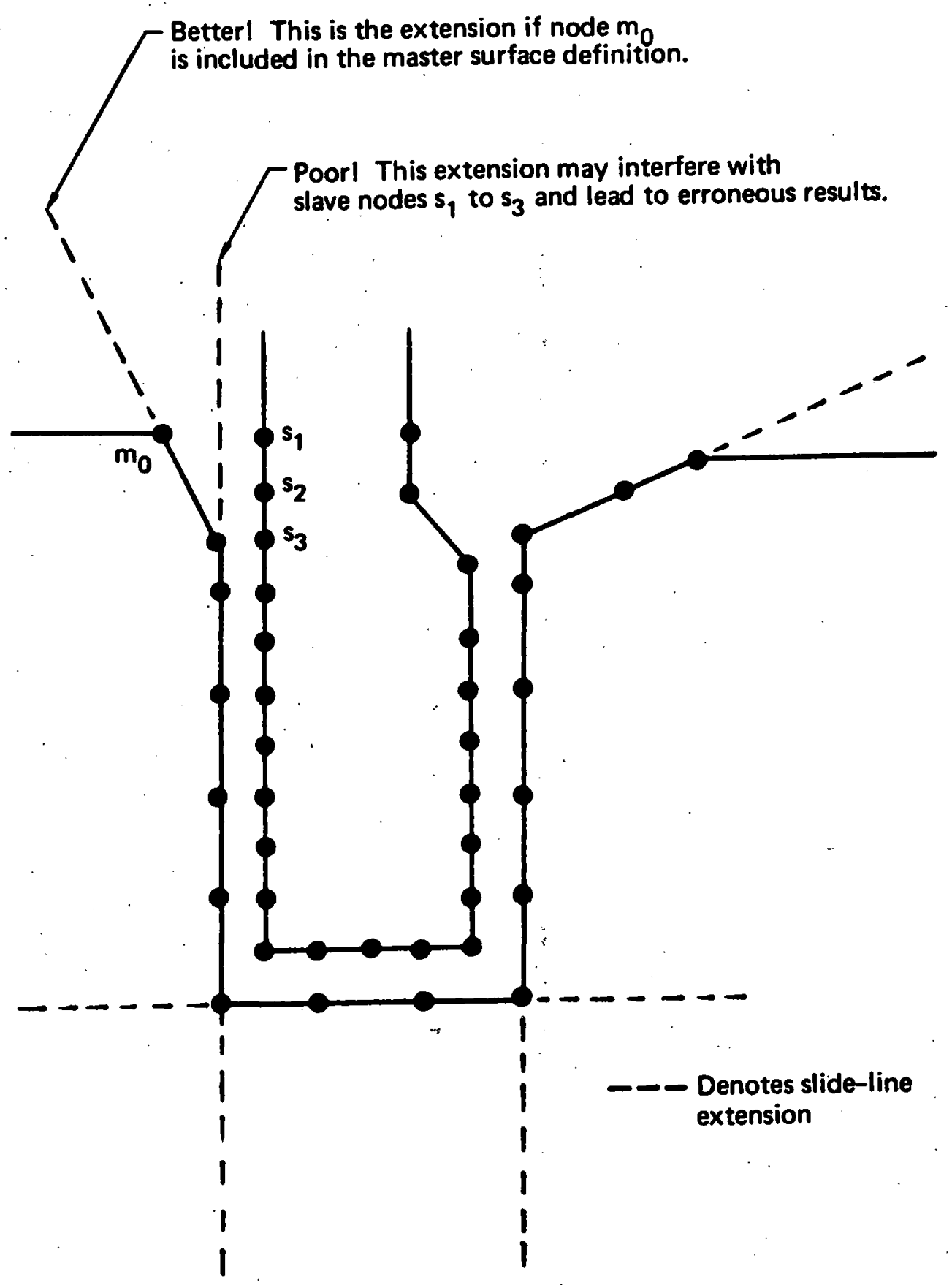

Fig. A2. Master surface extensions defined automatically by DYNA2D (extensions are updated every time step to remain tangent to ends of master sides of slide-lines unless angle of extension is defined in input). 
Note: A compressive loading is assumed.

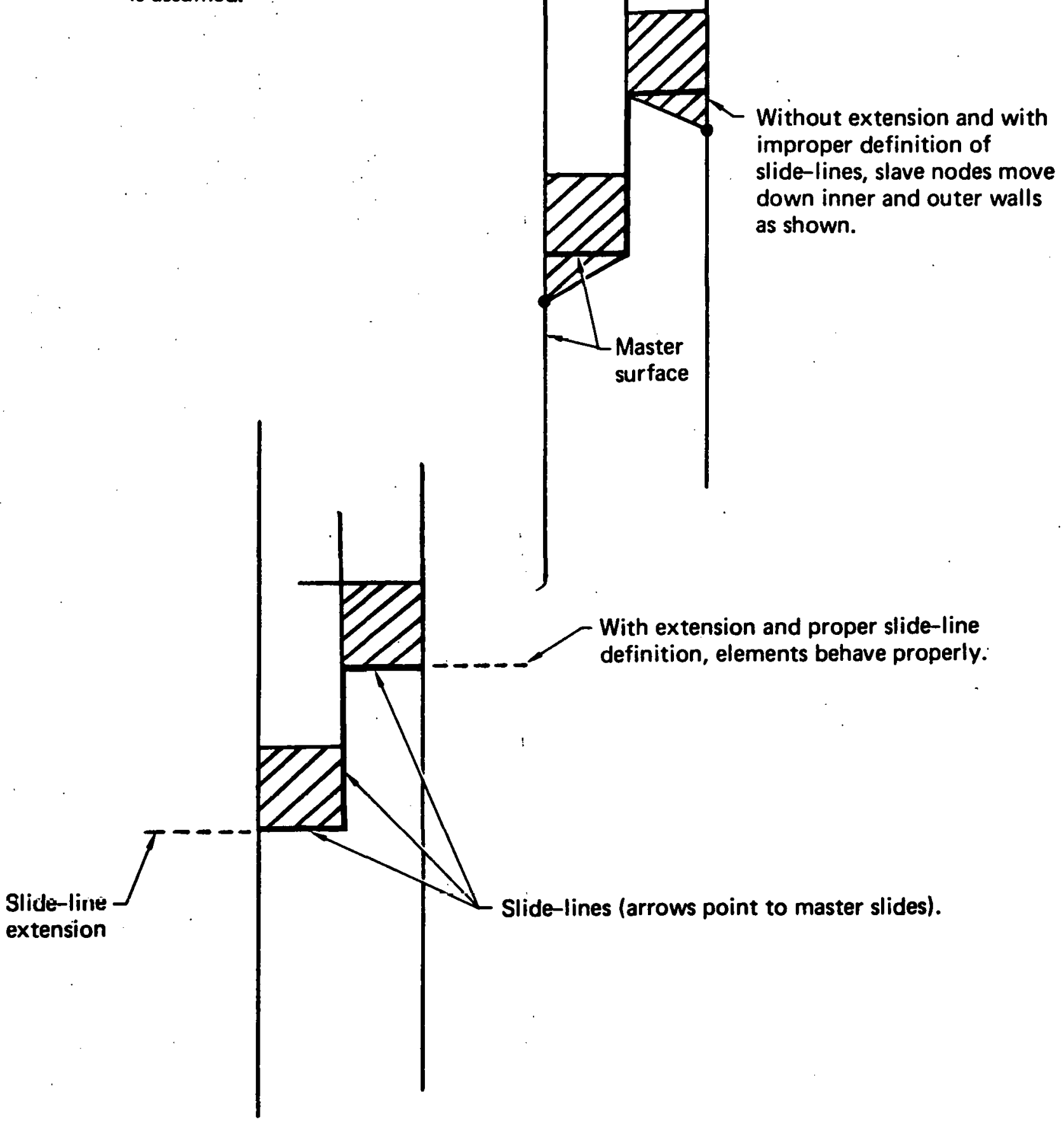

Fig. A3. Example of slide-line extensions helping to provide realistic response. 


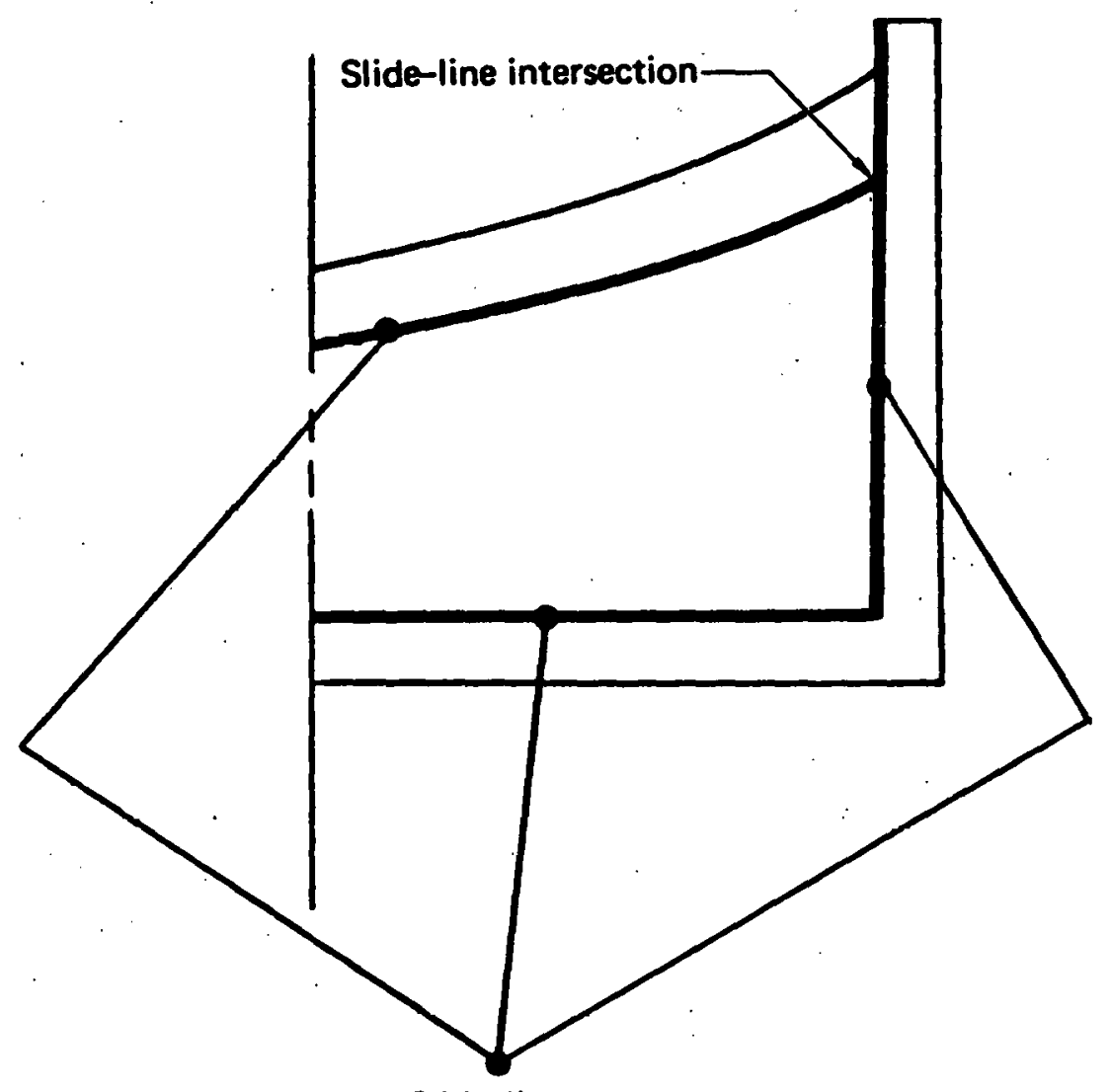

Slide-lines

Fig. A4. Example of slide-line intersection. 
This report was prepared as an account of work sponsored by the United States Government. Neither the United States nor the United States Department of Energy, nor any of their employees, nor any of their contractors, subcontractors, or their employees, makes any warranty, express or implied, or assumes any legal liability or responsibility for the accuracy, completeness or usefulness of any information, apparatus, product or process disclosed, or represents that its use would not infringe privately owned rights.

Reference to a company or product name does not imply approval or recommendation of the product by the University of California or the U.S. Department of Energy to the exclusion of others that may be suitable.

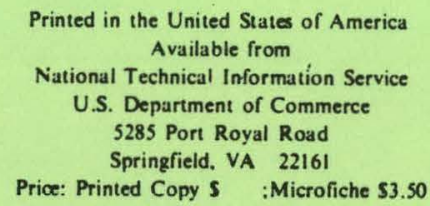

\begin{tabular}{|c|c|c|c|}
\hline Page Range & $\begin{array}{c}\text { Domestic } \\
\text { Price } \\
\end{array}$ & Page Range & $\begin{array}{c}\text { Domestic } \\
\text { Price } \\
\end{array}$ \\
\hline $001-025$ & \$ 5.00 & $326-250$ & $\$ 18.00$ \\
\hline $026-050$ & 6.00 & $351-375$ & 19.00 \\
\hline $051-075$ & 7.00 & $376-400$ & 20.00 \\
\hline $076-100$ & 8.00 & $401-425$ & 21.00 \\
\hline $101-125$ & 9.00 & $426-450$ & 22.00 \\
\hline $126-150$ & 10.00 & $451-475$ & 23.00 \\
\hline $151-175$ & 11.00 & $476-500$ & 24.00 \\
\hline $176-200$ & 12.00 & $501-525$ & 25.00 \\
\hline $201-225$ & 13.00 & $526-550$ & 26.00 \\
\hline $226-250$ & 14.00 & $551-575$ & 27.00 \\
\hline $251-275$ & 15.00 & $576-600$ & 28.00 \\
\hline $276-300$ & 16.00 & 601-up & \\
\hline $301-325$ & 17.00 & & \\
\hline
\end{tabular}

IAdd 2.00 for each additional 25 page inerement from 601 pages up. 
Technical Information Departmeni - Lawrence Livermore Laboratory University of California - Livermore, California 94550

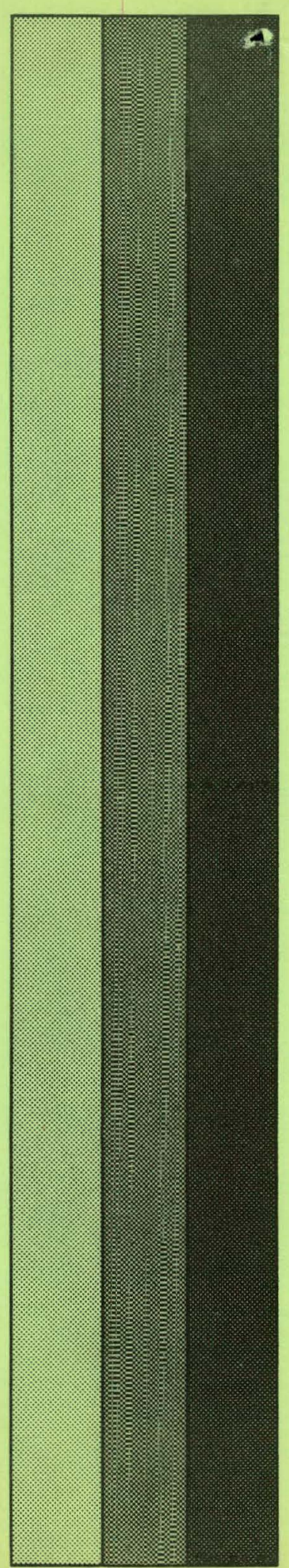

